\title{
SOCIAL ACCOUNTABILITY - ITS POSITION AND POTENTIAL IN THE DEVELOPMENT OF VIETNAM
}

\author{
By
}

Ta Thai Ha

A thesis submitted to the Victoria University of Wellington in fulfilment of the requirements for the degree of Master of Development Studies

Victoria University of Wellington

March 2016 


\begin{abstract}
Civil society organizations in Vietnam are experiencing critical transitions. As the nation is no longer a low-income country, an increasing number of civil society organizations are changing their directions from alleviating poverty to promoting more democratic governance. 'Social accountability', as one of their most common employed approaches, is often the combination of civic engagement, evidence-based monitoring, and advocacy. Carrying with it the expectation of improving accountability in Vietnam, the approach is still a new, foreign-imported concept that will challenge and be challenged by particular contextual factors in the country.
\end{abstract}

This study examines the practices of social accountability in Vietnam to find out its position and potential in terms of development of the country. Promoting social accountability in Vietnam is often based on the assumption that the approach will improve government's accountability, strengthening the state - citizen relationship. It is envisaged that the country will be eventually more open as a result. It is as yet an optimistic vision and will take time for practitioners to put in place. This study aims to analyse how early adoption of social accountability is affected by Vietnam's contextual factors, to what extent it is affecting governance and increasing people's participation, and what organizations can actually expect of social accountability.

The research aims to fill a gap in the literature regarding social accountability in Vietnam. As a new concept, social accountability is often introduced via materials provided by international organizations like World Bank and UNICEF. Most of the documents present successful cases of applying social accountability in other countries like India and Bangladesh, and countries in Latin America. Thus, a critical analysis of adopting social accountability in the Vietnam context is necessary to provide more insights for both practitioners and scholars on the topic.

Employing interviews as the key method, the study seeks input from key informants who are involved in the adoption of social accountability in Vietnam. From perspectives of government officials, development practitioners, and community members, the reality of practicing social accountability and how it is interacting and negotiating with other factors in society should be more clearly revealed. Practical expectations and recommendations to conceive of and practice social accountability in Vietnam are also suggested. 


\section{ACKNOWLEDGEMENTS}

One year ago when started the study, I did not have any idea on how it would be completed. There were countless times I struggled with the writing. Fortunately, I have always been received tremendous support from a number of kind-hearted people whom I always appreciate.

I would like to thank my supervisor, Professor Warwick Murray for giving his advice and keeping his patience with me. He has guided me through developing the thesis's structure to strengthening the conclusion. I also want to express my gratitude to Professor John Overton who supported me from Day 1 of the research.

I am thankful for the New Zealand Aid Programme for granting me the precious opportunity to study in New Zealand. Linshell and Helena, the two helpful coordinators of the programme, and the dedicate staff in their team have done an excellent job. They have been always supportive and kind. Without their guidance and support, I cannot imagine how I can manage both academic and daily life in the country.

I am indebted to a number of friends, my classmates who shared the learning curve with me, my flatmates who bared with me in my critical times, and my friends in Vietnam who always cheered me up. To Nguyen Nguyen, my Vietnamese cohort who treats me like his little sister. During the two years of the study, he always motivated and gave me advices when I was in need. To Minh Le Pham, my former colleague - my friend, who was always willing to discuss with me on every topics and to help revising my work.

I would like to express my appreciation to all participants of my interviews who spent time and shared their experiences with me. I was overwhelmed by their honesty, enthusiasm, and support to the study.

Finally, I am forever grateful for my family for always concerning for my well being, motivating me, and reassuring me throughout the years. To my boyfriend who now is my husband, thank you for loving me through all ups and downs during the process. From now, I am ready and happy to start a new journey with you. 


\section{LIST OF ABBREVIATIONS}

\begin{tabular}{|l|l|}
\hline AFAP & $\begin{array}{l}\text { Australian Foundation for the Peoples of the Asia and the Pacific in } \\
\text { Vietnam }\end{array}$ \\
\hline ANSA-EAP & $\begin{array}{l}\text { Affiliated Network for Social Accountability in East Asia and the } \\
\text { Pacific }\end{array}$ \\
\hline CPIA & Country Policy and Institutional Assessment \\
\hline CRC & Citizen Report Card \\
\hline CSOs & Civil Society Organizations \\
\hline DFID & Department for International Development \\
\hline GPSA & Global Partnership for Social Accountability \\
\hline ICT & Information and communications technology \\
\hline IDA & International Development Association \\
\hline MDG & Millennium Development Goals \\
\hline NGO & Non-governmental organizations \\
\hline PECSA & Project to enhance capacity in social accountability \\
\hline PETS & Public Expenditure Tracking Survey \\
\hline PRA & Procurement Reform Act \\
\hline UN & United Nations \\
\hline UNDP & United Nations Development Programme \\
\hline UNPA & United Nations Parliamentary Assembly \\
\hline VFF & Vietnam Fatherland Front \\
\hline
\end{tabular}




\section{TABLE OF CONTENTS}

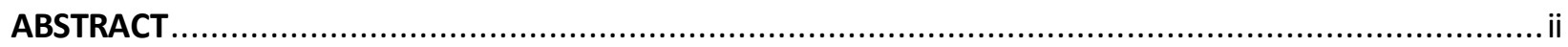

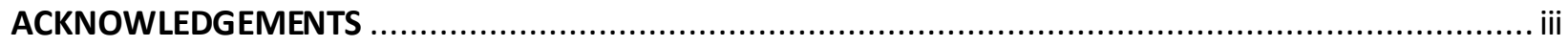

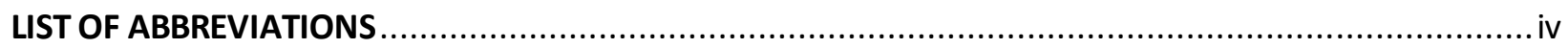

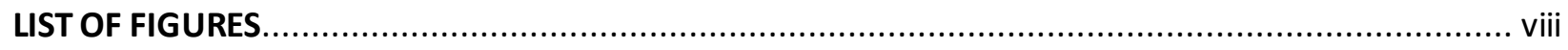

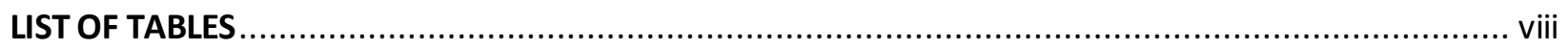

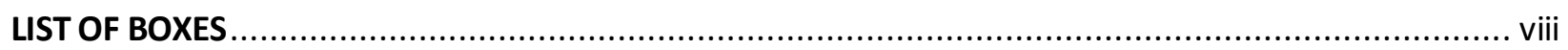

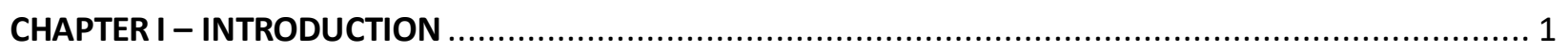

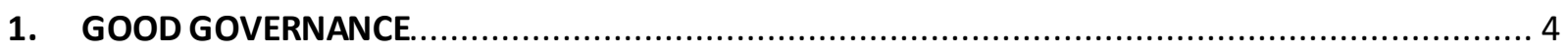

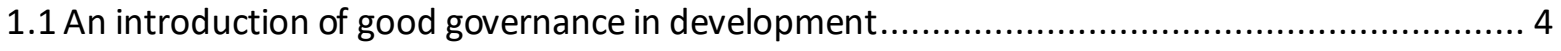

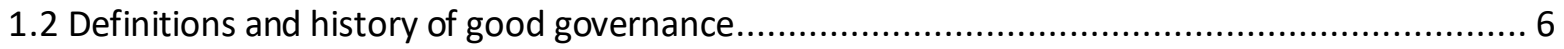

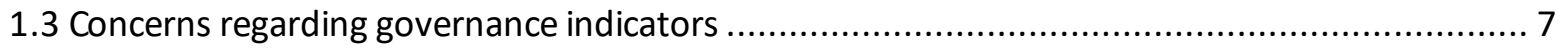

1.4 Governance in practices - Questions remained .................................................. 9

1.5 Summary on good governance in international development ............................................ 10

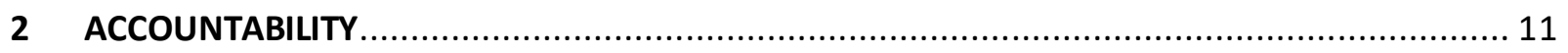

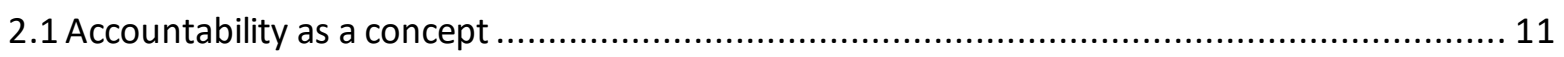

2.2 Accountability practices in human development..................................................... 13

2.3 Some gaps in knowledge and the need for further discussion ....................................... 15

2.4 Summary on accountability in development .......................................................... 16

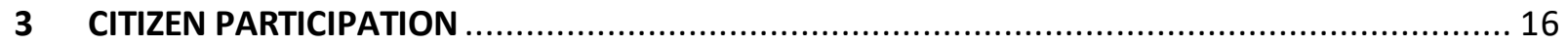

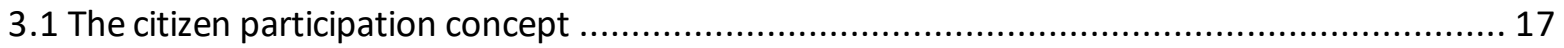

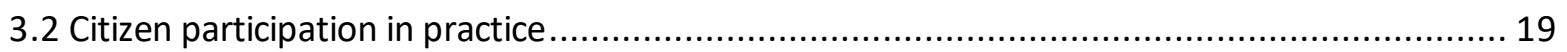

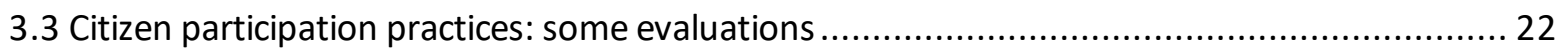

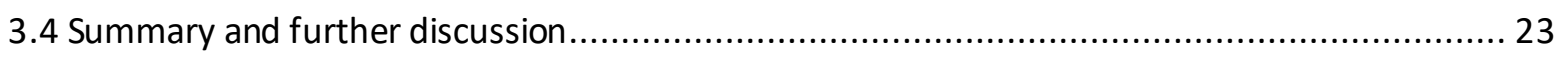

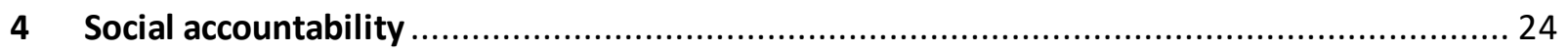

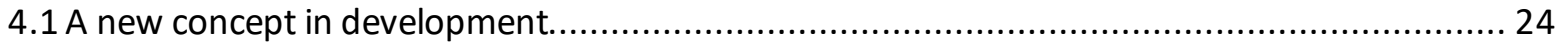

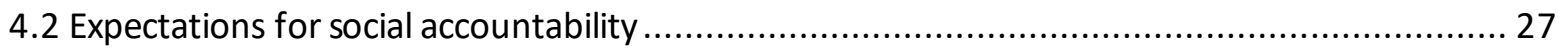

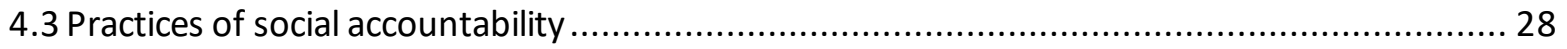

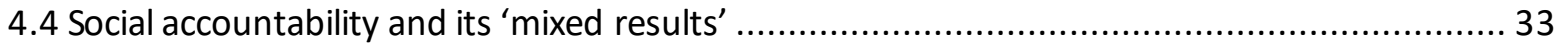

4.5 Social accountability in Southeast Asian - Cambodia and Philippines ............................... 35

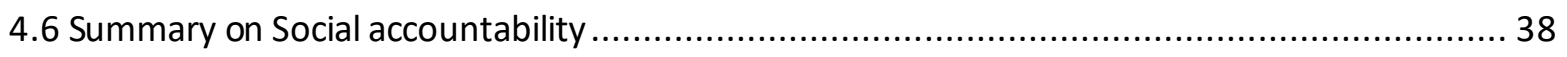

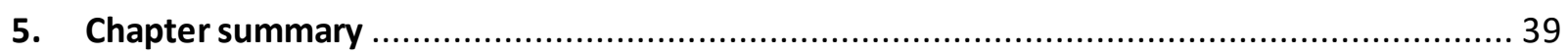




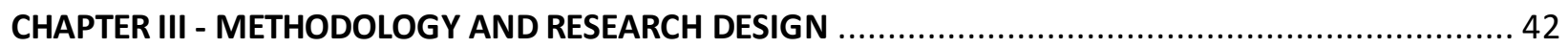

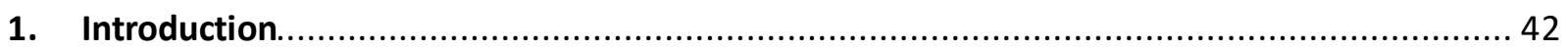

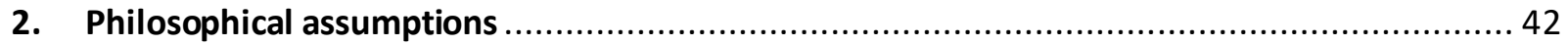

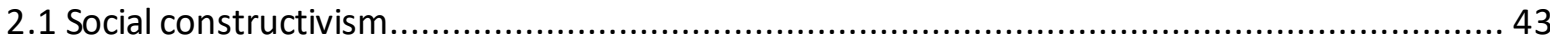

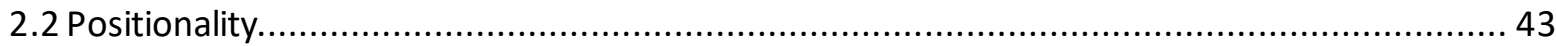

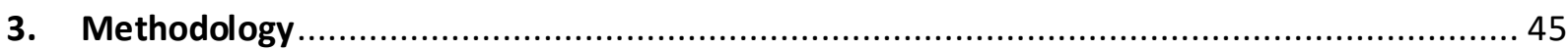

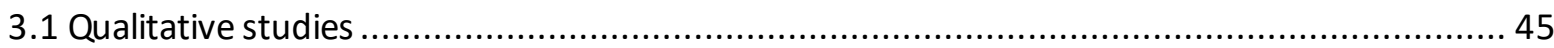

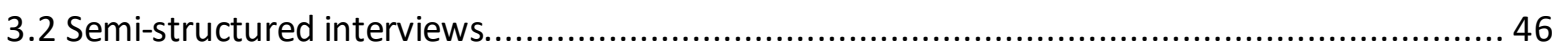

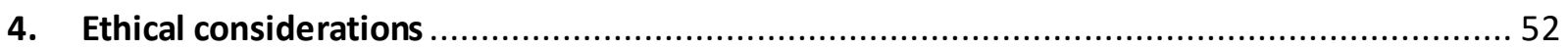

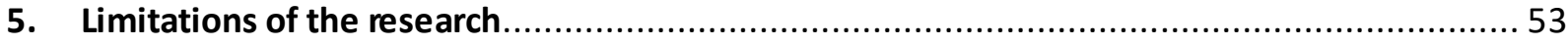

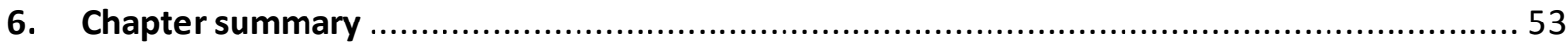

CHAPTER IV - VIETNAM CONTEXT FOR SOCIAL ACCOUNTABILITY ............................................ 55

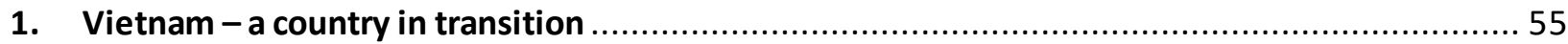

2. Policy context regarding governance and people participation........................................ 56

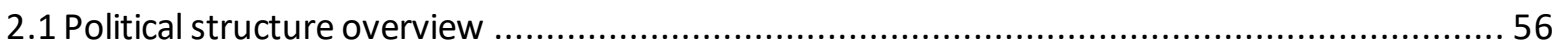

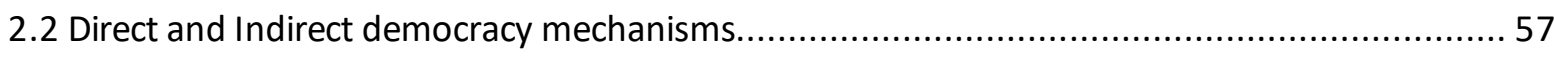

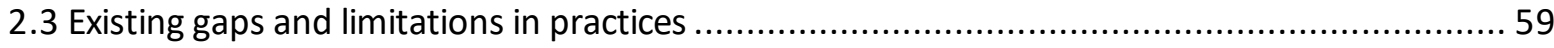

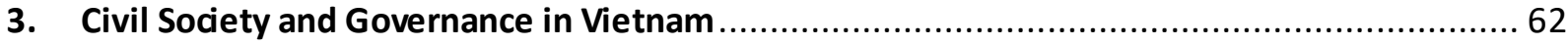

3.1 Signals of increasing interest in governance and social accountability ..............................63 63

3.2 Potential and opportunities for civil society organizations working in governance ................ 66

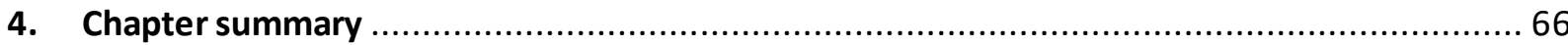

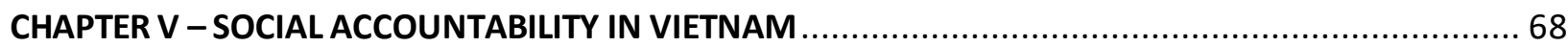

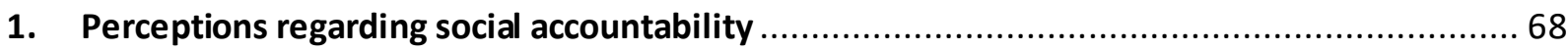

1.1 Social accountability in organizations' perceptions...................................................... 68

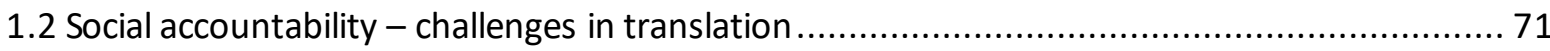

2. Potential of distrust and the emergence of social accountability in Vietnam...................... 73

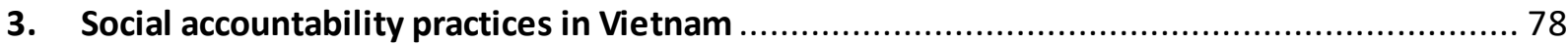

3.1 Aligning with the state - a common entry point of organizations........................................ 78

3.2 Information as evidence - the main practice of social accountability in Vietnam .................. 81

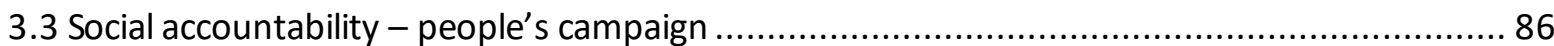

3.4 Next steps in practicing social accountability in Vietnam ............................................. 90

CHAPTER VI - IMPACTS, LIMITATIONS, AND REFLECTIONS ON SOCIAL ACCOUNTABILITY ................ 92

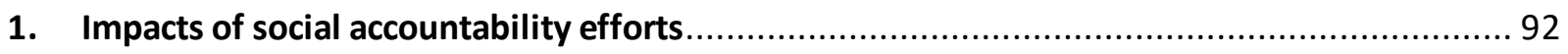




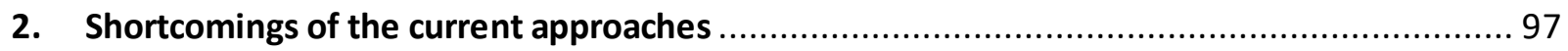

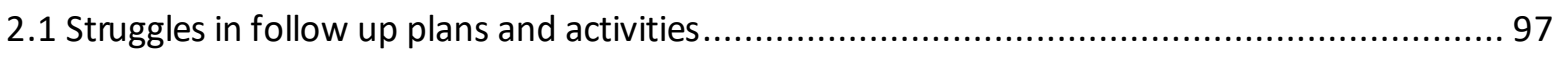

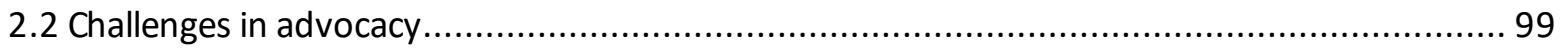

2.3 Scaling up, alignment with government, and technical nature of social accountability ......... 100

3. Reflection and discussion on the adoption of social accountability in Vietnam.................. 102

3.1 Strategic approach or tactical approach ............................................................. 103

3.2 Context is the key - Government support remains crucial............................................ 105

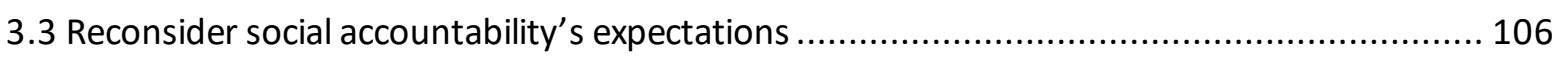

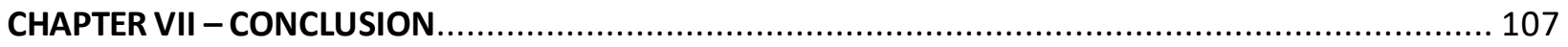

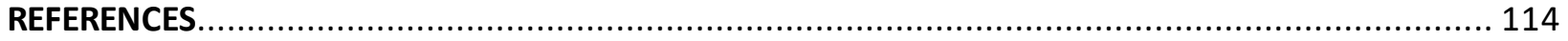

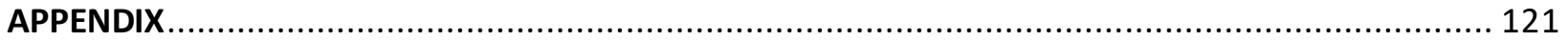

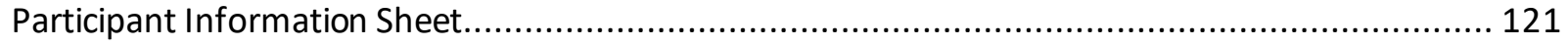

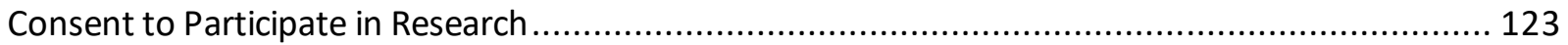

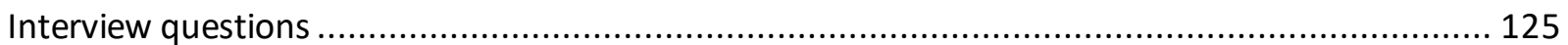




\section{LIST OF FIGURES}

\begin{tabular}{|l|c|}
\hline Figure 1: World Bank's long route and short route of accountability & 22 \\
\hline Figure 2: A shift in participation & 27 \\
\hline Figure 3: Vietnam Governance Indicators & 69 \\
\hline Figure 4: Fields of operation of interviewed CSOs in Hanoi and Ho Chi Minh City. & 73 \\
\hline Figure 5: Logic of research questions and research aspects & 125 \\
\hline
\end{tabular}

\section{LIST OF TABLES}

\begin{tabular}{|l|c|}
\hline Table 1: Examples of Social accountability practices & 38 \\
\hline Table 2: List of Interview Participants & 58 \\
\hline
\end{tabular}

\section{LIST OF BOXES}

\begin{tabular}{|l|c|}
\hline Box 1: Definitions of social accountability provided by the World Bank & 34 \\
\hline Box 2: Elements of social accountability & 38 \\
\hline Box 3: Tactical and strategic approaches to social accountability & 41 \\
\hline $\begin{array}{l}\text { Box 4: Examples of collective efforts of Vietnam civil society organizations in } \\
\text { governance }\end{array}$ & 73 \\
\hline
\end{tabular}




\section{CHAPTER I - INTRODUCTION}

Since 1990s, the world has witnessed the emergence of governance as one of the key priorities in international development (Ahmad, 2008). The World Development Report 2004 and 2006 both emphasize that the key for public services to support poor people is to improve accountability among policymakers, service providers and people (World Bank, 2004). The reports also suggest that for more effective service delivery, ordinary people need to have a stronger voice in decision-making and service monitoring, whilst policymakers can provide incentives for service providers to improve their performance (World Bank 2004, 2006). As a result, a wave of 'new' terms and concepts like 'civic engagement', 'governance', 'accountability', and 'transparency', etc. has become more popular in development practices and discourse. The idea of engaging people in order to enhance accountability and governance is received increasing attention among donors, scholars and practitioners.

During the context, social accountability, a relatively new concept has been promoted enthusiastically by influential organizations like the World Bank and UNDP. The concept is defined as "an approach towards building accountability that relies on civic engagement whereby ordinary citizens and/or civil society organizations directly or indirectly in exacting" (World Bank, 2014:3). Practices of social accountability are expected to enhance public service delivery, improve governance, and generate changes in relationship between states and people. As a result, the concept has been introduced and applied in a number of developing countries including Vietnam.

Vietnam is transforming from a low income to a middle-income country. Many significant changes have happened in terms of politics, economics, and society. The issues of governance and accountability has become an emerging concern among all actors in the society. Civil society organization, especially international non-governmental organizations have changed their directions from direct poverty alleviation programs to active engagement in promoting democratic governance (Vasavakul et al, 2015). 'Social accountability', as a result, is being adopted by an increasing number of both local and international NGOs and is expected to create 
positive, actual changes in policy implementation as well as to strengthen the relationship between the state and citizens.

However, the context of Vietnam is unique in terms of political, social, and economic structures. As social accountability is developed and promoted by international organizations, which greatly are influenced by Western roots and values, how the concept is going to be perceived, and practiced and which impacts it can generate in the society become an essential question to be addressed. Hence, the study is conducted in order to answer the research questions: What is the position of social accountability in the context of Vietnam? and How can agencies facilitate more effective, appropriate adoption of the concept? Necessary information to lead to the answers for the research question(s) would come from the subquestions as follows:

1. What are the legal framework and administrative procedures regulating social accountability initiatives in Vietnam?

2. What are the common approaches of adopting social accountability in Vietnam?

3. How do key actors (government, NGOs, and citizens) perceive impacts of social accountability initiatives?

4. What are lessons drawn from successful cases of social accountability initiatives in Vietnam?

The first and foremost expected outcome of the study is to contribute to the existing literature about social accountability in development. The study can also be used as a reference source for practitioners in Vietnam and in similar context where the exercise of social accountability is not yet institutionalized.

In order to explore the practices of social accountability in Vietnam, qualitative methodology has been employed with the main research method being interviews with non-governmental organizations, local government officials, and local community people. Fourteen semi-structure interviews were conducted with valuable insights to answer the research questions. The questions are addressed in several chapters, which have the structure as follows. 
Chapter 1 - Introduction. The chapter introduces the research questions, rationale of the study as well as brief description on the context of the study.

Chapter 2- Literature Review. This chapter reviews current literature and discussions on concepts including good governance, accountability, people participation, and social accountability. The four concepts have a close association; therefore, exploring the concepts will help understand social accountability more thoroughly.

Chapter 3-Methodology and Research design. The third chapter of the study introduces the methodology, method and research design for the study as well as rationale of selecting the approaches. The positionality of the researcher and limitations of the selected method are also presented.

Chapter 4-Vietnam context for social accountability. This part presents and analyses the country's contextual factors which can affect the practice of social accountability. It provides a review on the current political structure, accountability mechanisms with its strengths and weaknesses, altogether with changes in directions of civil society organizations in Vietnam.

Chapter 5 - Social accountability in Vietnam. This chapter analyses the perceptions and practices of social accountability via input provided mostly from NGO representatives of the study.

Chapter 6-Impacts, limitations, and reflections on social accountability. Though social accountability is still considered as new approach in Vietnam, it is necessary to review its impact as well as provide experiences of practitioners in adopting the concept. This part discusses the issues in order to have a complete understanding on the application of social accountability.

Chapter 7-Conclusion. The chapter is set out in order to summarize discussions through the study, answer mentioned research questions, as well as discuss on future directions of the research. 


\section{CHAPTER II - LITERATURE REVIEW}

This chapter presents relevant concepts to social accountability and existing discussions around the concepts. Since social accountability is still a relatively new concept, the research aims to explore the concept via studying other concepts which are closely linked to social accountability. Hence, key concepts to be discussed in this chapter include good governance, accountability and civic engagement. Social accountability and social accountability in SouthEast Asian countries will also be covered.

\section{GOOD GOVERNANCE}

Since mid-1990s, the concept of good governance has drawn remarkable attention among development practitioners, agencies, and academia (Thomas, 2006; Hout, 2009). Recently, the High Development Panel appointed by the UN Secretary General to review the post-2015 Millennium Development Goals has recommended that a governance indicator be added to the new MDG framework.

Undoubtedly, good governance with its increasing influence in development mainstream has sparked many discussions and different opinions. This section examines the history of the concept in international development, good governance in practice, and other discussions around the topic.

\subsection{An introduction of good governance in development}

Most scholars have agreed that the emergence of good governance in international development agenda started in 1989-1990 (Doornbos, 2010; Hout, 2009). In 1989, the World Bank published its first major revisionist analysis, Sub-Saharan Africa: From Crisis to Sustainable Growth, which highlighted key factors preventing African nations from implementing successful market-oriented reform programs. The document concluded that "underlying the litany of Africa's development problems is a crisis of governance" and proposed 'good governance' as one of the solutions for the issue (World Bank, 1989: 60). The Bank later defined governance as "the manner in which power is exercised in the management of a country's economic and social resources for development" (World Bank, 1992:3). Since then, 'governance' has been officially 
recognized as one factor influencing countries' development and 'good governance' has been recommended as a critical solution to development.

According to Moore (2001), the promotion of the good governance agenda is often a response to the argument that ineffective and unaccountable states are a major cause of poverty and poor living standards of many poor people in the world. In addition, as more attention in donors' countries is paid to the aid effectiveness, there is a shared recognition among donors that foreign aid could only be used effectively in well-governed countries (Thomas, 2006). Hence, to donors, governance is one possible answer for the poverty issue in poor countries and also an indicator to foresee if their money is spent wisely. The rationales altogether make the idea of promoting good governance in the recipient countries more convincing and appealing.

Questions of the importance of good governance in the theme of development have also been at the centre of many studies. Some N-large statistics studying cross-national correlation between governance and development have actually suggested a high level of correlation between the two (Grindle, 2007). Results of the quantitative studies are therefore often employed to suggest a relationship between good governance and development. According to Grindle, a World Bank review of 40 different quantitative studies concludes that there is "overwhelming evidence that good governance is crucial for successful development, as measured by high per capita income" (Grindle, 2007). However, as Grindle commented, the high level of correlation produced by using statistics cannot identify the cause and the result between the two- whether good governance leads to development or vice versa (Grindle, 2007). On the other hand, donors need to be aware that studies using qualitative methods like case studies often produce very limited impacts on good governance initiatives. The studies often mention struggles of development agencies in applying context-based good governance practices and the importance of customizing the practices to the context. (Grindle, 2007) International development organizations such as the World Bank, UNDP and DFID play a sensitive role in defining the concept, guiding the practice, documenting cases, and promoting the adoption of good governance (Hout, 2009). Publications such as the World Development 
Report, the Human Development Report, and DFID's 'Making the Government Work for Poor People' are important sources for disseminating the findings of academic literature about governance and development (Hout, 2009).

\subsection{Definitions and history of good governance}

The concept of good governance has evolved over the years from a term with great extent of technical nature to inclusion of 'modern concept' like participation, power, etc. Hout and Robison reviewed the development of the concept good governance since the 1990s and summed up in three main phases (Hout and Robison, 2009). The phases were illustrated as below.

\begin{tabular}{|c|c|}
\hline $\begin{array}{l}\text { First phase - } \\
\text { 1990s }\end{array}$ & $\begin{array}{l}\checkmark \text { A narrow view of good governance } \\
\checkmark \text { Emphasising technocratic measures to improve government effectiveness } \\
\text { and provide a legal framework for market-based development }\end{array}$ \\
\hline $\begin{array}{l}\text { Second } \\
\text { phase - Mid } \\
\text { 1990s }\end{array}$ & $\begin{array}{l}\checkmark \text { Realizing and expressing more concern for the 'organization of political and } \\
\text { social life, and stressed participation and inclusion of society' }\end{array}$ \\
\hline $\begin{array}{l}\text { Third phase } \\
\text { - 2000s } \\
\text { onwards }\end{array}$ & $\begin{array}{l}\checkmark \text { Increasing awareness of the importance of power, politics and social } \\
\text { conflict in shaping development outcomes and the difficulties of addressing } \\
\text { these through existing institutional and governance programmes }\end{array}$ \\
\hline
\end{tabular}

Source: Modified from Hout and Robison (2009)

Critics often look at the rise of good governance as a term rooted deeply in Western society and was another attempt of Washington Consensus to create a homogeneous world based on a Western's, especially the America, model of development (Moore, 1993). Adrian Leftwich and other scholars (Hout 2009, Mkandawire 2007) argued that true motives of all the interest of governments and organizations in good governance lie in the history of development itself. Events such as the failure of structural adjustment lending, the resurgence of neo-liberalism, the collapse of official communist regimes and the rise of pro-democracy movements in the developing world sparked the promotion of good governance as a response of large development agencies like World Bank (Leftwich, 1993). 
Moreover, the rise of good governance agenda also has been criticized that it has risen out of its original meaning, creating ambiguity, vagueness, and confusion. According to MKandawire former director of UNRISD, the initial emergence of good governance is to describe the situation in African countries specifically. The understanding was developed with significant contribution of African scholars. The initial idea regarding the concept was to improve statesociety relations with greater attention to issues of equity and inclusion. However, later on, the term has been promoted and interpreted with a great focus on technical sense, taking fiscal and financial reforms and other government reforms as core components of governance. In that sense, good governance differs from its original interpretation, and could be regarded as an instrument for ensuring the implementation of structural adjustment programs (Mkandawire, 2007).

\subsection{Concerns regarding governance indicators}

Though good governance practices have stepped into mainstream, there is still no consensus on the definition of the concept (Kauffman, 2010). Nonetheless, sets of indicators are introduced which can represent donors' implications on good governance. Both the construction and the adoption of the indicators raised concerns among scholars. This section will review two of the most influential governance indicators: the Country Policy and Institutional Assessment (CPIA) and the Worldwide Governance Indicators (WGI).

From 1999-2001, the World Bank introduced the Country Policy and Institutional Assessment (CPIA) as an additional measure for the quality of governance (Hout, 2009). From 2002 to 2004, the overall CPIA ratings were reported by quintile for countries eligible to borrow from the International Development Association (IDA), the concessional lending window of the World Bank (Kauffman et al, 2010). Since 2005, the individual country scores for the IDA resource allocation index, a rating that reflects the CPIA as well as other considerations, have been publicly available for IDA-eligible countries (Kauffman, 2010). The CPIA consists of four equally weighted clusters, each measured by three to five indicators. The clusters and indicators are:

- Economic management: macro-economic management, fiscal policy and debt policy; 
- Structural policies: trade policy, financial sector structure and policies, and business regulatory environment;

- Policies for social inclusion/equity: gender equality, equity of public resource use, service delivery in health and education, social protection and labour, and policies and institutions for environmental sustainability;

- Public sector management and institutions: property rights and rule-based governance, quality of budgetary and financial management, efficiency of revenue mobilisation, quality of public administration and transparency, and accountability and corruption in the public sector. (World Bank, 2004)

Hout (2009) argues that four of the six indicators are highly technically and administratively oriented with the bias toward business and economic activities, rather than the functioning of political systems. Moreover, political aspects, such as the accessibility of decision-making to marginalized groups and possible distortions of interest representation in the political system, are not addressed.

The 1999 papers 'Aggregating Governance' and 'Governance Matters' introduced the Worldwide Governance Indicators developed by Kaufmann and his team who were staff at the World Bank (Thomas, 2006). The Worldwide Governance Indicators (WGI) is a long-standing research project to develop cross-country indicators of governance. Since 1996, the WGI has been developed with six composite indicators covering broad dimensions of governance over 200 countries: Voice and Accountability, Political Stability and Absence of Violence/Terrorism, Government Effectiveness, Regulatory Quality, Rule of Law, and Control of Corruption (Kauffman et al, 2010). According to the World Bank, other donor governments, such as the Netherlands, also rely on the Worldwide Governance Indicators to monitor the quality of governance in aid recipient countries. Risk rating agencies as well as many non-governmental organizations also use them as a source of reference (Thomas, 2006 citing World Bank 2006). However, unlike the CPIA, the scores have not been officially adopted for decision making on allocations by the World Bank (Hout, 2009). 
Regarding this new set of governance indicators, Thomas (2006) holds a sceptical view. He argued that the WGI purport to measure fundamental concepts of governance, but these concepts are neither well defined nor rooted in theory. Explanation of the clusters is expressed as 'personal ideas of governance, but these ideas are not articulated' (Thomas, 2006). Overall, the WGI represent a "complex theoretical" and "poorly articulated hypothesis" for which no evidence has been presented (Thomas, 2006). Hence, in Thomas's opinion, for researchers, results obtained using the indicators are not reliable and as such should not survive peer review. For policy makers, reliance on the indicators is arbitrary (Thomas, 2006).

\subsection{Governance in practices - Questions remained}

With all the confusion in the definition and measurement of good governance, it is not difficult to foresee that the implementation of good governance agenda will face many challenges.

By analysing governance-related documents of development agencies (mostly from World Bank), Wil Hout (2009) argues that the attention to governance issues in the post Washington consensus has focused largely on formal institutions and technical instruments. Since 2000, many organizations have recognized the importance of understanding governance in relation with countries' political -economy factors instead of governance as standalone technocrat measurements (Hout, 2009). The author observed the confusion of development agencies in translating their understandings of governance into policy. Hout analysed the case of DFID and the 'Drivers of Change' that was the organization's approach to adopt a more politicaleconomic understanding of governance issues in developing countries. However, the approach was perceived as abstract and not easy to apply, especially as it suggested more direct political interventions that should be both time and resource consuming as well as more challenging for practitioners (Hout, 2009).

Grindle (2004) with his well-known articles about good enough governance also argues that the good governance agenda is difficult and over-loaded. Since good governance was initially linked to long-term issues of poverty reduction, the common project basis with time restrictions would be very difficult to address poverty issues or bring any significant effects. Moreover, Grindle argues that the current approach is mostly developed by outsiders without enough 
attention for real motives of the insiders like the people and the government (Grindle, 2004). Thus, he recommended the 'good enough governance' agenda be applied with a greater emphasis on contextual and content-related factors and setting priority based on time and cost of the actions. Though the good enough governance is not yet specific enough to guide actions, the shortcomings of good governance agenda as analysed by Grindle are still worth to consider (Grindle, 2004).

Another scholar, Matt Andrews looked at the existing good governance agenda as a one size fit all model, bringing lessons of developed countries to apply to other countries. He concluded that in practice, good governance recipes become inconsistent and inappropriate to use in particular contexts. Moreover, he noted that there is not yet a theoretical foundation that explains the relationship between good governance and development. And without such a theory, it is very difficult to explain why an approach works, in what situation it does not success, and how to implement it successfully (Andrews, 2008).

\subsection{Summary on good governance in international development}

The concept, practices and measurements of good governance have raised many concerns among both scholars and practitioners. Until now, there has been no consensus on the definition of the term. Over time, understandings of the concept vary and are adjusted reflecting the changing perception at the time. Although it is difficult to find a concrete evidence for the causal relationship between good governance and development, one cannot deny the fact that development donors have successfully put good governance in mainstream development agenda; and it will continue to be an irreversible trend in international development. Perhaps, the most convincing argument to support the idea of good governance by now is that good governance is certainly better than bad governance and there will be significant struggles for development if one country is governed poorly. Nonetheless, when practicing good governance programs organizations should keep a realistic viewpoint on the potential of the programmes and identify reachable goals based on the thorough analysis of their own context. 


\section{ACCOUNTABILITY}

As governance has been perceived as a significant component of development agenda, accountability, which has been considered as a 'cornerstone' of good governance, has also drawn great attention in development regime (World Bank, 2006). In contemporary governance discourse, accountability is found linked to almost every conceivable aspect of 'good governance' from developmental effectiveness to empowerment (Ackerman, 2004). Ackerman observed that the only way to guarantee good government is by institutionalizing powerful accountability mechanisms that can hold public officials responsible for his/her actions as a public servant (Ackerman, 2004). The 2000/2001 World Development Report and World Bank's empowerment framework recognize accountability as an integral component of 'empowerment' and hence poverty reduction (Ahmad, 2008). It is promoted as the complete and final solution to all governance problems - the chief instrument for combating the 'threeheaded monster' of corruption, clientelism and capture (Ackerman, 2005).

\subsection{Accountability as a concept}

According to Lindberg (2009), the central idea of accountability arose from both political science and financial accounting. The idea could be traced back from John Locke's theory of superiority of representational democracy and when the constitution of America was developed (Lindberg, 2009). Holding agents accountable - the core idea at the time, however, still stays true "when decision-making power is transferred from a principal (e.g. the citizens) to an agent (e.g. government), there must be a mechanism in place for holding the agent to account for their decisions and if necessary for imposing sanctions, ultimately by removing the agent from power" (Lindberg, 2009:203).

Over time, the concept of accountability has become fashionable in many areas other than politics (Lindberd, 2009). This proliferation has resulted in a diverse set of meanings and dimensions associated with the concept of 'accountability' (Lindberg, 2009). In the field of development, similar to the concept of good governance, there is no agreement on the exact meaning of accountability (World Bank, 2006). Some authors define accountability as a duty or liability (see for example Jones and Stewart, 2009), others as a process (see for example OECD 
2005, Ackerman 2005, Schedler et al 1999), and some as a relationship (Stapenhurst and O’Brien undated, Lawson and Rakner 2005, Newell and Wheeler 2006, O' Neill et al. 2007).

Interestingly, O'Neil in his evaluation of accountability approaches has recognized the differences in vocabularies adopted to describe an accountability relationship (O'Neil, 2007). Arisen from the economics' language, some commentators - most in donor community refer to the demand and supply sides of accountability, with the demanders being those who ask for answers and enforce sanctions. From a human rights perspective, accountability is about the relationship between a bearer of a right or a legitimate claim and the agents or agencies responsible for fulfilling or respecting that right (O'Neil, 2007 citing Gloppen et al 2003). Another way of referring accountability is as a relationship of an accounter and an accountee, with the accounter being the agent that demands answers and enforces sanctions (O'Neil, 2007 citing Moore and Teskey 2006). All the differences in vocabulary unsurprisingly suggest different perceptions and approaches of the organizations and scholars towards the concept. Variation of understanding on accountability has led to concern regarding the core meaning of accountability (Lindberg, 2009). There are a number of studies attempting to seek the core meaning of the concept. One of the noticeable arguments is from Lindberg's study, which affirms that accountability is one of several methods of constraining power and thus subordinate to the concept of power (Lindberg, 2009). He argues that at a very fundamental level, accountability is tightly linked with authority though not necessarily political authority. The concept, according to the author, can be found and used in different domains. The definitions of accountability in each domain can vary due to differences in the logic behind the domains. However, accountability still shares the core nature of constraining power. Scholars in studying the concept should firstly understand the domain in which it is applied (Lindberg, 2009).

Though varying on the understanding of accountability, many scholars and organizations has shared the work of Schedler (1999) as a key reference for their idea on accountability. Without specifying the definition of accountability, Schedler analyses the concept into two key dimensions: 'answerability' (the ability to ensure that officials in government are answerable 
for their actions) and 'enforcement' (rewarding good and punishing bad behaviour). According to Schedler, the two are continuous variables with varying mixes and emphases. Even if one or two of them are missing there may still be legitimate acts of accountability (Schedler, 1999). Schedler's analysis of accountability has greatly influenced organizations' definitions of the concepts. World Bank's Accountability in Governance (2006) has also employed his understanding of the concept with 'answerability' and 'enforcement' being considered as two stages of accountability. However, as even with the absence of one of the two variables, accountability may still exist. It is understandable that a consensus on the definition and approach towards accountability is difficult to reach.

\subsection{Accountability practices in human development}

Mainstream political science literature often distinguishes between vertical and horizontal accountability. Vertical accountability is referred to elections and other mechanisms by which citizens control governments, while horizontal accountability is the checks and balances in governmental systems designed to ensure that due process is followed in governmental decision-making (O’Donnell 1999).

Scholars tend to agree that mechanisms strengthening vertical or horizontal accountability alone are not enough (Goetz and Jenkins 2001, Sarker citing Younis \& Mostafa, 2000). According to Goetz and Jenkins (2001), both horizontal and vertical accountability mechanisms have shortcomings. Horizontal accountability or oversight institutions have long been perceived as ineffective whereas vertical accountability systems have many limitations. Take election as one example of vertical accountability mechanism. According to Ackerman, there are at least three structural problems with elections. The problems include the fact that elections can only hold elected officials accountable, ignoring a vast majority of appointed public officials, that election only happens once every few years, and finally, politicians have the tendency to favour patronage or corruption in order to gain support of an interest group (Ackerman, 2003).

To address the ineffectiveness of existing traditional mechanisms on accountability, development donors and agencies have piloted many different approaches. 'Voice' or people feedback has been incorporated in the new approaches in order to strengthen accountability. 
In the beginning of the 1990s, the focus of World Bank's work on accountability was on providing access to information, in recent years, the Bank has recognized and emphasized on the importance of parliament as a major tool to enable citizens to participate in the political processes (Maldonado, 2010). According to Maldonado (2010), in principle, the Bank followed Hirchmann's concept of 'exit and voice'. In this context, 'exit' means the possibility of the public to gain access to other service suppliers in case the state does not provide for the services in a satisfactory way. 'Voice' refers to the possibility of the public to influence the quality and quantity of public services by e.g. improving access to information and involving nongovernmental organizations (Maldonado, 2010). In practice, to address the more complicated relationship in development with three key stakeholders: citizens, the state, and public service providers, World Bank develops a framework of long route and short route of accountability with long route referring to citizens exercise 'voice' vis a vis politicians, and short route when citizens exercise 'client power' with 'exit' is the ultimate power. The framework (Figure 1) has been applied widely among many international donors and agencies. UNDP, for example, has used the framework to address the three key accountability questions: Accountability for

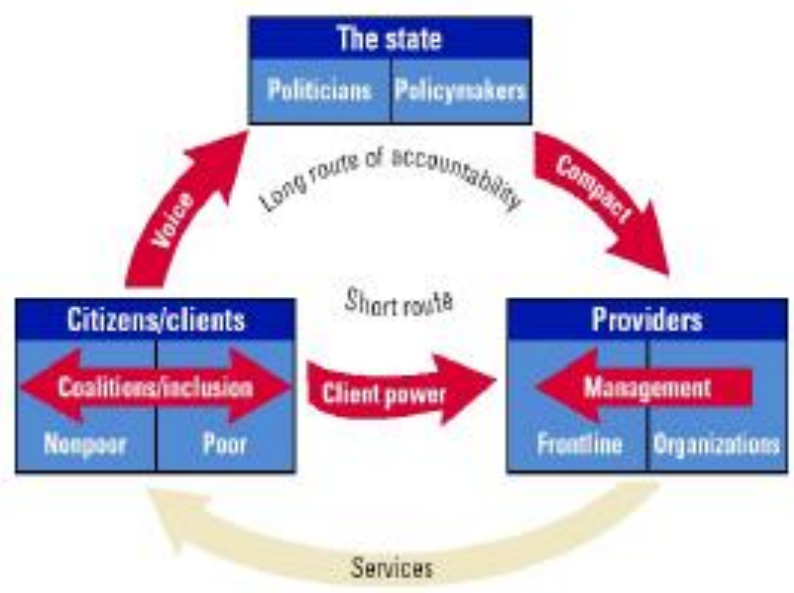

Figure1: World Bank's long route and short route of accountability what? To whom? Of whom? and constructed a set of possible accountability mechanisms based on the three relationship that the World Bank's framework set out (UNDP, 2008).

O'Neil in his influential “Evaluation of citizen's voice and accountability - Review of the literature and donor approaches report" has concluded that despite different approaches and interventions, overall, donors are unable to work directly on voice (an action) or accountability (a relationship). In practice, therefore, donors strengthen voice and accountability by seeking to create or strengthen the preconditions for the exercise of voice and accountability which 
include: the: (i) enabling environment; (ii) channels through which citizens can express their voice or hold government to account; (iii) the institutional framework required for voice and accountability; and (iv) the individual state institutions/agencies required for voice and accountability (O’Neil et al, 2007).

Finally, practices and understanding of accountability in development domain has continuously evolved over time. In recent years, there have been attempts to name new waves of accountability. Goetz and Jenkins (2001) have recognized that hybrid forms of accountability are being established when citizens are breaking away from official 'vertical' channel of accountability and influencing the closed 'horizontal' accountability functions. Four years later, in their 'Reinventing accountability: Making democracy work for human development', they call the emerging trend as new accountability agenda (Goetz \& Jenkins, 2001). All of the changes in accountability practices and discussions have reflected the recognition and emphasis on the role of citizens and their 'voices' in accountability issues.

\subsection{Some gaps in knowledge and the need for further discussion}

New understandings of accountability actually lead to questions on the actual impacts of accountability. Niraja (2008) argues that donors' promotion of the concept often makes accountability appear as a 'magic formula' to resolve most if not all problems of the public sector. However, similar with governance, he recalls that there is not yet a comprehensive theory explaining the causal relationship between accountability and poverty reduction in developing countries (Niraja, 2008).

Lacking of a specific theory also explains the difficulties in evaluating accountability interventions. There have been attempts of scholars and practitioners to address issues of complexity, confusion in practical directions and questions of causality of deciding factors of accountability (Rogers 2000, Stame 2004, Booth and Evans 2006b) as well as the need to integrate power as a key dimensions in study accountability (Gaventa 2003, VeneKlasen and Miller 2002). However, until now, according to O'Neil, donors are still unable to ascertain their effectiveness beyond intermediate outcomes (O'Neil, 2009). 
Finally, there is the absence of frameworks for understanding different contexts and how these relate to voice and accountability (O’Neil et al, 2007). There is a tension between recognising that the design and outcome of interventions are to a large part dependent on context and claiming that donors need to establish models with which to assess lines of causality and their contribution within this (O'Neil et al, 2007)

\subsection{Summary on accountability in development}

Being borrowed from the domains of financial accounting and political science, accountability has continued to evolve and adapt in practices and academic discussion in development field. The concept is still now a subject to explore and interventions on new forms of accountability will keep emerging. The lack of consensus in understanding accountability and efforts in conceptualizing the concept have brought difficulties to evaluate impacts or measure specific levels of accountability in a particular context. However, as many scholars stressed, at its core meaning, accountability in development is about power. It is expected that more discussion on power relations, and therefore, studies recognizing the importance of context should be in the central of further discussions on accountability.

\section{CITIZEN PARTICIPATION}

Citizen participation has been perceived as an indispensable component of the good governance and accountability. A review of the Millennium Development Goals implementation shows that increasing public participation in political processes and civic engagement at all levels is one of the conditions to ensure good governance and effective institutions (UNDP, 2013). Brodie et al (2009) has claimed that over the past decade, interest in participation, especially citizen participation has been much increased.

Different scholars and organizations prefer different names for the term, such as civic participation (engagement), public participation, political participation or vertical participation. In this study, the terms are used interchangeably in order to reduce complexity. 


\subsection{The citizen participation concept}

Similar to good governance and accountability, scholars and development agencies have developed different interpretations of citizen participation. In 1992, World Bank defined participation as "a process by which people, especially disadvantaged people, influence decisions that affect them" (World Bank, 1992:177). In the Citizen Participation Handbook, the Bank specified the concept as a bottom up process with citizens being organised at the grassroots level and working closely with non-governmental community organizations (World Bank, 2002). An emphasis on cooperation among all stakeholders was acknowledged but the recognition of the role of disadvantages people was simply not clear. Moreover, the definition emphasizes the importance of cooperation among all stakeholders and narrows down the issues to local issues, which closely relate to the people: "Citizens get most involved in this process when the issue at stake relates directly to them. Furthermore, citizen participation occurs when all the stakeholders cooperate to implement changes" (World Bank, 2012: pg.15).

If World Bank explains citizen participation as a process, the UN and other scholars often perceive it as the involvement of citizens itself, which does not necessarily include decisionmaking process. UN World Public Sector Report 2008 defines the term as "the involvement of citizens in a wide range of policymaking activities, including the determination of levels of service, budget priorities, and the acceptability of physical construction projects in order to orient government programs toward community needs, build public support, and encourage a sense of cohesiveness within neighbourhoods" (UNPA Glossary 2016 cited UN, 2008). With this definition, citizen participation is not necessarily started by the people, nor does it necessarily focus on grassroots level issues. Brodie et al, 2009 also provides a simple view on citizen participation, which is quite similar to UNDP's definition. Brodie's citizen participation is "the engagement of individuals with the various structures and institutions of democracy" (Brodie et al, 2009). The explanation endorsed by the World Bank and UNDP differ from the role of citizens, as well as the scope or the topics that people can participate in to influence changes. All these differences suggest different approaches of each organization towards building citizen participation in practice, specifically in deciding who should be involved, scope of participation, range of actions, and expectations. 
According to Gaventa and Valderrama (1999), the differences on definitions of citizen participation over time also imply 'a redefinition of the concept of participation'. The perceptions are moving from only being concerned with 'beneficiaries' or 'the excluded' to a wider range of engagement by citizens in policy formulation and decision making in key arenas which affect their lives (Gaventa et al, 1999). The shift was demonstrated as followed in Figure 2.

Figure 2: A shift in participation

$\begin{array}{lll}\text { From } & & \text { To } \\ \text { Beneficiary } & \Rightarrow & \text { Citizen } \\ \text { Project } & \Rightarrow & \text { Policy } \\ \text { Consultation } & \Rightarrow & \text { Decision-making } \\ \text { Appraisal } & \Rightarrow & \text { Implementation } \\ \text { Micro } & \Rightarrow & \text { Macro }\end{array}$

Source: Gaventa \& Valderrama, 1999

Several studies seek to explain the rise of citizen participation in national and local governance. Brodie et al 2009 recognizes four common expectations underlying the rising of participation. Firstly, participation is anticipated to strengthen the legitimacy and accountability of democratic institutions. Then, it is assumed to empower communities and help build social cohesion. Thirdly, it is believed to contribute to public services reforms so that the services become better suited to people's needs and more efficient. Finally, citizen participation can boost personal development via a wide set of social interaction skills and enhance self-esteem of individuals. To sum up, participation is promoted as a concept tightly associated with 'greater social justice, more effective public services and a society of self-confident citizens' as well as an expression of active citizenship (Brodie et al, 2009). Hence, it is understandable that citizen participation is interpreted as a "key ingredient in the recipe for democracy" (World Bank, 2012). In addition, recently, more and more organizations start recognizing and approaching citizen participation as a basic human right (World Bank 2004, DFID 2000, Cornwall citing Ferguson 1999). 
Irvin and Standsbury (2004) and Eversole (2011) tend to agree that all the expectations and the interest in citizen participation rest on the belief that an engaged citizenry is better than a passive citizenry. There is a firm assumption that communities of people possess the ability to act and be agents of their own development (Eversole, 2011). Hence, community ideas, energy, social capital and local knowledge can be perceived to be key ingredients for solving a range of entrenched policy challenges and fill in the gap that political systems are not able to (Eversole, 2011).

Though the idea of people participation has been incorporated in mainstream development, especially in good governance practices, the expectations and assumptions have raised the questions on measuring the actual effect of citizen participation as well as identifying specific level of participation and its potential.

\subsection{Citizen participation in practice}

Similar to ongoing discussion on participation in general, scholars often agree that citizen participation has different levels and can be classified into different versions (Brett, 2003). In his article, Brett suggests to adopt Michener's distinction between strong and weak definitions of the process with weak participation involving 'consulting or informing' and strong participation referring to 'partnership or ceding control'. Brett has observed that in practice, all interventions operate along the spectrum, which stretches from weak to strong, but emphasizing one as opposed to the other does have significant practical implications (Brett, 2003). While the strong theory emphasizes on the people in long term, the necessity of changing people's perceptions, improving their capabilities, and challenging the power relation between power holders and holdees, the weak theory sees people's participation as a source of local knowledge to improve programmes and services. Summary on Brett's observations on the differences on strong and weak theories and their implications on practices has been illuminated as below. 


\begin{tabular}{|c|c|c|}
\hline & Strong theory & Weak theory \\
\hline Implication & $\begin{array}{l}\text { An educational and empowering } \\
\text { process in which people, in } \\
\text { partnership with each other and } \\
\text { those able to assist them, identify } \\
\text { problems and needs, mobilise } \\
\text { resources, and assume } \\
\text { responsibility themselves to plan, } \\
\text { manage, control and assess the } \\
\text { individual and collective actions that } \\
\text { they themselves decide upon. }\end{array}$ & $\begin{array}{l}\text { Involving the need to inform and } \\
\text { consult users or intended } \\
\text { beneficiaries so that their needs, } \\
\text { aspirations and capabilities can } \\
\text { be taken into account during the } \\
\text { project/policy design. }\end{array}$ \\
\hline $\begin{array}{l}\text { Expected } \\
\text { results }\end{array}$ & $\begin{array}{l}\text { A way to expand people's } \\
\text { capabilities, increase their self } \\
\text { esteem, and improve performance } \\
\text { by obliging agencies. } \\
\text { This can lead to fundamental } \\
\text { changes in decision making } \\
\text { processes, and in the power } \\
\text { exercised by users over agencies. }\end{array}$ & $\begin{array}{l}\text { Better information about local } \\
\text { needs, capabilities, and the } \\
\text { impact of programmes, ways of } \\
\text { adapting programmes to local } \\
\text { conditions, delivering demand- } \\
\text { responsive services, mobilizing } \\
\text { local resources, improving } \\
\text { utilisation and maintenance of } \\
\text { state facilities, and ways of } \\
\text { increasing public recognition of } \\
\text { governmental achievements and } \\
\text { legitimacy. }\end{array}$ \\
\hline Disadvantages & $\begin{array}{l}\text { - 'Real' participation involving } \\
\text { direct control by local people in } \\
\text { large systems is virtually } \\
\text { impossible. Hierarchy and } \\
\text { representative democracy is } \\
\text { inevitable. }\end{array}$ & $\begin{array}{l}\text { - } \text { High transaction cost } \\
\text { - } \text { Raising excessive } \\
\text { expectations } \\
\text { - Substituting inappropriate } \\
\text { local for technical knowledge }\end{array}$ \\
\hline
\end{tabular}




\begin{tabular}{|l|l|l|}
\hline & $\begin{array}{l}\text { Unrealistic assumptions about } \\
\text { the ability of the poor to access } \\
\text { joint decision-making processes. }\end{array}$ & $\begin{array}{l}\text { Allowing local elites to } \\
\text { capture development } \\
\text { resources }\end{array}$ \\
\hline
\end{tabular}

Source: Summarized from Brett, 2003

Obviously, practices based on strong theory often embed ambitious expectations regarding to changes in power structure or social relations. However, the practices are not easy and often take a long time to realize their impacts. Hence, it is understandable that in reality, practices often fall into the weak version of citizen participation (Brett, 2003). Fung (2015) has also given the similar observation. According to Fung, although over the last decade, development agencies, especially the World Bank has invested greatly on development assistance for participation, public hearings and meetings, which are low on the scale of influence; and empowerment remains the dominant form of public engagement (Fung, 2015). In such kind of practices, external agencies often play a critical role in facilitating, helping social groups to acquire the information, resources, and organizational experience (Brett, 2003).

According to Gaventa, for practices aiming at more visible changes in state reforms, the decentralization process has offered spaces for a wider and deeper participation of citizens (Gaventa \& Valderrama, 1999). Governments throughout the world have simultaneously embraced participation, implemented strong state administrative structures to build partnerships and networks to enhance public and community participation (Eversole 2011, Bingham et al 2005). Bingham (2005) has listed a number of quasi-legislative new governance processes, which aim at greater role for public participation. The processes include deliberative democracy, e-democracy, public conversations, participatory budgeting, citizen juries, study circles, participatory budgeting, and other forms of deliberation and dialogue among groups of stakeholders or citizens. Nonetheless, Eversole recognizes that governments are often not actually willing to compromise their essential identity as hierarchical organizations (Eversole, 2011). When faced with differences in the institutions through which governments and communities work, community members are expected to shift their ways of doing and knowing while governments are much less interested in how communities actually work and often tend 
to impose their way on the people. Failures to recognize and respect the differences can lead to tensions when governments and communities are trying to work together but cannot reach an actual positive engagement (Eversole, 2011).

All the conclusions above have confirmed that citizen participation have received great attention from both governments and development agencies. Practices to enhance citizen participation vary and often bend towards the weak or strong end of the spectrum with different scopes, expectations, and stakeholders. There are large amount of examples in which the weak theory is applied due to its simpler and less challenging nature. While governments have implemented mechanisms to encourage citizen participation, they have not shown genuine interests in changing the way they work and perceive. Hence, the next important concern is if the practices have brought about expected outcomes.

\subsection{Citizen participation practices: some evaluations}

According to Fischer (2012), a range of experiences shows that community participation can improve the efficiency of programs and effective projects in the provision and delivery of services (Fischer, 2012). Gaventa and Barrett (2010) conducted a meta-case study analysis of a ten-year research programme on citizenship, participation and accountability with a sample of 100 research studies in 20 countries. The report has indicated that citizen participation has the tendency to bring positive outcomes in terms of constructing citizenship, strengthening responsive and accountable states and developing inclusive and cohesive societies, as well as strengthening existing participation practices.

However, both Fischer and Gaventa are very cautious when drawing any conclusions on impacts of citizen participation practices. Fischer argues that it is possible that a positive association between efficiency and participation may only reflect a process of reverse causation - that is, community members had already chosen to participate in those projects which promised to be efficient. Gaventa in the evaluation report also emphasised that all the possible effects of citizen participation practices depend on the context and supporting conditions at the site (Gaventa and Barrett, 2010). 
Commenting on other goals of citizen participation, including increasing democratic legitimacy and equitable outcomes, Fung (2015) criticizes that the expectation is an ambition rather than a guarantee. Fischer also voiced concerns that decentralized participation can also weaken efficiency (Fischer, 2012). Moreover, he has mentioned that it can lead to resource allocations that violate the true preferences of community members, as some may withhold or distort information about their preferences and choices, especially in external donor funded projects (Fischer, 2012).

Though citizen participation has been claimed to have potential in favouring the voices of the disadvantaged, redirecting public policy towards the needs of citizens, increasing effectiveness of public service delivery, some scholars are concerned about the real impacts of citizen participation. Koch (2013) has realized three pitfalls of citizen participation. First, some scholars argue that participatory processes are not more inclusive than those employed in representative institutions because of the social selectivity of participation which decides who should and can be participate. Second, as participation processes operate as complements to representative bodies of political decision-making, outputs of the local participation cannot be easily incorporated into the organizational routines of governments and public administrations. Finally, Koch has mentioned that some scholars argue that participatory arrangements often fail to empower a broad range of citizens. However, it is worth to realize that the critics are about practices of improving participation, but not about the idea of people participation. Hence, questions on what practices lead to the expected goals still remain and require more pilots and studies to explore.

\subsection{Summary and further discussion}

Under the umbrella of governance and accountability, citizen participation has become mainstream in development discourse and practices. Some scholars may argue that citizen participation in this sense remains a buzzword as participation in general. However, one cannot deny that it has the potential to bring positive impacts whether at its weak versions. It is difficult to conclude that if strong version of participation or weak version would be the better versions. In fact, it depends on the context to decide which form of participation can be the 
most appropriate. Therefore, the most crucial question at this time regarding citizen participation is not why we should practice it but how we can implement good citizen participation practice within limitations of time, scope, resources. Only understanding the context may help identify the relevant expectations and then decide how one may practice citizen participation.

There is also a strong need to distinguish the expectation of citizen participation as to increase the efficacy of regulation, improve the provision of public goods and services or to advance social justice and repair power relation. Decisions on this issue will help sketching the whole intervention and evaluation plan as well as to identify possible political challenges the practice may face.

Finally, though participation has shifted from an emphasis on voices of disadvantaged to a sense of collectiveness in community or citizens' participation. There should still be an interest on study motivations of individuals in participating in governance, especially disadvantaged and/or poor people who do not possess favourable conditions to raise their voices and are often located in remote areas.

\section{SOCIAL ACCOUNTABILITY}

All the interest in good governance, accountability and citizen participation has led to social accountability. The term is relatively new in international development agenda but has created new waves in development practices. World Bank has affirmed that social accountability is officially "seeping into the mainstream" (World Bank, 2003).

\subsection{A new concept in development}

Similar to other concepts discussed, it is very difficult to find a consensus on the definition of social accountability. According to Joshi and Houtzager (2012), as the term has emerged since 2000s, development world has observed continuous efforts to conceptualize and reconceptualise social accountability. 
World Bank - as the leading agent in promoting social accountability also is recreating their understanding of social accountability over time. Some of the definitions introduced by the World Bank are listed in Box 1.

Social accountability includes a broad range of actions and mechanisms (beyond voting) that citizens can use to hold the state to account, as well as the actions on the part of government, civil society, media and other societal actors that promote or facilitate these efforts. (World Bank, 2006)

Social accountability is extent and capability of citizens to hold the state accountable and make it responsive to their needs" in other words, "accountability-enhancing actions that citizens can take beyond elections" (World Bank 2012)

"Social accountability is as an approach towards building accountability that relies on civic engagement whereby ordinary citizens and/or civil society organizations participate directly or indirectly in exacting" (World Bank, 2014:3).

\section{Box 1: Definitions of social accountability provided by the World Bank}

The three definitions all reflect the expectation of social accountability to improve the accountability of the state via increasing people's participation. If the first two definitions describe social accountability in terms of actions and mechanisms, the latter starts realizing social accountability as an approach, which may imply longer-term practices with different implementation stages. The 2006 and 2012 definition of social accountability both have "hold the state accountable' as their main objective whereas the 2014 definition only mentions 'accountability' in general. These changes signal a significant adjustment in not only the perception towards the state but also the role they should take in the adoption of social accountability led by the Bank. Finally, none of these definitions specifies which actions or approach should fall under the category of social accountability. Hence, there can be "a broad range of actions and mechanisms" which may confuse practitioners when exercising the concept. 
On the other hand, some organizations perceive social accountability as another form of accountability, beside vertical and horizontal accountability. UNDP, for example, defines social accountability as a form of accountability that emerges from actions by citizens and CSOs aimed at holding the state to account, as well as efforts by government and other actors (media, private sector, and donors) to support these actions (UNDP, 2013). The definition recognizes the role of government and other actors beside citizens and civil society organizations in achieving the goals of social accountability. Since social accountability is perceived as a result arisen from stakeholders' actions, the actions are not necessary to be defined and can be very flexible in practice.

The Bank has realized the confusion between social accountability and citizen participation, stressing that the emphasis on accountability makes social accountability distinct from citizen engagement (World Bank, 2015). According to UNDP, social accountability has an element of demanding responsiveness and accountability from the state, which is not necessarily present in all forms of civic engagement (UNDP, 2010). Thus, actions by citizens to promote social accountability constitute one form of civic engagement but not all forms of civic engagement contribute to social accountability (UNDP, 2010). Overall, it can be understood that social accountability involves a wide range of initiatives and measures, other than voting, aiming at improving the accountability relation between the state and the people via, and not limited to participation of people.

The lack of specification in the existing definitions of social accountability has also caused confusion and questions among scholars. Joshi and Houtzager (2012) question what does not constitute social accountability, implying that the concepts can be understood and applied in many different ways, incorporating terms like citizen participation, accountability, and governance. Joshi and Houtzager (2012) argue that the current conceptualizations of social accountability have tended to focus on it as 'mechanisms' or 'widgets' rather than focusing on the processes through which poor people make claims. Thus, they suggest an alternative conceptualisation that focuses on disaggregating social accountability actions, and viewing them as part of a long-term ongoing political engagement of social actors within the state (Joshi et al, 2012). World Bank itself in their latest document 'Opening the black box: The contextual 
drivers of social accountability'(2015) agrees that the term 'social accountability' is becoming 'fuzzy', and have the tendency to be a 'catch-all' term that encompasses a descriptive label with a desirable value. In an attempt to redefine the concept, instead of having a concrete definition, the Bank proposes a new way to conceptualize social accountability based on the five constitutive elements - citizen action, state action, information, interface, and civic mobilization (World Bank, 2015).

\subsection{Expectations for social accountability}

The reason social accountability is promoted widely in international development is because the term has been received high expectations from both development agencies and supporting scholars. Barbaric (2014) concludes that the rationale of social accountability lies in the expectations that it has potential to (1) improve governance; (2) increase development effectiveness through improved public service delivery and more informed policy design and (3) empower citizens (Malena, Forster and Singh, 2004:4). According to Malena et al, good governance can be achieved because "social accountability practices enhance the ability of citizens to move beyond mere protest toward engaging with bureaucrats and politicians in a more informed, organised, constructive and systematic manner, thus increasing the chances of effecting positive change" (Malena, Forster and Singh, 2004:5).

World Bank (2015) has suggested that there are two intellectual roots of social accountability concept: the principal-agent model and the voice and participation model. The principal-agent model treats social accountability as an extension of new public management, introducing the idea of 'client power' as conceptualized in the World Development Report 2004 (World Bank, 2015). New public management emphasizes the importance of market principles in reforming public service delivery systems, which citizens viewed principally as "clients" who reward good service with loyalty or punish poor performance by choosing to 'exit' and opting for other alternatives.

In contrast to the principal - agent model, the voice and participation model views social accountability as a means of creating 'active citizens' and strengthening democracy. Hence, addressing social exclusion as a primary source of poverty through greater citizen participation 
and voice is at the core of social accountability, and there is a need to deepen the direct participation of people in political processes. This model of constructing social accounta bility shares commonality with the rights-based approach to development (World Bank 2015, Ackerman 2005).

The effort of World Bank to distinguish the two different roots which are influencing perceptions and expectations of people regarding social accountability as well as the approach to practice social accountability should be appreciated. However, simply admitting the existence of the two without analysing and deciding on one does not make the discussions on the concept social accountability any less fuzzy.

\subsection{Practices of social accountability}

Big development agencies like World Bank and UNDP are enthusiastic in leading the rise of social accountability. World Bank has published an online sourcebook, which serves as a knowledge resource for understanding and practicing social accountability. In 2012, the Bank established the Global Partnership for Social Accountability (GPSA) working in two main themes: funding and knowledge sharing. More than 260 organizations from civil society, the donor community, private sector and academia have expressed their endorsement for the objectives and strategy of the GPSA. The Bank apparently is having a significant influence on the understanding and practices of other organizations in the adoption of social accountability. UNDP, on the other hand, also expresses its interest in leading the promotion of social accountability due to the agency's strong comparative advantage (UNDP, 2013a).

The first and foremost reflection on social accountability practices is its diversity which has also been implied in the definition of the term (UNDP, 2013b). According to UNDP, social accountability initiatives often are designed based on context, hence they may differ in term of processes, actors, levels and sectors (UNDP, 2013b). The organization realizes that the goals also vary from a narrow goal, such as improving particular services in a particular location, to broader agendas, such as enhancing citizen participation (UNDP, 2013b, citing Greenhalf, forthcoming). In its sourcebook on social accountability, World Bank also agrees on the diversity of social accountability practices (Social Accountability Sourcebook Homepage, 2016). 
According to the Bank, social accountability encompasses a broad range of methods and practices. Some of the practices and tools are introduced in the table followed.

Table 1: Examples of Social accountability practices (Source: Ringold et al, 2012)

\begin{tabular}{|c|c|c|}
\hline $\begin{array}{l}\text { Government } \\
\text { Function }\end{array}$ & $\begin{array}{l}\text { Social Accountability } \\
\text { Process }\end{array}$ & $\begin{array}{l}\text { Social Accountability Mechanisms and } \\
\text { Tools }\end{array}$ \\
\hline Policies and Plans & $\begin{array}{l}\text { Participatory Policy } \\
\text { Making and Planning }\end{array}$ & $\begin{array}{l}\text { Local issue forums } \\
\text { Study circles } \\
\text { Deliberative polling } \\
\text { Consensus conferences } \\
\text { Public hearings } \\
\text { Citizens' juries }\end{array}$ \\
\hline $\begin{array}{l}\text { Budgets and } \\
\text { Expenditures }\end{array}$ & $\begin{array}{l}\text { Budget Related Social } \\
\text { Accountability Work }\end{array}$ & $\begin{array}{l}\text { Participatory budget formulation } \\
\text { Alternative budgets } \\
\text { Independent budget analysis } \\
\text { Performance based budgeting } \\
\text { Public education to improve budget } \\
\text { literacy } \\
\text { Public expenditure tracking surveys } \\
\text { social audits } \\
\text { Transparency portals (budget websites) }\end{array}$ \\
\hline $\begin{array}{l}\text { Delivery of Services } \\
\text { and Goods }\end{array}$ & $\begin{array}{l}\text { Social Accountability in } \\
\text { the Monitoring and } \\
\text { Evaluation of Public } \\
\text { Services and Goods }\end{array}$ & $\begin{array}{l}\text { Public hearings } \\
\text { Citizens' report cards } \\
\text { Community scorecards } \\
\text { Public opinion polls } \\
\text { Citizen's charters }\end{array}$ \\
\hline Public Oversight & $\begin{array}{l}\text { Social Accountability and } \\
\text { Public Oversight }\end{array}$ & $\begin{array}{l}\text { CSO oversight committees } \\
\text { Local oversight committees } \\
\text { Ombudsman }\end{array}$ \\
\hline
\end{tabular}


The introduction of a wide range of tools and methods, though is not the core of social accountability initiatives' (Social Accountability Sourcebook Homepage, 2016), is recognized as "important ingredients for successful social accountability approaches" (Ibid). On the Sourcebook homepage, World Bank visualizes government or civil society to proactively seek citizen input and draw on the wide variety of existing tools to ensure transparent, inclusive and effective public participation and deliberation. Interested organizations or individuals can select a particular tool based on their own objectives. However, since it is crucial to take into account the reaction and motivation of each stakeholder including the state and the people, introduction of a variety of tools can only be seen as too simple. The key for improving service delivery or generating change in state-society relationship does not lie in the instruments, but from commitment and determination of all relevant parties. Hence, putting too much concentration in instruments may prove misleading when it comes to realizing and solving roots of the issues.

The Bank's building blocks of social accountability have also embedded the shortcoming. According to the Bank, there are three common elements to most social accountability approaches, including: (1) accessing information; (2) making the voice of citizens heard; (3) engaging in a process of negotiation for change (Social Accountability Sourcebook Homepage, 2016). In this process, citizens are expected to provide their input and raise their voices unitedly and engage in a negotiation directly or indirectly. However, there should be another element in the list, which is follow-up activities and encouraging governments or any other involved parties to fulfil their commitments. Without concrete actions after the application of any approach, it cannot be a success and people can lose trust easily.

Hence, UNDP's four elements of social accountability that recognises the importance of preparing community and civil society groups to engage as well as using information to bring about the delivery of commitments are more complete. The differences from the World Bank's perspective may be lessons drawn from UNDP's first hand experiences in undertaking social accountability practices. 
Box 2: Elements of social accountability (Source: UNDP, 2013b)

1. Preparing community and civil society groups to engage - includes raising the awareness of citizens, building confidence and capacity for engagement, building networks and coalitions

2. Collecting, analyzing and using information - includes finding, securing and anlysing information on government activities, translating it into different formats, styles and languages, and sharing it through the media and social and political networks

3. Undertaking accountability engagements with governments -includes using instruments such as scorecards, audits and budget analysis to engage with a government, either by using existing formalized spaces for participation in planning or policy cycles or by developing new ones, or by mobilizing social protests

4. Using information from accountability engagements with governments - includes advocacy, lobbying and campaigning work to follow up on the delivery of commitments

In 2014 and 2015, World Bank published two noticeable publications on social accountability which are 'Opening the black box - the contextual drivers of social accountability' and 'Social accountability - What does the evidence really say?' in response to the lack of clarity in terms of the concept as well as mixed results of social accountability interventions. The publications reflect the Bank's determination to solve the limitations of social accountability via conceptualizing the concept and suggesting new directions for practices of social accountability. Regarding social accountability practices, the publications emphasize the need to understand the concept and adapt the practices accordingly. They also realize the role of the state in adopting social accountability and the importance of studying incentives and drivers for state's action. In the publication 'Social accountability - What does the evidence really say?', the author distinguishes two social accountability approaches: tactical and strategic approaches. The differences between the two approaches are summed up as follows. 
Box 3: Tactical and strategic approaches to social accountability

Tactical social accountability approaches involve:

○ Bounded interventions

○ Limited to society side voice

- Assume that information provision alone will inspire collective action with sufficient power to influence public sector performance

- Are bounded to local arenas

Strategic social accountability approaches involve

- Multiple, coordinated tactics

- Enabling environments for collective action, to reduce perceived risk

- Citizen voice coordinated with governmental reforms that bolster public sector responsiveness

- Scaling up and across

○ Iterative, contested and therefore uneven processes.

Source: GPSA, 2015

According to the author, localized, voice-only, tactical interventions are extremely weak versions of social accountability and can be considered 'under-dosage'. Hence, the author suggests and calls for more strategic approaches to social accountability with the application of sandwich strategy where citizen voice coordinates with governmental reforms to 'shift power with state-society synergy'.

Hence, it is expected that social accountability practices are moving from introduction and application of instruments to 'more strategic' approaches with more focus on understanding the context and encouraging the state to engage in the approaches. However, they are only directions; how to actually carry out the practices remains a question for practitioners. 


\subsection{Social accountability and its 'mixed results'}

Similar to the adoption of accountability and participation, there is no clear answer for the question on the actual impacts of social accountability. There are some attempts to measure the impacts of social accountability, however, most end up concluding that the interventions often bring 'mixed results'.

Brinkerhoff and Wetterberg (2015) studies the impacts of social accountability in governance, services, and citizen empowerment by examining four projects funded by USAID in four developing countries: Indonesia, Philippines, Guinea, and Rwanda. In all cases, the social accountability interventions have shown benefits in improving effectiveness of service delivery while citizen empowerment mostly remains as potential with citizen having more opportunities to participate in (Brinkerhoff \& Wetterberg, 2015). In Guinea where citizen empowerment outcomes are assessed as primary contribution of the social accountability intervention, the activities of parents' association - one of the most critical outputs of the project need to have continuous support from donor or international NGOs in order to sustain (Brinkerhoff \& Wetterberg, 2015). One of the noticeable characteristics of the projects is its small scale with the scope limited to district, commune levels or three health facilities in two provinces in the case of the Philippines. Moreover, while the study has demonstrated significant results of social accountability in terms of improving service delivery and governance, it is not known whether there was other interventions from the government, people or CSOs. Hence, the conclusion on the effects of social accountability can be challenged.

In the report "Do they work: Assessing the Impacts of Transparency and Accountability Intiatives in Service Delivery", Anuradha Joshi reviews a wide range of both quantitative and qualitative applied research to decide impacts of specific social accountability interventions. The study has concluded that there is evidence suggesting that the social accountability mechanisms have been effective in their immediate goals: successfully introducing and implementing the mechanisms and circulating information (Joshi, 2013). There is also evidence of impact on public services in a range of cases. According to Joshi, mechanisms helping to expose corruption have had the clearest impact in terms of bringing to light discrepancies 
between official accounts and the reality of practice. Studied initiatives have also been quite successful in increasing awareness of entitlements, empowering people to demand accountability and claim rights as well as increase the practice of active citizenship (Joshi, 2013). The evidence is less straightforward in terms of the impact on actual quality and accessibility of services themselves. Joshi suggests that the direct social accountability mechanism has little traction unless they are able to trigger traditional accountability and impose formal sanctions (Joshi, 2013). UNDP and Babovic (2014) shared Joshi's view on direct social accountability mechanisms often fail on delivering long term changes, or contributing to good governance (Babovic, 2014). UNDP in its publication 'Reflection on social accountability' has also recognized that social accountability generates changes, but only at intermediary levels (UNDP, 2013b).

GPSA's publication "Social accountability: What does the evidence really say?" is an endeavor to challenge the arguments that impacts of social accountability are often unclear. The report lists three common conclusions of existing studies on impacts of social accountability which are 'information interventions only are not enough', 'bottom up monitoring often lacks ability to sanction', and 'community driven development programs are often captured by local elites'. According to Jonathan Fox - the author, the conclusions are deprived from weak assumptions such as "information is power", "decentralization brings the government closer to the people" and "community participation is democratic" (Fox, 2015). He then suggests a ddressing the issue by distinguishing tactical and strategic approaches, categorizing interventions that are arisen from the weak assumptions as tactical approaches and supporting for more long-term strategic activities (Fox, 2015).

Despite of differences on conclusions on impacts of social accountability, it is difficult to deny its potential in generating changes, especially intermediate ones such as disseminating information, building up mechanisms for people to raise voice and familiarizing government officials with the idea of people's participation. However, in terms of longer impacts, existing interventions have not brought many concrete impacts. Moreover, there is no one size fits all mechanisms of social accountability. Organizations cannot simply take an intervention which is a success in another location to apply to their locations without taking into account differences 
in the contexts. Hence, measuring and concluding on impacts of social accountability are challenging and can lead to contradictory conclusions.

\subsection{Social accountability in Southeast Asian - Cambodia and Philippines}

This section discusses social accountability experiences in Southeast Asian countries in order to have a better understanding of practices of social accountability in Vietnam later. Case studies regarding social accountability initiatives in Asia or South Asia often name examples in India and Bangladesh. Southeast Asian countries often are mentioned with two representatives: Philippines and Cambodia, both countries are members of the World Bank-supported Asian Network for Social Accountability.

\section{5a Social accountability in Cambodia}

The Affiliated Network for Social Accountability in East Asia and the Pacific (ANSA_EAP) in its scoping study on social accountability practices in Cambodia has reviewed literature on the topic as well as conducted interviews with stakeholders to explore the implementation of social accountability. According to the study, the term social accountability is a relatively new concept in Cambodia that is poorly understood by public. The concept is understood as responsibility, honesty, and transparency, which is semantically related to social responsibility or moral responsibility of the leaders and citizens (ANSA_EAP, 2010). According to Babovic and Vukovic (2014), NGO's understanding of social accountability in Cambodia was significantly influenced by World Bank doctrine and the PECSA program. Interviewed respondents in their study have shared their understanding of the concept using non-confrontational discourse of social accountability (Babovic \& Vukovic, 2014). That is quite similar to the observation of ANSA that beside some are skeptical on the future of social accountability in Cambodia, others see it as an opportunity to build trust between state and citizenry (ANSA_EAP, 2010).

In accordance with this perception on social accountability, organizations' activities have been focused on facilitating dialogue between citizens and government and on organizing social accountability events (Babovic \& Vukovic, 2014). The work they have conducted in local communities is mainly on training local activists and citizens on various social accountability tools and mechanism, facilitating social accountability events and negotiating with the 
government organs regarding noted problems. Many of their projects are consultancy in their nature such as providing training, facilitating processes (Babovic \& Vukovic, 2014).

One interesting finding of Babovic and Vukovic's study is that NGOs participating in the study do not emerge from the communities with whom they work; most are based at the capital city. Therefore, they are not seen as being rooted in communities but as a 'bridge between the government and communities' (Babovic \& Vukovic, 2014). They perceive themselves as being as closely related to the donors and government as to the citizens. In addition, participated NGOs express that they have a thorough understanding on the limitation of their approach such as limited time span of a project, the inadequate government structure, unresponsiveness and lack of awareness among various levels of government, and the low level of empowerment of citizens (Babovic \& Vukovic, 2014). However, the solutions they propose such as creating personal and professional relations are considered as unsustainable and lack of thinking on institutionalization issues (Babovic \& Vukovic, 2014).

In conclusion, both studies of ANSA_EAP and Babovic and Vukovic suggest that social accountability practices have led to some improvements in the performance of local administration and public service (ANSA_EAP 2010, Babovic \& Vukovic, 2014). However, these improvements either were of less significance or were limited to the period of project activities. The study of Babovic and Vukovic also challenges the common assumption that social accountability can be easier promoted at grassroots levels as they have observed some challenges of NGOs in working with the local authorities who can be as distant as higher levels of authorities (Babovic \& Vukovic, 2014).

\section{5b Social accountability in Philippines}

The extent of social accountability initiatives in the Philippines is such that it has been proclaimed, alongside India, as the Asia-Pacific regional leader in social accountability (Arroyo and Sirker, 2005). Consequently, Filipino trainers and activists, particularly associated with the School of Government at the University of Ateneo in Manila, have been exported under World Bank programs to countries such as Cambodia to disseminate information and build capacity for social accountability (Oxford). 
According to ANSA_EAP, social accountability is the process of constructive engagement between citizens and government in monitoring how government agencies and their officials, politicians, and service providers use public resources to deliver services, improve community welfare, and protect people's rights. (ANSA_EAP, 2012)

In Philippines, social accountability work, both at the local and national levels, is undertaken predominantly by coalitions rather than individual organizations. Although there is a wide range of social accountability practices, there is a narrow spectrum of groups and organizations involved in such practices. According to ANSA_EAP (2012), there is an overlap of membership in the various networks and coalitions involved. The majority of the social accountability practices reviewed in their scoping report were implemented by organizations independent of government and are primarily driven by the desire to curb corruption and promote transparency and accountability in government within the framework of participatory governance. It is interesting to note that at the local level, the social accountability practices reviewed by the study were implemented in partnership with local government.

The passing of the Procurement Reform Act (PRA) in 2002 was a landmark for social accountability in the Philippines. Crucially, while democratic notions of accountability were significant within the transnational and national coalitions supporting the PRA, they were also often subordinated to, or articulated in conjunction with, liberal and moral rationales. Thus, although the political authority of citizens to scrutinize state power is advanced through the participatory rural appraisal (PRA) approach, this has largely been, particularly in the implementation phase, on the basis of directing civil society energies toward demanding technical and administrative tasks to improve governance. While helping consolidate coalitions between domestic business and middle class critics of corruption and attracting support from external funding agencies, this orientation also places limits on the scope for critical evaluation of the reform agenda by diverting efforts for building stronger and more cohesive grassroots constituency representation so fundamental to democracy. 


\section{5c Conclusion}

Though both Cambodia and Philippines are members of the Asian Network for Social Accountability, approaches and understanding of social accountability in the countries differ according to each country's context. In Cambodia, where democracy is still considered relatively weak, social accountability has mainly focused on local levels and the key achievement is to improve capacity of local activists or officials. The Philippines, on the other hand, is often said to play a leading role in promoting social accountability in the region, partly because their society is more open to the idea of democracy to spirits of democracy. The practices of social accountability are implemented mostly by coalitions or networks, focusing on transparency and combating corruptions. Though the Philippines' social accountability cases often are mentioned in donors' publications as success examples, it still is considered too technical and limits the ability of original citizens to participate in or truly drive the process. Hence, the conclusion of Sirker and Cosia (2007) that compared with other regions, social accountability initiatives across South and Southeast Asia have a much greater element of community participation and involvement should be re-evaluated. Moreover, seeing the differences in approaching social accountability in the two countries emphasizes the necessity of adapting the practices according to each country's context and the importance of understanding the context beforehand.

\subsection{Summary on Social accountability}

Social accountability is a relatively new term in mainstream development. It is often perceived as approaches or actions beyond voting, which can increase accountability of the state or the authorities. Social accountability can be easily misunderstood for civic engagement in governance since it often requires a great extent of participation of people. However, despite the great interest among organizations regarding the term, there is still no consensus on the definition of social accountability. In practice, World Bank has introduced a wide range of mechanisms and instruments, which can be adopted depending on the objective of practitioners. However, critics of this approach has pointed out that it tends to narrow down 
the impacts of social accountability into intermediary changes only. Long-term impacts like increasing accountability of the state or changing mindset and behaviours of people are still yet to be seen. Moreover, dependence on specific instruments makes it hard for local people and government officials to adopt social accountability as the application of the instruments require

a particular level of technical capacities. Recently, Jonathan Fox in a publication of the GPSA has distinguished between tactical and strategic approach to exercise social accountability. He suggests that the practices of social accountability has reached an 'early middle' stage and the mixed results of existing social accountability initiatives are often due to 'underdosage' interventions without sanctions and more about tactical approaches. Hence, he calls for more strategic approaches in the future of social accountability practices. Finally, though there are recognitions on the importance of understanding the context in adopting social accountability, it is still difficult to incorporate local input into the practices of social accountability, which may require more study. The differences in promoting social accountability in Philippines and Cambodia have supported the reflection. Though the two countries are members of one social accountability network in the South East Asia area, the perceptions, practices, and impacts of social accountability between the two largely differ due to the differences in history, culture, and politics. Hence, it can be unreliable if social accountability is promoted as 'one size fit all' solution for different contexts and its practices can be applied similarly in all countries.

\section{Chapter summary}

The chapter reviews literature regarding four concepts good governance, accountability, citizen participation and social accountability. Social accountability is a new concept which involves a certain extent of citizen participation in order to strengthen accountability and improve governance. The four concepts are closely associated and all concepts have been officially streaming into international development discourse. The concepts have been promoted with great potentials and expectations, being framed as one of the solutions for the development of countries. However, they also shared some shortcomings in terms of definitions, practices, and evaluation which require more study efforts and time to reconceptualise as well as enhance and confirm its actual impacts. 
As relatively new concepts, understandings on the terms vary among scholars, practitioners, and organizations. It is challenging to achieve consensus on the definitions of the terms. Attempts to conceptualize and reconceptualise have been taken over the past decade but it will continue to progress due to new experiences and reflections on the practices of the terms in reality. The roles of government, citizens, and NGOs should be challenged and put in specific contexts in order to decide on their position in the implementation of the concepts.

Regarding practices of the concepts, there is a shared criticism that the practices are often quite technical and have the tendency to be applied regardless of differences in the contexts. In order to tackle the issues, there are suggestions to distinguish between short and long route of accountability, weak and strong participation, and tactical or strategic approaches to social accountability. Hence, practices of accountability, citizen participation, and social accountability are not necessarily bound into one category but can be at any point of the spectrum. That approach offers more space for practicing the concepts and requires more thorough consideration when measuring the practices' impacts.

Finally, there are also discussions on the actual impacts of the concepts. There has been number of evidence for the correlation between governance, accountability and developments, as well as records for positive changes with participation and social accountability interventions. However, the recognitions are often drawn from quantitative, mega data study that can suggest the association of the practices and development but cannot clarify which factor is the cause and which is the result. Moreover, qualitative studies and studies aiming at identifying long term changes often results in more concerns and questions. Practices of social accountability are considered as able to bring intermediary changes like improving capacity of practitioners and transferring the knowledge of using the tools rather than significant changes in mindset and behaviours of people and the states.

It is interesting to see that there are similarities in conclusions regarding the four concepts. Beside the fact that the concepts are closely linked together, another factor to consider is the possibility that the underlying ideas behind the promotion of the terms in development practices mostly come from organizations like World Bank. It is difficult to deny the influence of 
the Bank and other organizations like UNDP, DfiD in the emergence of the concepts. However, as discussed, there is an increasing necessity for them to consider specific conditions at local contexts and take into account local knowledge as well as experiences and perspectives of local people. The emergence of the concepts is irreversible but certainly, their definitions and practices will continue to be revised and draw more attention from scholars and practitioners. 


\section{CHAPTER III - METHODOLOGY AND RESEARCH DESIGN}

\section{Introduction}

The chapter explains the research design of the study. It includes a description of philosophical assumption and a discussion on the researcher's positionality. The methodology and methods of the study are going to be described in detail. The process of selecting participants for interviews and processes of data collection and analysis are then outlined after a presentation of the methods. The chapter finishes with ethical considerations and limitations of the research.

\section{Philosophical assumptions}

Philosophical worldview can be described as 'a general philosophical orientation about the world and the nature of research that a researcher brings to a study' (Creswell, 2014). In scholars' work, it also has been named as paradigms, epistemologies and ontologies, or broadly conceived research methodologies. In this discussion, the word philosophical worldview will be used to keep the meaning simple and straightforward.

Philosophical worldviews are the underlying guide for researchers to situate knowledge. It forms the perspectives under which the research questions is developed and answered as well as explains why data will be collected and interpreted in a particular way (Bryman, 2012; Creswell, 2014). Therefore, though philosophical ideas are often not expressed clearly throughout research, researchers should identify theirs explicitly in the beginning of the studies.

Researchers often fall under one in four groups of philosophical worldviews: post positivism, constructivism, transformative, and pragmatism (Creswell, 2014). As this study is couched with a constructivist paradigm, a short explanation of the concept will be provided in the next section. 


\subsection{Social constructivism}

'Knowledge is actively constructed' (Fosnot, 2005: 1)

Constructivism is based on the assumption that rather than existing and being able to be examined outside, knowledge is actually constructed in the mind of individuals (Creswell, 2014). Therefore, A's view of one issue may vary from B or C's perspective. In addition, there is no objective truth as different people develop subjective meaning of one particular object (Crotty, 1998). According to Crotty, by engaging with the realities in our world, we subjectively come up with meaning or truth (ibid).

Thus, researchers who are employing the constructivist's lens understand that social reality is 'an ongoing accomplishment of social actors' (Bryman, 2012, pg. 32). Hence, instead for narrowing meanings into a few categories or ideas, the researchers look for the complexity of views (Creswell, 2014). As a child who is carefully looking at its kaleidoscope, researchers aim to collect and analyse as much as possible on the participants' views of his/her studied situation (ibid). Via discussions or interactions with other people, researchers conclude to him/herself the meaning and the answer they are searching.

\subsection{Positionality}

In its simple sense, positionality could be understood as how researchers affect the process of their fieldwork simply because of his or her presence. Positionality is constructed by aspects of identity along axes of race, class, age, gender, sexuality, nationality, level of education, disabilities, and other attributes (Marsha et al, 2009). According to Gillian Rose, the combination of 'facets of the self' (e.g. professional or institutional privilege) and 'aspects of social identity' (e.g. race, nationality, class, religion, caste, and sexuality) form the basis of a researcher's positionality (ibid). Villenas (996:722) realizes that 'as researchers, we can be insiders and outsiders to a particular community of research participants at many different levels and at different times' (cited by Merriam et al, 2010). Being perceived as insiders or outsiders may affect the work of the study as that affects the attitude and expectations of the study's participants on the research and the researchers. Therefore, at first, researchers should 
recognize their positionality and expect what it can lead to in specific situations. (Marshall \& Rossman, 2011). My considered positionality is discussed as follows.

I have worked for the Australian Foundation for the Peoples of Asia and the Pacific (AFAP) in Vietnam since 2013. The organization is an Australian non-governmental organization (NGO) working in Vietnam since 1996 making it one of the earliest NGOs arrived in Vietnam. I started working as a program intern and later as a project assistant focusing on social accountability thematic programmes. By working at AFAP, I have learnt about social accountability movements in Vietnam and built up my connection with interested organizations in this field. In December 2014, I returned to Vietnam during summer break and participated in the organization's national workshop on social accountability in Vietnam. Participating in the workshop has not only gained me further insights into social accountability's practices in Vietnam but also helped me to identify active actors in the field.

It is true that my experiences working with AFAP have brought me the curiosity and the determination to understand more on social accountability position in Vietnam. I also selected my contact list for the research's interview mostly from my networking contacts when working with AFAP Vietnam.

Working as an insider in the field certainly has gained me privilege to see the perspectives and practices of different stakeholders from the inside. As people often regard myself as an insider, they were more comfortable to be contacted and interviewed. Moreover, interviews with NGOs in Vietnam turned to be very straightforward and most participants were not reluctant to share their own perspectives.

However, when interviewing community people in Vu Quang district, Ha Tinh province (one of the two provinces I travelled to collect people's feedback), I experienced to be referred as an outsider and faced people's reluctance to share. At that time, the participants viewed me as an unknown person who wants to ask them questions related to democracy - a quite sensitive topic without any official notification from public officials at district level. They treated me with caution and was very careful with their words. 
Being insider and/or completely outsider to the person interviewed was expected before I conducted the interviews. For the latter situation, recognizing my position reminded me to stay calm and carefully explain to the people my purpose and persuade them to participate. In most cases, although I presented and kept reminding myself as an independent researcher, the advantages and disadvantages of my position in others' views are, to some extent, unavoidable. On the other hand, the attitudes of people towards me are probably reflecting their attitudes towards the topic I was studying. Moreover, it will be discussed later in the Analysis and Discussion chapter.

\section{Methodology}

\subsection{Qualitative studies}

As my study aims to explore the understandings and practices of social accountability, especially the application of the concept in the context of Vietnam, experiences and perceptions of people directly involving in the field are required. Putting together different opinions from different group of people can draw up the picture of social accountability in the country's reality. Keeping this purpose in mind, I believe qualitative approach is the appropriate methodology for the research.

According to Bryman (2012), qualitative research is characterised by three features. First, it provides an inductive view of the relationship between theory and research, whereby theory is generated out of the research. Second, it aims to understand the world through interacting with and interpreting the actions and perceptions of its actors. Third, rather than conducted in separate or constructed context, qualitative studies tend to collect data in natural settings with the implication that social properties are outcomes of the interaction between individuals (Bryman, 2012; Brockington \& Sullivan). In short, qualitative research is pragmatic, interpretive, and grounded in the lived experiences of people (Marshall \& Rossman, 2011).

Advantages of qualitative approach is in recognizing the important of context, setting and participants' frames of reference (Marshall \& Rossman, 2011). Hence, qualitative research can provide powerful insights into the world (Brookington \& Sullivan). 
In qualitative approach, individuals are interviewed at some length to determine how they have personally experienced oppression (Creswell, 2014; Bryman, 2012). It is important to stress the role of researcher in qualitative research. As in this kind of research, researchers are not distant neutral being (Grbich, 2013) but instead, taking an important role in collecting and interpreting data. Therefore, researchers should reflect well on his/her own positionality and be aware that the study is subjective in its nature.

Qualitative methods include a wide range of different techniques, from ethnography/participant observation, qualitative interviewing, focus groups, language-based approaches, to qualitative analysis of texts and documents (Bryman, 2012). For this study, semistructured interview and review of documents are employed to be the two key research methods.

\subsection{Semi-structured interviews}

In a semi-structured interview, researchers prepare a list of questions or topics to be covered. In the interviews, they can ask new questions that follow up interviewees' replies and can vary the order and even the wording of the questions. Normally, all the questions will be asked and a similar wording will be used from interviewee to interviewee (Bryman, 2012).

One advantage of semi-structured interview is that they can provide a much fuller and richer data set than highly structured questionnaires because of its higher level of flexibility, yet still be able to collect all needed information. On the negative side, there is also a risk of the interviewer being biased through prompting and question phrasing. Moreover, the success of the interviews depends on the interviewer's interpersonal skills as well as his or her ability to connect to the needed informants. Another note is that doing interview means all the interviews must be recorded adequately for analysis afterward (Castree et al, 2013).

Considering the advantages and disadvantages of doing semi-structured interviews, I believe the method is right for my study. The data collection process was also my learning towards the topic. Therefore, I did not want to limit information and prevent interesting experiences by applying a rigid questionnaire method. Semi-structured interview provides enough space for my 
study to collect different, unexpected stories and opinions yet still be organised enough for me to not get lost and concentrate on the research questions.

\section{2a Participant Sampling}

Participant sampling is an essential part of the research design, determining the quality of the research. Different from quantitative research, the use of probability sample is often limited in qualitative approach (Bryman, 2012). In qualitative research, researchers tend to gain access to as wide a range of individuals relevant to their researches as possible, so that many different perspectives and ranges of activity are explored (ibid). Purposive sampling, as a result, often is entailed more in qualitative research. In purposive sampling, researcher samples and selects cases and/or participants in an on-purpose way, always keeping in mind his/her research questions and making sure that those sampled are relevant to the questions (ibid).

Because of the nature of the research is to exploring the practice of social accountability in Vietnam, I adopted the participant sampling for my interviews and believe it is the most suitable one for my study.

Interviews were conducted with participants from a wide range of organizations. The range includes managers in international NGOs and local NGOs, local public officials representing for either public service delivery side or monitoring side, and community people who are both the service users and have participated in at least one social accountability initiative. The nongovernmental organizations were selected based on their experience and interest in governance and social accountability in Vietnam. In total, fourteen interviews were conducted. Fieldworks were carried out in Hanoi, Hoa Binh, and Ha Tinh provinces.

Hanoi is the location of most of international NGOs and other interested organizations. While visiting Hoa Binh - a Northern mountainous province and Ha Tinh - a province in the central part of Vietnam gave the interviewer opportunities to observe understandings and impacts of social accountability at grassroots levels. Da Bac district, Hoa Binh province and Vu Quang district, Ha Tinh province are two project sites of my former organization (AFAP Vietnam). Choosing the two districts as sites for my study gave me the convenience to access to the people and public officials as well as to understand the view of implementation partners. 
Moreover, it can reveal if there is any signs of the differences in perceiving social accountability and governance issues in general based on cultural differences.

In addition, a semi-structured interview with one member of a youth-based group in Hanoi was also conducted. The group has published a series of videos on social issues recently and drawn attention of young people impressively. Their most recent video was to disseminate knowledge of budget transparency and has turned to be an influential campaign targeting young people in big cities.

As mentioned in the book "Social research methods" written by Bryman (2012), purposive sampling does not allow the researcher to generalize to a population. Findings concluded based on the interviews stay true for only the interviewed participants. By selecting a range of interested but diverse group of participants, the research is expected to compile relevant stories on social accountability practices in Vietnam. 
Table 2: List of Interview Participants

\begin{tabular}{|c|c|c|c|}
\hline Code Number & Participant & Location & $\begin{array}{l}\text { Date of the } \\
\text { interview }\end{array}$ \\
\hline Interview 1 & NGO & Hanoi & $2 / 6 / 2015$ \\
\hline Interview 2 & NGO & Hanoi & $15 / 7 / 2015$ \\
\hline Interview 3 & NGO & Hanoi & $18 / 7 / 2015$ \\
\hline Interview 4 & UN organization & Hanoi & $18 / 7 / 2015$ \\
\hline Interview 5 & PMU & Da Bac, Hoa Binh & $20 / 6 / 2015$ \\
\hline Interview 6 & $\begin{array}{l}\text { Community people } \\
\text { - Group } 1\end{array}$ & Da Bac, Hoa Binh & $19 / 6 / 2015$ \\
\hline Interview 7 & $\begin{array}{l}\text { Community people } \\
\text { - Group } 2\end{array}$ & Da Bac, Hoa Binh & $19 / 6 / 2015$ \\
\hline Interview 8 & $\begin{array}{l}\text { Education } \\
\text { Department at the } \\
\text { District level }\end{array}$ & Da Bac, Hoa Binh & $19 / 6 / 2015$ \\
\hline Interview 9 & $\begin{array}{l}\text { Fatherland Front at } \\
\text { the District level }\end{array}$ & Da Bac, Hoa Binh & $19 / 6 / 2015$ \\
\hline Interview 10 & NGO & Vu Quang, Ha Tinh & $2 / 7 / 2015$ \\
\hline Interview 11 & Community people & Vu Quang, Ha Tinh & $4 / 7 / 2015$ \\
\hline Interview 12 & $\begin{array}{l}\text { Fatherland Front } \\
\text { and People's } \\
\text { Committee at the } \\
\text { District level }\end{array}$ & Vu Quang, Ha Tinh & $3 / 7 / 2015$ \\
\hline Interview 13 & $\begin{array}{l}\text { Agriculture } \\
\text { extension centre }\end{array}$ & Vu Quang, Ha Tinh & $3 / 7 / 2015$ \\
\hline Interview 14 & Student group & Hanoi & $22 / 6 / 2015$ \\
\hline
\end{tabular}




\section{2b Data Collection and Analysis}

A list of key interview questions was developed for each group of participants including: development practitioners - NGOs; government - local authorities; and community people. Questions were categorized into six aspects in order to seek input in: (1) context for social accountability in Vietnam, (2) perception of key actors regarding social accountability (3) common practices and existing approaches, (4) achievements and impacts (5) expectations and (6) suggestions for better social accountability practices. Specific questions for each group of participants were developed based on their relevant experiences and exposure to the topic. For instance, questions for NGOs were more detailed and focusing on their practices whereas questions for community members were simpler and emphasizing on their understanding on social accountability and its impact to their lives.

Although the list of questions were not sent to key informants before interviews, the content of the interviews had been contacted clearly beforehand via e-mails and phone calls. Before the actual interviews, the researcher also did some research to update on the participants' work on social accountability and governance. The interviews often lasted for $40-50$ minutes. The interviews were often framed as a conversation rather than a serious ask and answer series. Questions were flowed as naturally as possible and the question list was used as a guidance only. Nonetheless, at the end, all the needed content was still covered.

The interviews often took place in the participant's office. Four of them were at cafes due to the interviewees' request. For community people, I attempted to visit them at their houses so as they did not need to travel. Subjectively speaking, though at home and cafes, there were more noise and distractions, participants seemed to be more comfortable and easier to express their thoughts.

Interviews at Da Bac (Hoa Binh) and Vu Quang (Ha Tinh) districts were coordinated by my colleagues who were working with my organization's partner or my organization's project management unit. Since they were more familiar with the local people and authorities, they acted as the focal point and helped me to contact and have people join in my study. Most interviews at the fields were carried out smoothly. However, there were some adjustments and 
some unexpected events happened while I were at the sites. First, interviews with local people were turned to be group interviews (3-4 people per group) instead of one-on-one interview due to the interviewer's time constraint and the people's convenience. Second, though I had asked my colleagues to help me access to ordinary local people, miscommunication happened and caused some difficulties. In Vu Quang district (Ha Tinh), I was heading to a community house

where I had been told that there were three local people waiting for me after their weekly community gathering. As I arrived, there were three seniors discussing seriously on follow up actions after the meeting. They were in fact, leaders of the community - members of the Party. In addition, the quite awkward conversation between the people and I started as mentioned in the positionality section since they thought I were a stranger disrupting their important discussion. After asking me several questions on my purpose and reason I did not have any official permission from higher level of authority, they still gave me 15-20 minutes to interview but with cautious attitude.

Perceptions of the participants toward the interviewer certainly affected their answers and attitude to some extent. Therefore, these experiences are lessons learnt for me as they reminded me to be more careful in analysing the data and emphasized the importance of thorough preparation, especially if interviews are coordinated via indirect contacts.

Data analysis started with transcription and translation of the interviews. As data from various sources was collected, transcription consumed quite a lot of time. For translation, important information was selected and retrieved from the original recordings then translated. Double checking was employed to ensure the quality of the translation work. Input was then categorized under relevant groups depending on the content and its source.

\section{2c Review of relevant documents}

The review of documents included an analysis of documents from a wide range of valid sources. Legal framework and guidance from the government, studies on Vietnamese culture, civil society organizations in Vietnam, people and media's participation were collected and analysed to develop a context analysis for the study. Reports and workshop materials from different 
NGOs and interested organizations were also included in order to examine their approach, summarize their lessons learnt and evaluate impacts of their initiatives.

\section{Ethical considerations}

Research ethics is an important component of any research that provides security of a project to be conducted with a respect and responsibility towards its participants. To correspond to research ethics, the researcher had to meet Victoria University of Wellington Human Ethics Committee requirements for conducting research work. Other ethical considerations like avoiding leading questions and avoiding siding with participants had to be acknowledged as well.

Receiving approval from the Human Ethics Committee before undertaking any fieldwork was essential because the University requires it for research that involves human participants. To obtain the University's permission to conduct the research, an application for approval of research projects and designed participant information sheet consent form and interview checklist were submitted (see Appendix). These forms helped participants to understand the goal of the study, their role, conditions of voluntary participation and withdrawal and such important issues as security of data, confidentiality including coding of participants and using of quotes.

As most of the time being referred as an insider, I need to remind constantly of my positionality; self-reflection has proved to be a good technique for me to remain as independent and objective as possible. Since I had obtained some observations during the time working at AFAP, it was a tendency for me to express my opinions while interviewing key informants. Expressing my own opinions could be risky as I could easily forget my study purpose, ask leading questions and take a side with participants. The twos would affect answers of participants and the quality of the research significantly. Hence, it was crucial for me to remain neutral and stick to the questions prepared. I reminded myself constantly that voices of other people were what I needed and I had to collect those voices without interrupting their freedom to express their own thoughts. All of the considerations help preventing me from only 
collecting what I expected as well as what was align with my own observation and experience on the topic.

\section{Limitations of the research}

One great regret for the researcher is that there was no interviews carried out with high-level authorities in Vietnam. By the time the researcher's fieldwork took place, the authorities were busy preparing for one of the most important government meetings in Vietnam. Hence, it was very difficult to approach them. Their perceptions, as a result, had to be identified and analysed via their speech at relevant events like workshop, seminar, and media interviews as well as to be reflected via official documents and movement of the government.

The ability to generalize is another limitation of the study as the research was conducted in qualitative manner and using semi-structured interviews as the primary source for all the analysis. As discussed in the qualitative approach section, the findings and conclusions of the study can only be applicable for particular participants of the research instead of suggesting larger implications to other organizations and people.

Finally, a possible limitation of the research is the context analysis of governance in Vietnam. As the purpose of the study is to identify the position of social accountability in Vietnam, an insightful analysis of the country context towards governance movements is necessary. In order to have a detailed analysis, more materials should be collected including both qualitative and quantitative sources, for example a survey on people's willingness on participating on social accountability initiatives can be a great input to be incorporated in the analysis. In addition, a more rigorous context analysis framework can be developed to cover all necessary aspects. However, as the time and resources for the study are limited, all of the discussion can only be considered for further and deeper study of the topic.

\section{Chapter summary}

The chapter describes the process of research design for this study. The first and foremost influential factor to the design is the aim of the research which is to explore the practice and identify position of social accountability in Vietnam. This purpose drives the whole process of 
selecting methods, participants, and references for the study. Another factor that guiding the methods selection, data collection and analysis is the recognition and adoption of constructivism as the philosophical worldview is the underlying guide for the whole study.

Keeping the two factors in mind, qualitative approach was employed to be the methodology of the study with semi-structured interview and review of relevant documents to be the study methods. A discussion on data collection and analysis was outlined, providing my personal reflection notes. Overall, being reflexive and aware of the researcher's positionality are the most important lessons during the whole process of collecting and analysing the data.

Finally, the possible limitations and ethical considerations are presented. As generalization becomes the greatest limitation of the study, the researcher suggests that a further study should be conducted with a combination of both qualitative and quantitative approach. This further study can be constructed based on the findings of the particular research. 


\section{CHAPTER IV - VIETNAM CONTEXT FOR SOCIAL ACCOUNTABILITY}

\section{Vietnam - a country in transition}

Vietnam is transforming from a primarily rural to a primarily urban economy accompanied by a transition from a state dominated economy to a socialist market economy (EU-ACVN, 2008). Political and economic reforms (Doi Moi) launched in 1986 have transformed the country from one of the poorest countries in the world, with per capita income around $\$ 100$ to lower middle income status with per capita income of over \$2,228 in 2015 (World Bank, 2014).

The country has made remarkable achievements in poverty reduction. According to the country's overview on the World Bank website, using the \$1.90 2011 PPP line, the fraction of people living in extreme poverty dropped from over $50 \%$ in the early 1990 s to $3 \%$ in 2014 . The country has achieved a number of MDGs and targets such as (i) eradicate extreme poverty and hunger, (ii) achieve universal primary education, (iii) promote gender equality in education (UN, 2015).

Fundamental policy reforms underpin Vietnam's transition and economic dynamism. Since 1990s, Vietnam has begun a process of decentralization, moving away from the centrally planned economic approach adopted after the end of the American war ${ }^{1}$. There also have been steady moves since then, notably through the Public Administration Reform (PAR), the Grassroots Democracy Decree (now the Grassroots Democracy Ordinance), and the State Budget Law (allowing allocations to lower levels of government). Globalization is an undeniable trend and bringing significant changes to the country. Accession to the World Trade Organization (WTO) in January 2007 has resulted in lower barriers to trade and opened service sectors to competition. The Trans Pacific Partnership Agreement is also expected to trigger changes not only in economic development but also in structural political and social reforms. Nonetheless, Vietnam has also faced an increasing number of unprecedented development issues. The 2012 National Report at the United Nations Conference on Sustainable Development $(\mathrm{RIO}+20)$ concluded that required conditions for Vietnam to become an industrialized country has not sufficiently taken shape implying the country is quite vulnerable

\footnotetext{
${ }^{1}$ American War is often referred in the West as the Vietnam War (1955 - 1975)
} 
to global economic crises. As inequality continues to expand, economic vulnerability will have greater effect on poor people (World Bank 2014, UNDP 2015). Despite a high rate in poverty reduction, poverty recurrence also remains high, especially in certain areas such as high mountain areas, ethnic minorities' areas and natural disaster-prone areas (Vietnam Profile, 2012). With the current urbanization rate of $27 \%$, challenges regarding social security, unemployment have increased and become more complicated. Unstable economy, high rate of urbanization and its negative effects, environmental degradation, corruption and growing disparities are some of the difficulties facing the country today.

As a result, urgent policy responses are expected from the government. The Vietnam SocioEconomic Development Strategy 2011-2020 calls for 'breakthroughs' in structural reforms, environmental sustainability, social equity and macroeconomic stability. However, some scholars remain sceptical regarding the ability of the government in dealing with the major challenges as Vietnamese polity is considered hierarchical and conservative (Wischerman, 2010). Hence, improving governance, including engaging more citizen participation, has been recognized as one of the most critical factors defining sustainable development in Vietnam (UNDP, 2012; World Bank, 2010, 2012).

\section{Policy context regarding governance and people participation}

\subsection{Political structure overview}

The Socialist Republic of Vietnam is a one-party state under the lead of the Communist Party of Vietnam - "the representative of the people and the nation" (Article 4, Vietnam Constitution 2013). The National Assembly, established according to the Constitution of 1992 is the supreme organ of state and the only body with constitutional and legislative power.

The Government is the executive organ of the National Assembly, the highest organ of state administration of the Socialist Republic of Viet Nam. It carries out overall management of the work for the fulfilment of the political, economic, cultural, social, national - defence, security and external duties of the State.

In terms of formal structure, Vietnam's local administration system is divided geographically into three levels: 
- Provinces (about 60 units including three municipalities)

- Districts (about 600 units); and

- Communes (about 10,400 units)

At all three levels, there is a representative body (people's council) and an executive body (people's committee). The people's committees and people's councils often have overlapping membership. The local people elect the people's council, the candidates for which are usually nominated by the Vietnam Fatherland Front and approved by the higher-level administrative unit. The people's council selects the chairperson and vice-chairman of the people's committee.

The existing mechanisms to monitor and supervise the state's power can be categorized into two main groups. The first one is state monitoring, including monitoring of National Assembly and People's Councils to state administration agencies, top-down monitoring within the authorities, monitoring of judiciary bodies, and of supervisors in the state's structure. The other mechanism is social (people's) monitoring with involvement of social-political organizations, mass organizations, associations, and individuals. Different from state monitoring, the social monitoring mechanism can only send requests and feedback to authorities. Whether the requests are responded is not regulated by law and is up to the authorities (Nguyen, 2012).

The function of 'social monitoring and criticism' as written in Vietnam Constitution is assigned to the Viet Nam Fatherland Front. The Vietnam Fatherland Front is an overarching political alliance organization of all the mass organizations in Vietnam including the Veteran's Union, the Women's Union, the Youth Union and the Farmer's Union. The mass organizations are the only social institutions that exist across the board in all localities and have the stated role of supporting people to gain access to the state and government (Phan Xuan Son 2002 cited in UNDP 2006).

\subsection{Direct and Indirect democracy mechanisms}

Vietnam's political system provides numerous structured possibilities for citizens to participate in decision making and monitoring. The two principles 'People know, people discuss, people execute and people supervise' and 'Government of the people, by the people, and for the people' which have been repeatedly mentioned in documents and policies of the Viet Nam's 
Communist Party reflect the wish of the Government to encourage every social organization and citizen participating in formulating, implementing and monitoring state's actions. According to the 2013 Constitution, "the people shall exercise state power through direct democracy and through representative democracy in the National Assembly, People's Councils and other state agencies" (Article 6, 2013 Constitution).

Direct democracy refers to direct participation of people in policy and management, particularly at the local levels through meetings and other forms of interaction with state authorities (UNDP, 2006). Participation requires that citizens, first, be aware of local governance structures and opportunities for participation. Second, people typically participate through one or more organised groups or associations, which may be officially established (such as in the case of mass organizations) or informal and unregistered (as in local clan, lineage, and most cultural groups). Through these and other structures, people contribute to local socio-economic development programs and policies, such as land allocation, budget formation and monitoring, or poverty reduction programs implemented by state agencies, sometimes with the involvement or funding from international lenders or NGOs. Finally, people have important roles in monitoring implementation of local authorities, making formal complaints in case violations occur, and resolving disputes among citizens or between citizens and authorities. The law prescribes that citizen should monitor local government performance through vertical accountability structures, forming the lowest level of direct participation, with People's Inspection Boards (PIBs) and Community Investment Supervision Boards (CISBs).

Indirect or representative democracy refers to governance through elected representatives and deliberative bodies, primarily local village leaders, People's Councils and the National Assembly. It is manifested in the right of citizens to elect local leaders - village head in rural areas and residential group heads in urban areas, local people's council members at different administrative levels on a five-year basis and deputies to the National Assembly every five years. According to the 2013 Constitution, "the elections of deputies to the National Assembly and People's Councils must be conducted on the principle of universal, equal, direct and secret suffrage" (Article 7, 2013 Constitution). Further legal requirements for elections are set out in the Law on People's Council Elections (2003), Law on National Assembly Elections (2010), and 
the Grassroots Democracy Ordinance (for village head elections) (Oxfam- UNDP, 2015). Recently, in order to improve the institutions of representative democracy, Vietnam has adopted 'Vote of Confidence'. The National Assembly now has the right 'to cast a vote of confidence on persons who hold positions elected or ratified by the National Assembly'. The first vote of no confidence was held in 2004 when the National Assembly dismissed the Minister of Agriculture and Rural

Development from the cabinet following allegations of corruption (UNDP, 2006).

Citizens have also been granted the right to hold confidence votes for elected posts in their localities. Officials will need to have at least $50 \%$ support in order to stay in office. The Fatherland Front is supposed to organise confidence votes for key elected positions each year.

\subsection{Existing gaps and limitations in practices}

The establishment of the direct and indirect democracy mechanisms can be considered as the state's attempts in improving the country's governance and encouraging people's participation. Only after the introduction of the Grassroots Democracy Decree in 1998, the mechanisms are eventually developed. However, over years, the country's governance is still low-ranked in international governance indicators. Below is the ranks of Vietnam's governance indicators from 2004 - 2014 published by the World Bank. 


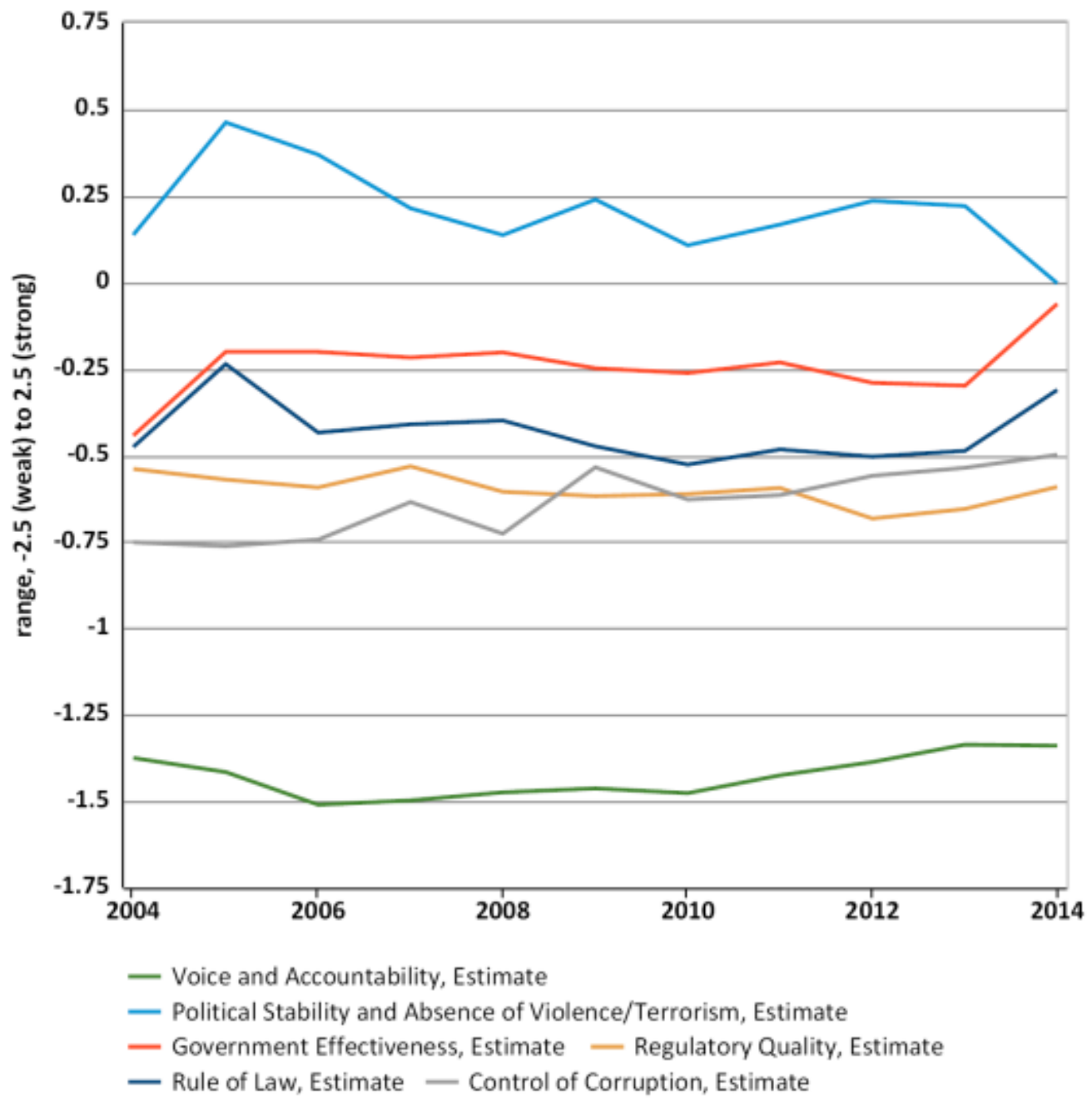

Figure 3: Vietnam Governance Indicators (Source: The World Bank)

Figure 3 reveals that governance in Vietnam is very weak in all criteria with political stability having the best score (0.5) in 2005 on a scale from -2.5 to 2.5. Voice and Accountability is improving yet still remains as the lowest. Although some argues that the indices were rooted in Western countries where political-administrative systems are very different from Vietnam (Andrews et al, 2010), the low ranking in the particular aspects still suggests poor implementation of policies towards increasing people's voices and strengthening government's transparency.

As abovementioned, Vietnam Fatherland Front plays a critical role in practicing social monitoring and improving direct democracy or participation. It is worth noting that the 2015- 
revised draft on Law on Local Government does not contain mechanisms for citizen feedback to local government, the function to provide feedback is still only reserved as the mandate of the Fatherland Front. However, citizens' consultations run by the organizations are very often formalistic, bureaucratic and one-way communication with regular meetings aiming at only informing people about state polices and plans without discussing (Oxfam-UNDP, 2015). The Fatherland Front and the mass organizations under it are often concerned for their lack of ability to monitor state's performances. The Vietnam Provincial Governance and Public Administration Performance Index (PAPI) study - an annual nation-wide quantitative study based on citizens' experiences has found that over time, though associational membership increases, citizen monitoring of local government performance remains the lowest performing area of direct participation (PAPI, 2015). Hence, the Oxfam-UNDP report argues that participating in these organizations is not necessarily linked to contribution to local governance plans and polices (Oxfam-UNDP, 2015).

Another direct democracy mechanism - the primary format for citizen participation in socioeconomic development is village meetings. The Grassroots Democracy Ordinance and other legislation stipulate that village meetings should occur, but do not specify how meetings should be organised, how often, or with what specific contents. Much participation in meetings is seen as superficial and nominal. Citizens' consultation meetings though happen regularly, often are regarded as a one-way communication channel from the authorities to the citizens, but hardly organised in a way to facilitate citizens' involvement (Charlier, 2015). Although opportunities for engagement are present, they may not equate to real influence on governance (OECD 2014).

Other monitoring mechanisms at grassroots level like People's Inspection Boards (PIBs) and Community Investment Supervision Boards (CISBs) are often not functioning as designed; and their members lack the necessary basic skills to be in a position to efficiently fulfil their mandates (Charlier, 2015).

Regarding indirect participation, the study conducted by Oxfam and UNDP has also found out that interviewed people are more interested in election of their village head as they find it 
more relevant to their life. Elections at higher levels do not draw their attention due to lack of information of the candidates' profile; some people reported that they only saw the picture of the candidates and brief information on their work experience before coming to the voting place (Oxfam - UNDP, 2015). Though the election should be kept 'universal, equal, direct and secret suffrage', the issue of 'proxy voting' - head of the family can vote for other family members still exists and limits the objectivity of the results (Oxfam - UNDP, 2015). One study of UNDP in 2006 in improving democracy in Vietnam has found that only members of the Fatherland Front - who are party members, can 'vote for confidence' (UNDP, 2006). Hence, it can raise the concern of the representativeness of the voting results, particularly when members of the Fatherland Front are often dual-appointed as some local government officials.

Finally, though the legal framework has favoured participation of people, the two important laws - Law on Information and Law on Association have not yet taken effect. The gap in legal framework remains a challenge for people to exercise their rights and be protected by law.

\section{Civil Society and Governance in Vietnam}

At the Economic Spring Forum May 2014, the former minister of Industry and Trade Truong Dinh Tuyen surprised the public by stressing that it is the time for Vietnam to recognize and admit the role of civil society organizations. According to him, recognizing the role of civil society is necessary and it will help correct shortcomings in the state's functions. The speech echoed with the speech of Vietnam Prime Minister Nguyen Tan Dung at the New Year Eve 2014 (which also stressed the importance of having a strong and healthy civil society), which are both considered as breaking the ground and the taboo existing in Vietnam for years that civil society is a "countervailing power" of the state (Perinova, 2004:7).

Because of the cautious perception regarding civil society, a key constraint for the development and operation of the organizations is the lack of a legal framework for civil society organizations (DfID, 2012). In accordance with Vietnam constitution, people only have the right to associate under certain limited conditions set by the State. In relevant decrees and legal documents, it is stipulated that the "party/state" "allows" people to associate and allows certain civic organizations to be established under specific conditions (Wischermann, 2011). In order for a 
foreign NGO to operate in Vietnam, they have to apply for a range of permissions of the Government of Vietnam including Permit for Operation, Permit for the Establishment of Project Office and Permit for the Establishment of Representative Office. Hence, it is understandable that civil society in Vietnam is relatively a young force in the society of Vietnam and is under strict regulations as well as some cautious perceptions.

Nonetheless, the country is still observing the growing number of working civil society organizations. According to Civil Society Index Report for Vietnam 2006 (CIVICUS), among 100 Vietnamese citizens, 74 people are members of at least one organization (including mass organizations); $62 \%$ are members of more than one civil society organizations. The number of NGOs operating in Vietnam also increases from 183 in 1992 to 514 and 800 in 2003 and 2010 respectively.

\subsection{Signals of increasing interest in governance and social accountability}

"Civil society actors outside of mass organizations remain mostly unengaged in policy discussions and do not yet form a strong conduit between citizens and the state" (UNDP, 2006: iv). The conclusion of UNDP in 2006 seems to be valid in the current time in Vietnam. Poverty alleviation and community development are the focus areas for Vietnamese civil society organizations (CSOs). These activities have been particularly concentrated in remote or predominantly ethnic minority areas. With the recent expansion of civil society, the themes have become broader in terms of ranges of livelihood models and focus areas such as education, gender equality, natural resource management, and climate change (Figure 4). 


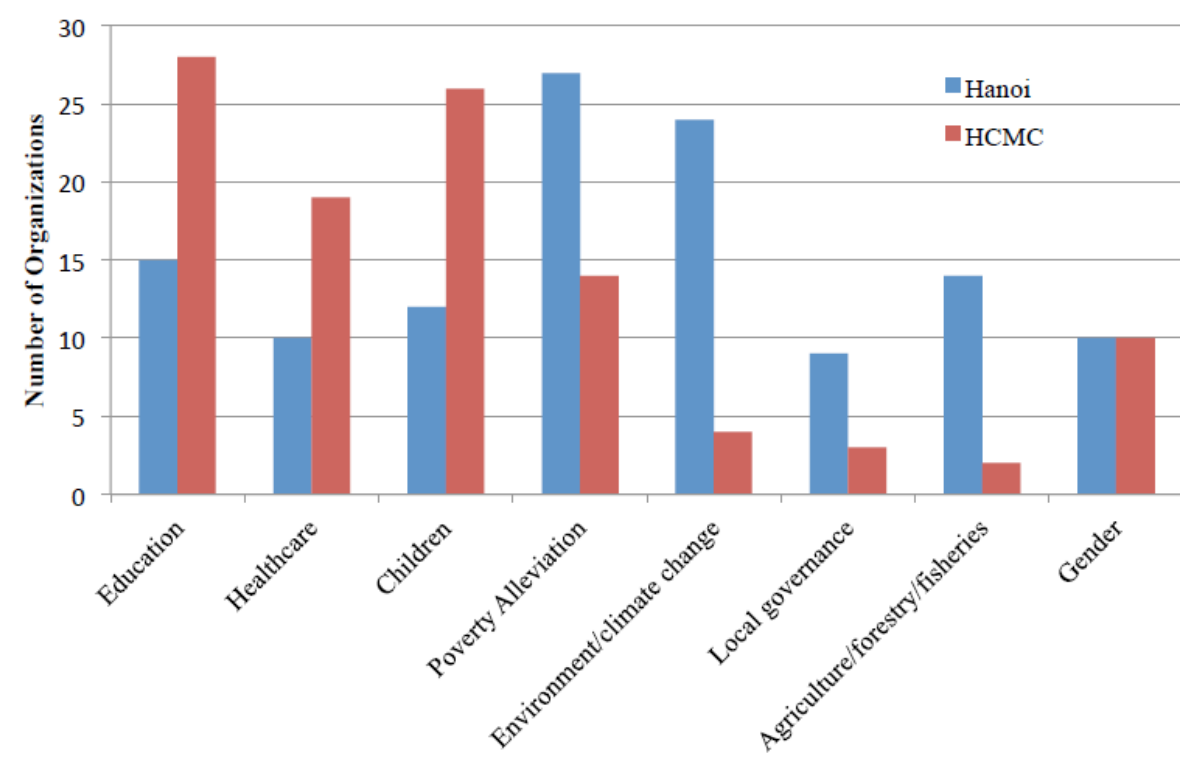

Figure 4: Fields of operation of interviewed CSOs in Hanoi and Ho Chi Minh City.

(Source: Civil Society Report, 2012)

However, according to the Civil Society Report, a significant number of organizations interviewed shared that they have changed their priorities in order to adapt to changes in socio-political needs. Shifts from direct assistance as a service provider to approaches that utilize communication and advocacy strategies are recognized as one of the discernable trends in operation of the organizations. In the study "Toward Governance for Sustainable Development: Vietnam's International Non-Governmental Organizations in Transition", the authors argue that since Vietnam has moved to a low middle income country, INGOs in Vietnam are adapting themselves to the country's transition. Their merging programs are now focusing on developmental governance, including capacity building, empowerment, participation in decision-making, market governance, and social accountability (Nguyen et al, 2015). 
Although considered as new concept and new trend in thematic programs of CSOs, the work of the organizations in governance still brings positive impacts which can lead to a greater level of engagement of civil society in governance. Two of the successful examples of CSOs in policy advocacy and consultation are the involvement in Drafting Amendment to the 1992 Constitution and the work of the People's Participation Working Group (PPWG) (See Box 4).

\section{Box 4: Examples of collective efforts of Vietnam civil society organizations in governance}

1. The process for amending the 1992 Constitution of Vietnam has been initiated since August 2011 with the National Assembly's adoption of Resolution 06/2011/QH13 to amend the 1992 Constitution and to set up the Committee of Drafting Amendment to the 1992 Con stitution. The amendment is expected to bring about big changes in the 1992 Constitution, based on comprehensive review of the Constitution implementation. The public have been invited to provide inputs and comments on any aspect of the Draft Amendment. Civil Society Organizations in Vietnam actively involved in the process and ran several initiatives to advocate for changes in the Constitution. One survey conducted to collect, process and consolidate views and opinions of professional-social organizations and civil society organizations on selected issues in the amendment to the 1992 Constitution. About 545 organizations from 45 provinces and centrally affiliated cities responded to the survey. A working group consisted of different NGOs working in Vietnam lead by Oxfam worked closely with the National Assembly to provide comments for the Amendment. (UNDP, 2013)

2. The People's Participation Working Group (PPWG) was established in 1999. It is an informal network that acts as a forum for organizations and professionals - such as donors, government employees, NGOs, project managers, consultants and researchers - to exchange information and ideas on issues relating to people's participation, grassroots democracy and civil society. As a partnership group, it provides inputs to the Vietnam Consultative Group, the high-level meeting held twice a year between the Vietnamese Government and the donor community. The group has work effectively in providing inputs for law making process, especially regarding human rights. It participated in consultation for developing Law of Information Access in Vietnam and recently is advocating for changes in Law of Land and Law of same sex marriage. (Source: ngocentre. org.vn)

One of the most significant approach of civil society organizations, especially NGOs is adopting social accountability in their work. The concept has been introduced first by international organizations like UNDP, UNICEF, Oxfam, ActionAid, AFAP, etc. and emerged in work of local NGOs as well. The practices of social accountability will be discussed in the following chapters. 


\subsection{Potential and opportunities for civil society organizations working in governance}

According to the Vietnam Sustainable Development Strategy for period of 2011 - 2020, one of the key identified objectives for the development of the country is: "To develop a democratic, disciplined, harmonious, equal and civilized society" which will be achieved by "improving the role and responsibility and enhance the participation of business community, socio-political organizations, social-professional organizations, non-Governmental organizations and residential communities in deploying sustainable development: ...in deploying, consulting, criticizing, and proposing sustainable development policies". The objective and approach show a greater commitment of the State in working with non - state actors toward a democratic governance as well as recognition the importance of the actors. Together with all changes that have happened in the last few years, it is possible to believe that in the upcoming years, there will be more opportunities and invited spaces for civil society organizations to take a more significant role in enhancing governance in the country.

\section{Chapter summary}

Vietnam is in its most critical transition from a poor to a low middle-income country. During the process, the country has enjoyed a number of great achievements not only in economic development but also in improving people's basic living conditions. However, more and more complicated challenges have been facing the country as there are more unprecedented changes. Growing disparity and high urbanization rate are some of the issues needing urgent policy responses. The situation hand in hand with a greater extent of globalization have led to higher demand of people from all walks of life to participate in policy design, implementation, and monitoring.

As a response from the government, a large number of attempts have been made in order to establish more favourable conditions for participation of people. Through direct and indirect democracy, citizens' voices are expected to be heard through a wide range of mechanisms. However, the practices of the policies have been regarded as formalistic, bureaucratic and oneway communication as they greatly rely on mass organizations under Vietnam Fatherland Front. Limitations of capacity of officials and people in practicing people's right to participate 
remain constraints for better implementation of the policies. Moreover, as law on association and on information have not been validated, there are still critical gaps in the existing legal framework to motivate participation of the people.

Meanwhile, international and local NGOs are endeavouring to address the shortcomings in governance and to cope with changes in the country. Focusing on developmental governance has been perceived as one of the key directions for thematic programs of the organizations in Vietnam. The organizations have employed and introduced the concept of social accountability as well as operated an increasing number of initiatives to improve the role of people's participation. 


\section{CHAPTER V - SOCIAL ACCOUNTABILITY IN VIETNAM}

\section{Perceptions regarding social accountability}

\subsection{Social accountability in organizations' perceptions}

Social accountability is often considered to be first introduced in Vietnam in 2003-2004 when the World Bank, Sweden International Development Agent and Vietnam Ministry of Home Affairs piloted Citizen Report Card - a social accountability instrument in four cities in the country (ActionAid, 2011). Since then, the term has attracted attention and interest of many organizations, especially non-governmental organizations. However, perspectives of organizations on the question of 'what is social accountability' can vary to a great extent.

One interviewee perceives social accountability as a form of vertical accountability - which is quite similar to the understanding held by UNDP. According to the participant, social accountability is a means for people to exercise their 'customer power' on the government, which is taking on the role of service provider.

I see social accountability as one form of vertical accountability. It helps people to exercise their role to demand their governments as from service users and service providers. (Interview, July 2015)

Another NGO representative also shares the view but from a different angle where social accountability is to encourage the 'responsiveness' of service providers.

Social accountability is to facilitate the 'responsiveness' of service providers. It is all about increasing people participation, people monitoring, and improving the answerability of implementation bodies. It is more than just mere instruments. (Interview, July 2015)

Another perspective shared by a manager of a local NGO does not frame the main relationships of social accountability through the lens of a service delivery relationship. The person understands that there is not yet a consensus on the definition of social accountability. According to the interviewee, social accountability is a process where people can participate and contribute to a government's work. Social accountability comprises people's participation 
aiming at 'holding the state accountable', but the most critical element of social accountability should be the engagement of people.

Social accountability definition is still a subject to discuss. I understand it as people participation in contributing and raising feedback in all government's work relevant to their life. Social accountability is both about people participation and accountability but the first and foremost element is the engagement of people. (Interview, July 2015)

Finally, a manager of an international development organization perceives social accountability as a tool or set of tools to monitor and evaluate socio-economic strategy.

There is still no concrete form of social accountability approaches among big organizations. Myorganization frames it as one tool to monitor and evaluate socioeconomic strategy. (Interview, July 2015)

The variety of views shared on social accountability differ from their expected levels of people participation, their implication on the relation of state and people, as well as whether to see social accountability as a technical instrument. However, their understandings of the concept are quite similar to definitions and explanations provided by World Bank or UNDP. The idea of facilitating people's participation to hold the state accountable can be seen as the core idea of World Bank's definitions over years as mentioned in Chapter 2. As the term is not rooted in Vietnam and is promoted enthusiastically by the large development agencies like World Bank, it is understandable that NGO managers are influenced greatly by ideas of the organizations while studying the concept of social accountability.

Despite differences in their understandings of the concept, the managers all express their understandings of the term by using non-confrontational discourse. There are no signals in their answers implying the potential of social accountability to challenge the existing power structure. In their answers, social accountability is perceived as a complementary to the current vertical accountability mechanisms, monitoring and evaluation tools, means for people to raise their voice and to increase the state's responsiveness. None of the participants implies the possibility that social accountability can sanction wrongdoings. Instead, social accountability is expected to 'help the government' to be more effective, transparent, and efficient but not for it 
to be challenged. The employment of non-confrontational discourse is also recognized by Babovic and Vukovic (2014) in their study on social accountability in Cambodia. According to the authors, this approach is realistic in the political context of Cambodia where spaces for democracy activities are still limited (Babovic and Vukovic, 2014). In the context of Vietnam, the conclusion can also be applied especially when social accountability is still in a pilot stage and organizations often choose to collaborate with the government to practice the concept.

It is interesting that some organizations perceive the relationships between people and the government as the same as customer and service provider relationships. According to Niraja Gopal Jajal, the perception is driven by the rise of neo-liberalism when citizens were often redesignated as consumers or users (Jajal, 2008). In the context of Vietnam, framing the relationships between people and the state as customers and providers can resettle the role and rights of both people and the government. It can be helpful in the country since some government officials and people still have the 'ask-give' mindset. Through the old-school mindset it can be understood that officials hold the rights to decide on whom should receive what service or benefit and people, especially poor or people in remote areas keep seeing themselves as beneficiaries of the services. Thus, the customer-provider perception that positions people as customers and officials who are in charge of providing services as service providers challenges the ask-give mindset as well as the underlying power imbalance. Customers have the right to raise their feedback and expect appropriate responses from service providers; otherwise, they can choose other providers and withdraw from the service. However, seeing people and government officials as customers and service providers can embed the risk of simplifying the power struggle in the Vietnam context, especially with the poor. This concern has been expressed by one participant as follows. According to him, people can exercise their customer power of a particular public service when they can exit or choose alternatives of the service. Therefore, it must be very challenging for the poor to exercise their power when they cannot access alternatives due to their remote location or lack of finances, and they cannot exit from the service provided by the government. In this case, the customer service provider assumption cannot be applied. 
One of the key roles of the government is to provide services to people. Seeing people and the government as customers and providers in this sense is undebatable, the only issue is whether the government accept that role. Customers 'power comes from 2 aspects: ability of the customers to exit and their ability to raise voice. If the poor cannot exit (because they have no other choices) and cannot raise their voices, they cannot exercise their power as a customer. In the worst scenario, they can react extremely. (Interview, July 2015)

In a nutshell, organisations in Vietnam perceive social accountability, as a new concept, differently in many aspects. It is understandable that organizations' views on social accountability are greatly influenced by ideas and rationale of World Bank and other organizations which promote the concept. However, in the context of Vietnam, organizations often choose non-confrontational discourse in order to describe social accountability and its potentials. The use of the discourse also reflects organizations' expectations and practical approach towards the adaption of social accountability in Vietnam. Finally, the understanding of the concept often promotes the customer - service provider relationship and challenges the ask-give mindset in the role of people and government officials. The old school mindset clearly should be challenged. However, it is not recommended to promote the customer - provider relationship as a one size fit all solution in the context of Vietnam, especially where poor people have no other choices than services provided by the state.

\subsection{Social accountability - challenges in translation}

There are discussions among interested organizations on how to translate the term 'social accountability' into Vietnamese. In the National Workshop on Social Accountability hosted by the Australian Foundation for the Peoples of Asia and the Pacific (AFAP) in Vietnam and UNICEF in December 2014, one of the key concerns among participants is the lack of consensus in translating the term. As organizations are using and promoting different translations, attempts in disseminating knowledge and building up networks among organizations can be restricted. 
There are currently two ways to translate social accountability. One of the translations is 'social audit' ${ }^{2}$ which is being used by UNICEF Vietnam. The term is often criticized as it may cause misunderstandings since the word 'audit' is easily mistaken to financial audit. 'Audit' may suggest supervision on money issues which is considered as sensitive in the context of Vietnam. Moreover, the term is also the name of a social accountability tool introduced by the World Bank $^{3}$. Hence, adopting the translation can cause confusion and caution from involving stakeholders. Here is the experience of one local NGO which adopted the 'social audit' tool for the first time at its location.

One or two years ago, we adopted 'social audit'. At that time, our local partners mistook 'audit' as supervising, checking and controlling. Only until they participated with us to operate the activity, they started realizing what social audit actually is and stopped seeing it as 'sensitive'. (Interview, July 2015)

The other translation is 'social supervision' or 'social monitoring' proposed by AFAP Vietnam. AFAP is using the term which has been introduced and recognized in legal documents so it is easier for government officials and the public to understand and accept. According to a Vietnamese dictionary, monitoring or supervision means the action of observing and checking the execution of a task or activity. For some officials, the words can be interpreted to mean their work is checked by the community and their wrongdoings or mistakes will be publicized. Hence, the translation loses the implication of cooperation among people and the state and sounds more confrontational than organizations' actual interpretation on social accountability. Moreover, social supervision and criticism as stated in legal document is the mandate of the Vietnam Fatherland Front and its member organizations. Article 25.1, Chapter V, Law on the

\footnotetext{
${ }^{2}$ According to UNICEF Vietnam, a social audit is management tool and accountability mechanism that can be defined as the range of methodologies, tools and techniques that are used to assess, understand, report on and improve the social performance of an organization, a plan or a policy (UNICEF, 2011).

${ }^{3}$ According to the World Bank, Social Audit (sometimes also referred to as Social Accounting) is a process that collects information on the resources of an organization. The information is analyzed and shared publicly in a participatory fashion. Although the term "Audit" is used, Social Auditing does not merely consist in examining costs and finance - the central concern of a social audit is how resources are used for social objectives (Social Accountability Sourcebook Homepage, 2016).
} 
Vietnam Fatherland Front has explained the meaning of supervision by the Vietnam Fatherland Front:

Supervision by the Vietnam Fatherland Front means that Vietnam Fatherland Front Committees at all levels shall themselves, or request member organizations of the Vietnam Fatherland Front to, monitor, consider, assess, and make proposals on, the operation of agencies, organizations, popularly elected deputies, cadres, civil servants and public employees in the implementation of policies and laws.

As a result, adopting 'social supervision' as the translation of social accountability may assume that in order to undertake social accountability, organizations should develop a close working relation with the Vietnam Fatherland Front. The partnership can be a good entry point for organizations to practice social accountability. However, it can also constrain its independence.

\section{Potential of distrust and the emergence of social accountability in Vietnam}

Answers for the question if 'social accountability' is a new concept in Vietnamese society vary according to the perception on 'what is social accountability'. Should social accountability be considered as adopting feedback and monitoring tools like the Citizen Report Card, it certainly is a new concept. However, if the core of social accountability lies in the idea of citizens participating and contributing to the work of the government, it is indeed not a new story. According to one participant, there were cases when people reacted to corrupt officials and managed to protect their rights.

(Social accountability) is not new but it is getting more and more attention. That people raise their voices when they do not agree with the work of the government happened years ago. For instance, the case in Thai Binh province ${ }^{4}$, people stood up against the local government due to its lack of transparency. The case has brought to the introduction of the Grassroots Democracy Decree. (Interview, June 2015)

\footnotetext{
${ }^{4}$ In May 1997, Thai Binh peasants protested against corrupt local officials, punitive tax demand, land dispute, unfair rice price and compulsory labor contributions. The government's response was to discipline some of the officials involved, and to adopt the Grassroots Democracy Decree. Between 1998 and 2001, a number of additional documents were issued to implement grassroots democracy (Smoke et al, 2006).
} 
Despite the lack of consensus in social accountability's definition, the idea of people involving in activities to hold the state more accountable gains strong support from Vietnam's civil society. That idea has arisen in a context with favourable conditions for it to grow as well as existing gaps for it to address.

Social accountability is a trend. It is an emerging demand of the society. It has also become one of new priorities of the government. Recently, terms related to social accountability have been spread more and more widely. The Vietnam Fatherland Front and the People's Council are expected to represent and strengthen people's voice but it is difficult for them to meet the expectations. Both society and the state have recognized the importance of people's monitoring. The government needs to be more transparent and open with the idea of social accountability due to pressure from domestic society as well as international organizations. (Interview, July 2015)

Participants in the study share two observations regarding the context of Vietnam. They all agree that the situation has changed positively and there are more spaces for people to express their opinions. However, even though the situation seems to be more favourable, mechanisms provided by the state for people's monitoring are still not exercised effectively. A NGO manager shares the example of the Public Investment Law. In 2014, the National Assembly issued the Public Investment Law which allows the Vietnam Fatherland Front to represent community and supervise local public investment. According to the participant, due to limitations in financial and human resources, the Vietnam Fatherland Front cannot exercise their role fully.

For instance, the state has issued Public Investment Law which sets out the mechanism for community to monitor and supervise public investment at their areas via the Vietnam Fatherland Front. However, the Fatherland Front does not have enough resources, for example, budget. They are also having other issues which hinder them from exercise their role effectively. (Interview, July 2015)

In recent years, people's satisfaction has been recognized as one of the indicators to measure performances of state organizations. Some ministries have started to collect input on people's satisfaction levels regarding their work and use it as a source to review and improve. The 
movement can be seen as a positive initiative towards a system showing more respect to the people. However, the new endeavour seems to be not as 'unbiased' as its expectation. One interviewee has shared his story as a member of a consultation team for one ministry.

I am a member of a consultation team for a ministry. Our job is to develop an index to measure people's satisfaction to their services. The officials at the ministry have realized that measuring people's satisfaction is becoming a trend. However, before we undertake the satisfaction study, they told us the result level should be $60 \%$. The number is not too low and not ridiculously high either. Therefore, they reckon $60 \%$ is a reasonable result which will please their bosses. (Interview, July 2015)

Another potential step confirming changes in government's awareness is their plans to issues law which allows more voices to be raised. The country is planning to issue law on referendum in order to acknowledge the opinion and knowledge of the people on important national issues. Yet according to the interviewee, even members of the National Assembly get confused regarding the possibility that people's opinion differs from the state's determination.

They are confused if people's opinions are different from the state's opinions. Some members suggest that in that situation, the state and the assembly need to give explanation again and convince the people, as well as to reorganise the referendum until people's opinion is the same with the state's. (Interview, June 2015)

To explain for all the failures in government's attempts to strengthen people's voices in the country, participants often pointed out existing shortcomings of the system which cannot easily be erased in the near future. The first and foremost critical factor deciding the success of the attempts is mindset and attitude of officials who are carrying the missions. According to some interviewees, the current system does not motivate the officials to be accountable to the people. The reality that feedback of the people that they serve does not affect their performance review or promotion opportunities demotivates officials' desire to serve and respect their customers.

Local officials are not account to their people; they are accountable only to their bosses. People's feedback has no significance so it is often ignored. The current system is set up 
for it own benefits, not for people's benefits. There are some exceptions with officials genuinely wanting to serve people. However, whether people like and respect the officials is not considered in their promotion opportunities. In this context, people's voices are actually, insignificant. (Interview, June 2015)

That Vietnam maintains a one party system and members of official people's representation organizations like Vietnam Fatherland Front or People's Council need to be the Party member also limit the independence of these organizations, then do not grant them the required power to exercise their voices and necessary sanctions.

People in the People's Council are also members of the party. They cannot simply refuse the party's decisions. The same goes with the Vietnam Fatherland Front, its president is a member of the Politburo. He or the organization cannot confront the government. All presidents of provincial VFF are also party members. Thus, the VFF and the People's Council do not have real power to exercise their roles. (Interview, June 2015)

Shortcomings in the political system together with the mindset preferring fast-growing economic development than strengthening civil society and political rights are weakening the potentials of the people-oriented attempts.

In Vietnam, there is tendency to consider economic rights more important than political rights. The government and majority of people think that political rights are not crucial to their lives. That is because we just overcome a period of hunger and poverty, being able to satisfy basic demands like food and clothes is already a good life. Even the state wants the people to keep that perspective. (Interview, July 2015)

All the factors can explain why civil society organizations have not been officially recognized in Vietnam's law and law on political rights like law on information, demonstration, and referendum are postponed for years.

There are not yet civil society organizations in Vietnam. The law on association has not been passed for 10-15 years. That law and law on referendum, law on demonstration 
are always postponed. We only focus on economic rights, leaving the political rights very weak. (Interview, July 2015)

A system which does not support the representation and the voices of people as well with deep-rooted mindset of both officials and people on their roles have hindered efforts in practicing direct and indirect democracy mechanisms. However, other factors like global and regional integration, economic development, more opportunities for people to travel oversea, etc. have led to the wider and deeper integration of freedom and democracy values. People, especially in urban areas are more aware of their political rights and as a result, are more demanding for their rights to raise voices. The wave of the new demands clash with the cautious system have led to the potentials of better changes in society and the state or fading trust in the people.

A group of local people in Hoa Binh told their story of not being able to give their feedback and receive proper responses from their officials. A cement company was operating in their neighbourhood. The company's heavy trucks were going past their houses every day, leaving the community road in bad situation. The company exploded rocks days and nights creating noises and polluting the surrounding environment. The people have reported to the local authorities and higher levels of government using all provided mechanisms but there have been no response as well as actions from the governments. Their comments below can be affected by their emotion towards the case but also reflect the difficulties of people in need of expressing their opinions.

People have many concerns that we do not know to whom we can express. If we reach to the commune and district levels, our concerns are not going to be solved. If we report to the higher levels, they say it is not their responsibility and tell us to inform the lower levels. (Interview, July 2015)

If the situation remains, trust towards government will be the first thing to be lost.

There are many corrupted officials. We are losing our trust. This is happening everywhere. There are still some officials who care for the people. However, they need to 
survive in their own politic war to remain on their seat. I feel hopeless. (Interview, July 2015)

To sum up, there is a growing demand from the people in Vietnam to know and be included in the work of the government. The mindset of the people is eventually changing from being appreciated with any services provided by the state to actually questioning the services they are received and the system's performance. Until now, the demand has not been satisfied by measures provided by the state. The existing gap in people's demand and the state's commitment can be the cause for both improvement or more conflict and confrontation between the two parties. Hence, the rise of social accountability and the engagement of nongovernmental organizations in governance are expected to resolve the potential conflicts and better off the situation.

In this context, NGOs or other organizations have a crucial role in raising people's awareness on their own rights and advocate the government to improve their monitoring mechanisms. (Interview, June 2015)

\section{Social accountability practices in Vietnam}

\subsection{Aligning with the state - a common entry point of organizations}

Although social accountability is expected to fill in the gap between the increasing demand of the people and the constrained democracy mechanisms of the state, the adoption of social accountability at the first place certainly is not an easy story. All research participants who have experiences in employing social accountability in Vietnam agree that the common entry point for their initiatives is through collaborating with the government. The first and foremost rationale for the collaboration is the necessity to receive support from the government for such movement like social accountability. Without the approval from the government, it can be very challenging for organizations outside of the state to undertake any activities. Below is the reflection of one participant of the study working at a local NGO on his experience to carry out social accountability project at commune and district levels - two of the lowest levels in the administrative system in Vietnam. 
"In Vietnam, to do anything, we need to have the support of the whole political system from all administrative levels. Government operation is mainly based on a top down approach. Social accountability is good, it is people centric. However, in order for it to be feasible, approval of the district will be needed. In case there is no support from the district, the commune cannot implement, and the district itself will have to say no if officials at the province do not agree." (Interview, July 2015)

In order to seek the support from the government, organizations often decide to collaborate with the government agencies or organizations which have close links with the government the approach similar with direction of Cambodia CSOs as mentioned in Chapter 2. It is because organizations outside of the state do not have the mandate to carry out activities on issues such as collecting people's opinions, consulting the people on the state's performance. By partnering with the organizations which have the authority to represent people and monitor the state, it is less challenging for the civil society organizations to practice social accountability in Vietnam and to pilot the practices at their targeted areas.

In order to practice social accountability, the first step is to confirm if our partners have the mandate to carry out this kind of activities. We cannot collaborate with an organization which does not have the authority to undertake the initiatives. (Interview, July 2015)

As a result, the Vietnam Fatherland Front and People's Council are often considered as potential partners for CSOs since they have the mandate to represent the people and monitor the government officials' performance. Civil society organizations often position themselves as supporters of the Fatherland Front in implementing its function of representing people's opinion and monitoring the state's activities.

According to the law, the Vietnam Fatherland Front has the mandate to represent people and monitor the state but whether they want to carry out the responsibility is the question. Organizations like ours need to advocate social accountability to the Vietnam Fatherland Front so that they have more attention and motivation on this topic. I think our entry point will be to address the gap in their capability, not only in terms of how to 
practice social accountability, but also the ability to scale up, and replicate as well. (Interview, July 2015)

Another possible entry point is to work with line ministries in order to improve its performance by providing feedback of the people. That is the approach that big organizations like UNICEF, World Bank, UNDP have applied. The pilot of social accountability tools like Citizen Report Card, Social Audit, and Citizen Scorecard has been implemented by World Bank and UNICEF with the cooperation of Ministry of Home Affair or Ministry of Planning and Investment. The support from the national administration levels is necessary for the introduction of the new initiatives so that they can be practiced in local sites. Hence, civil society organizations in Vietnam are choosing to align with the government and work with the government's organizations in order to introduce the concept of social accountability, and to advocate for more people's participation in governance and service delivery. When working with the state, organizations do not only seek for the support but also expect to improve the awareness and capabilities of the officials.

However, the question is how government officials, especially who are working at local governments perceive social accountability. A manager of a local NGO has shared his experience of introducing social accountability terms and piloting its practices at his area. In 1995 - three years before the issuance of the Governance Democracy Decree, his organization cooperated with an international nongovernmental organization in initiating a local governance themed programme. At the time, both concepts like nongovernmental organizations or local governance were not familiar with people and government officials. The Vietnamese translations of the terms also seem to imply the meaning of challenging the state's power or doing the state's job. Therefore, local officials first reacted to the programme with hesitance and caution. In order to tackle the scepticism, the international nongovernmental organization in his story replaced the misleading terms with terms used in official documents like grassroots democracy in order to achieve support of the officials.

During 1995-2000, when an international organization initiated their governance program in Vietnam, local government was quite sensitive. Our government partners did 
not understand much about NGOS, they thought 'local governance' was 'let the local government govern'. Moreover, 'govern' was quite a sensitive word itself. At that time, the word was avoided, the international organization decided to replace it with terms like 'grassroots democracy' and grassroots democracy governance as the terms were already clarified in Vietnam legal documents. (Interview, July 2015)

Nonetheless, though the words and the nature of social accountability have been questioned at first, government officials and people are getting more familiar with the concept now and are more willing to apply it in their daily life.

Now, authorities do not mind the words, even the people can use them. (Interview, July 2015)

For about 20 years, social accountability has been promoted in and emerged more deeply in Vietnam. At the beginning, it caused both confusion and caution from the government and people. Social accountability related terms were considered 'sensitive' and were avoided. However, perception of the government and society has changed towards being more open to the concept. The change in the mindset of the state can be considered as one of the impacts of the aligning strategy. Since the Citizen Report Card was introduced first in 2003, nongovernmental organizations have maintained partnership with the state's ministries or organizations like Vietnam Fatherland Front, National Assembly, or People's Council - which have the mandates to exercise vertical accountability.

\subsection{Information as evidence - the main practice of social accountability in Vietnam}

In social accountability practices, information is often considered a key to improve accountability. According to the World Bank, social accountability interventions refer to efforts to provide information to citizens and channels to enable them to use the information to hold service providers accountable (World Bank, 2012). In the document, the Bank provided explanations of two sets of social accountability mechanisms: first, information interventions which are expected to influence providers by engaging citizens to use information and second, grievance redress mechanisms, which are formal channels for citizens to demand their rights, complain, and provide feedback to providers and policy makers about service delivery. The 
book has introduced a range of particular tools for each set of mechanisms since social accountability was referred to as a "set of tools that citizens can use to influence the quality of service delivery by holding providers accountable" (World Bank, 2012, pg. 7). Since 2012 to now, the understandings of social accountability have been changed as discussed in Chapter 2 . However, information interventions are still popular in the practices of social accountability, especially in Vietnam.

In their report on participatory monitoring to improve accountability in Vietnam, UNDP has listed nine participatory monitoring mechanisms in Vietnam which are not institutionalized by the state (UNDP, 2014). All nine mechanisms refer to provide information via studying and collecting input from people in order to assess different aspects of service delivery. Four among of the nine mechanisms are social accountability tools introduced by the World Bank which belong to the category of information interventions. Hence, it is understandable to argue that social accountability practices in Vietnam involve a significant extent of collecting information and piloting information interventions which have been promoted by the World Bank.

The emergence of initiatives using information instruments can be explained by its nonconfrontational nature and its ability to involve people's voices and provide different perspectives of stakeholders. Organizations often see the approach's benefits as engaging people, increasing their power by accumulating their collective voice, and use the voice as evidence to improve performance of service providers or governance. Most of organizations interested in social accountability are pursuing the information approach; and their practices can be categorized into two main groups. The first one mainly focuses on improving the responsibility of local governments and to improve the quality of service delivery by creating a sense of competition and tackling their sense of embarrassment. It is often achieved by conducting comparative studies in which governments at different locations or sectors are ranked or are compared with their own performances over time. The second approach emphasizes on triggering dialogue between people and government officials, expecting to raise people's awareness on their own rights and gradually change both mindset of all stakeholders including government officials. Hence, organizations invest more on generating a platform for the stakeholders to discuss and share their point of views. 
Social accountability is a platform in which all related information on one construction, one issue is publicized and all stakeholders can provide their perspectives on one issue. Then, they all can discuss and agree on what works and what does not. Finding what does not work is not for the purpose of criticism but to agree on a solution and have an unbiased, evidence-based assessment on the issue. (Interview, July 2015)

The study has collected input from two practitioners who are more familiar with one approach than the other. Their sharing based on their own experiences will help to illustrate the application of social accountability in reality.

\section{2a An example of implementing a study using social accountability tools}

The sharing below is from a practitioner who is working as a local partner for an organization based in Hanoi. The practitioner and his/her organization are acting as the focal point at the site, facilitating activities at the location. The person has experiences in practicing CRC and PETS.

The organization in Hanoi works with us to decide the schedule of the study and asks us to collect relevant information. The schedule is really short, just one weekfor training, piloting and conducting interviews. We help them in data entry and they will do the analysis. Then, they will come back and report their findings. All stakeholders only know the findings at the consultation workshop, then, they are quite passive. Government officials therefore cannot give well-prepared responses to the findings. Another thing I notice is that though people participated the interview training, some still does not get the questions and end up collecting wrong information. Recently, the NGO changes their way a little bit. They collect ideas at our site, research local needs, consider the issues with their directions, and ask members of the interview team to select the study's topic. (Interview, July 2015)

The process for the application of the tools are described as a study with three main phases: preparation, data collection, and dialogue/data dissemination. In the preparation phase, the two organizations work together to decide the topic and to collect relevant information. The second phase is the data collection using the selected tool. Before the actual study, there are training and piloted interviews for interviewees/surveyors. One of the noticeable practices is 
the recruitment of local government officials, and officials in associations like the Vietnam Fatherland Front, People's Council, Women Association, etc. into the interview teams. The practice is expected to not only increase attention of the people on the studied issue but also to improve their capacity in working with people and assessing the government's performances using people's input. The international nongovernmental organization in the story also expect that the officials, especially from the Vietnam Fatherland Front and People's Council can be more familiar with the social accountability tools and can apply the tools in their monitoring work later. Input after collected will be analysed and disseminated in a seminar or workshop with participation of ideally representatives of all stakeholders. The seminar is served as a platform for all stakeholders to present their opinions and agree on what should be done to improve the quality of the studied service. In a comparison with the UNDP's four elements of social accountability, the abovementioned process contains three out of four elements. The fourth step, 'using information from accountability engagements with governments', is relatively insignificant or can be considered as the weakest chain in the whole process.

The process as described above is not a standardized process for all interested organizations aiming at adopting social accountability instruments. However, the frame is a quite common practice in Vietnam. Since aligning with local government is identified as an entry point for the practice of social accountability, organizations often integrate the purpose of improving the capacity of local government officials by involving them in most parts of the process. The practice certainly has its benefits. Firstly, it can have educational benefits for both local officials and people who are involved in the process of the study. In remote areas where people are not aware and have the habit of their rights to raise voices, the activity can help to bridge the distance among officials and people. Secondly, since the nature of the process is to collect information and generate dialogues, it does not directly attack local governments or imply any confrontational aims. Thus, the practices can be adopted and replicated with approval from the government. The characteristics also explain why information interventions are a popular choice for organizations that want to pilot and promote social accountability.

However, as the participant mentioned, due to limited resources, time at local site often is cut down to one or two weeks, which makes it hard for the officials to fully understand the 
methods and be motivated to apply it later. Moreover, the practice requires setting up a focal point at the location, which has close relation with the government. With all the factors considered, practicing social accountability tools at the remote areas is probably not simple and easy enough for new organizations to initiate.

\section{2b Collecting information to rank governments}

One of the most well known examples of monitoring tool using citizen experience in Vietnam is PAPI. PAPI stands for the Vietnam Provincial Governance and Public Administration Performance Index - currently the largest time-series national governance and public administration performance monitoring tool in the country. Based on citizen input exclusively, PAPI provides a set of indicators that help assess the performance in governance and public administration. It is expected to generate an incentive for provinces to improve their performance over the long term. The Index is a joint collaboration between the Centre for Community Support Development Studies (CECODES) and the United Nations Development Programmne (UNDP) in Vietnam since 2009 with a close partnership with the Vietnam Fatherland Front. The initiative is supported technically by a national advisory board and a group of international governance measurement experts.

Since 2009, PAPI has captured and reflected the experiences of nearly 61,000 citizens. In 2011, PAPI was conducted for the first time in all 63 provinces in Vietnam. The output is Viet Nam's first publically available dataset providing an objective evaluation of governance from the perspective of citizens. Hence, PAPI is expected to not only be able to provide a useful indicator for central and local government performance, but also a metric to assess how performance has changed over time.

The motive behind the philosophy of PAPI and the likes is to trigger competitiveness and embarrassment of the study's subjects. One of the members of PAPI team has shared that:

PAPI follows the approach of ranking provinces in order to tackle the shame factor. It generates a sense of competition which motivates the provincial administration to change. If officials at a low-ranked province does not feel embarrassed because of low ranking, they are not bound to. Hence, do not expect too much from PAPI. It is just a mechanism for one 
issue raised by many people so it can make people in charge feel embarrassed. It has no power to request them to change. (Interview, July 2015)

Impacts of PAPI will be discussed later. However, it is undeniable that developing and applying indicators like PAPI are getting more attention of both the government and civil society organizations. Since the study is often conducted by a think tank, the academia consider it as a creditable source to use in their discussion. In addition, because of its annual and large-scale nature, attention of the media is also increasing over years. All the factors together can help trigger the pressure for the poor performance governments to change as expected by the organisers.

However, the approach emphasizes on improving the government's performance instead of empowering people to raise their voice. It creates chance for people to participate by providing their input and collective voice of people is compiled to generate evidence of the projects.

\subsection{Social accountability - people's campaign}

Beside the approach of information dissemination, another approach has emerged recently in Vietnam, which is campaigns driven by people's concerns with decisions or actions of the government. One participant of the study has shared that recognition.

There are two main approaches which can be called social accountability now. One approach is NGOs implementing projects like PAPI in order to exercise social accountability. The approach is somewhat conventional. Recently, there is another approach emerging with non - official groups formed in order to reflect people's perspective in one particular issue. The campaign is increasing in terms of numbers and getting more powerful, compensating greatly for current activities of NGOs. (Interview, July 2015)

The meaning of 'non-official' groups is understood as the participation of different groups of people in society. The year 2015 has marked a year of people's campaigns with small scale, short term campaigns taking place across the country, but mostly in big cities like Hanoi and Ho Chi Minh city. In March 2015, in Hanoi, there have been small but unusual protests against the city authorities' plans to cut down 6700 trees which were claimed as old and sick by the 
government. Facebook protest pages have been launched and experts have voiced out that the plan to replant is unconvincing. The Facebook group "6700 people for 6700 trees" sought 6700 likes but had more than 55000 likes. Protests took place in weekends with the participation of diverse groups of people. All the actions led to decision of the head of the city People's Committee to postpone the plans until they could be reviewed. It is not the first time public outcry has led to a review of plans. In 2014, criticisms over plans for a cable car in Son Doong Cave, the world's largest cave, caused uproar with many signing online petitions to stop it from being implemented. There was also a protest in Ho Chi Minh city in 2014 against tree cutting with a Facebook group started called Happy Tree in Saigon.

Public protests are still not common in Vietnam but online protests and campaigns have become more common in recent years. Facebook, now used by a quarter of the country's 93 million citizens, is one of the most common venues. Todocabi - a youth led campaign on transparency of state budget can be seen as a success case of targeting young people and using Facebook as a main channel to go viral. Todocabi advocates for a written recommendation that is "State budget allocation should be published at all levels before approval", submitted to the National Assembly meeting in June 2015. A social media youth group named Ếch Phu Hồ (Building frogs) implements the Todocabi campaign focusing on: (1) Producing products illustrating knowledge related to State Budget and people engagement in the topic, (2) Building a voting platform for viewers to share their ideas and comments, (3) Gathering public opinions to send to the National Assembly's delegates before the National Assembly Meeting in June 2015. Ech Phu Ho's clip titled “Tien ve noi dau?” (Where does money go?) which uses cartoons, upbeat music, a funny chipmunk voice and teen slangs quickly became a hit with young netizens. The clip, which calls on viewers to speak out in favor of a proposal that the government should announce public expenses before finalizing them, has nearly 125000 views on Facebook and 72000 views on Youtube. The campaign has been sponsored by Oxfam -a non-governmental organization and is part of the work plan of a group of organizations working on budget transparency comprised of both international and local NGOs in Vietnam. 
One of the key factors of the campaigns is the involvement of civil society organizations. All NGO participants in the studies agree that civil society organizations have to take part and support the campaign to a significant extent. Campaigns as a recognition of civil society organizations have the potential to attract media and public attention, inform government officials as well as people's representatives, and generate pressure for the authorities in charge to respond.

Key participants mostly are from CSOs. Core team of the 6700 tree campaign are people working in non-government sector and the same with Todocabi. There is a trend recently among the organizations that they cannot advocate alone; networking is a must in order to generate collective bargaining power and influence. We need to renovate ourselves, incorporate a wide range of methods, attract public's attention, apply technology, create public outcry and raise awareness. (Interview, July 2015)

All these cases are bottom up participatory activities. However, I think the involvement of CSOs in both cases are quite significant. The Todocabi is driven by external forces (a part of the transparency campaign of a group of (SOs), the 6700 tree campaign is truly internally driven which arose from the people's concern. (Interview, July 2015)

In the campaigns, civil society organizations often takes a facilitating role and motivating people from behind. Instead, people despite of their background who all share the concern are the key driven force of the campaigns.

The interesting characteristic of the 6700 tree campaign is people behind the campaign are very diverse. They could be engineers, teachers, workers, students, old people, etc. They are new factors and very necessary in the story of people's participation. NGOs should help them more familiar with raising their opinions. We need to create an organised mass so that the people in the mass will be active; this is better than NGOs being the leading force all the time. We should place ourselves in behind with helping purpose being the main purpose. (Interview, July 2015) 
However, there are still concerns regarding the new approach. One of the concerns is the approval of governments for the activities to emerge more widely. As the purposes of the campaigns often are to advocate for a change in a policy or a plan, it can be considered as challenging the state and will face skepticism from the government as that kind of activities are still new.

The issue is how the state perceives the activities. Whether they will encourage the similar activities remains a question. How can these activities be scaled up in an environment that does not support the idea. (Interview, July 2015)

Moreover, approach using social media and targeting youth can be considered lacking of seriousness from older generations. The nature of the activities may restrict its advocacy impacts as said by one participant.

For example, Todocabi may not be taken seriously since many people find youth's voices inconsistent and insignificant. (Interview, July 2015)

Finally, one of the similarities of the campaigns is that it happens in big cities like Hanoi and Ho Chi Minh city with people having a better education background. It will be more challenging to facilitate the same kind of campaigns in remote areas where media does not show much of interest and people are having more concerns on their daily life. Calls for participation in the big cities for issues that are not close to them, for instance, issues which happen in other provinces, districts, or communes will certainly be a challenge. When people's attention span is short, collecting their power will be more difficult.

Hence, the increase in number of campaigns regarding social concerns recently has marked a positive change in Vietnam society with people being more attentive to policies and issues around them. It can be a potential approach for organizations aiming at advocating for social changes and raising people's awareness. However, as the campaigns are greatly reactive and short term, organizations will consider it only as one-step in its advocacy efforts and not that all issues can draw public attention. Hence, for the approach to be more successful, studies on people and the mass's psychology need to be conducted in the future. 


\subsection{Next steps in practicing social accountability in Vietnam}

Beside the two key directions that have been observed in the society of Vietnam, there are also signals for upcoming initiatives that may be worth a closer observation. The two trends are expected to emerge is increasing number of networking efforts and applications of information communication technology (ICT).

The National Workshop on Social Accountability in December 2014 can be considered as one of the very first attempts to connect interested organizations on the practice of social accountability. The workshop had participation of 26 organizations, both international and local which has experiences in piloting social accountability in Vietnam. It was expected to be a platform for the organizations to share their lessons learnt and may trigger networking opportunities later on. During the workshop, the need of cooperation and networking among organizations have been expressed widely. Organizations have realized that individual efforts often lead to insignificant impacts and voices due to its small scale, short term, and limited resources. Networking is seen as an opportunity to exemplify the voice, utilize resources and experiences of organizations. Altogether, united voice and attempts are expected to bring more significant changes to the society.

It is not the first time when the idea of more networking has been brought to the table. The People's Participation Working Group has been established since 1999 in order to promote the implementation of the Grassroots Democracy Decree. However, the idea of networking is not easy to be fulfilled. The difference in term translation, each organization's perspective and approach towards exercising social accountability, and their own priority have been the constraints for attempts to create and reinforce networking among organizations.

In order to connecting organizations, there is a need for a focal point-a person or organization who is willing to take charge of facilitating the process. It is hard to find that focal point. Organizations may need to see if it is their mandate, if they can have support from their donors. Networking is like an add-on, it is not a priority in the list of programmes and projects that organizations are carrying out. (Interview, July 2015) 
Despite all the difficulties, there are still some attempts so far to make networking easier. After the workshop, AFAP Vietnam has held some meetings with key organizations in the social accountability field aiming at establishing a network of organizations on the topic. They are also working with some of the organizations to publish a website on social accountability which will introduce the concept and serve as a resource centre for any person or organization to learn more about it. Ideas like sharing funding opportunities, expertise and experiences, and uniting in one advocacy campaign are beneficial for all organizations working in the field. Hence, although there is not yet any official network founded after the workshop, it is expected that networking will be a trend in the future with more voices united and greater scale.

Beside the potential of networking, applying ICT on exercising social accountability is becoming recognizable. CECODES - the organization behind PAPI is launching Toidibenhvien (I am going to hospitals) - a website where people can rate and comment on their hospital experiences. As shared by the director of CECODES, the project cannot give people the 'exit' option when using services but can introduce to them better alternatives, generating more demand for hospitals with better services and quality, and can serve as an indicator reflecting hospitals' performance. M-Score or mobile scorecard is an initiative of Oxfam piloting in Quang Tri province. The idea of $\mathrm{M}$-Score is to give people the chance to comment on the services they have been provided right after they go out of the government offices. Questions will be sent as text messages to their phone and they can give their comments straight away without paying any fees. The data has been collected and analysed so that the government officials can know which areas are still performing poorly and can have idea on how to improve on the areas.

The common feature of these attempts is to offer people easy, convenient tools to provide their comments and to collect data that can be useful in analysing and improving public services. ICT has changed the way organizations collect their needed feedback. Instead of organizing expensive yet short-term studies, using convenient means like mobile text messages, apps or internet has brought a whole new horizon for different pilots and projects which are easy to scale up as well. In the future, more ICT incentives are expected in practicing social accountability. 


\section{CHAPTER VI - IMPACTS, LIMITATIONS, AND REFLECTIONS ON SOCIAL ACCOUNTABILITY}

\section{Impacts of social accountability efforts}

Although social accountability has only been introduced and emerged in Vietnam recently, the biggest question around the concept raised by interested organizations is about its effectiveness and impacts. The participating organizations often set high expectations for the practices, and expect that the practices (them - not it) should not only generate social changes in long term but also improve service delivery in short term. Below is the sharing of one participant on his expectation of successful social accountability. The interviewee is looking at social accountability in a way that it should generate long-term changes in the society and improvements in terms of state governance and for the people.

Successful social accountability means that it can create positive changes for people, generate motivation and pressure for policy makers to perform better, reinforce mutual trust between authorities and the people. The changes are hard to measure but all are important social values. (Interview, July 2015)

However, despite all the expectations on social accountability, organizations are aware that actual impacts can be very limited. One of the reasons for the shortcoming is the dependence of organizations on funding of international donors and the short periods of available grants. According to participants, in most cases, social accountability projects often can only be implemented up to five years because of grants' conditions. Considering this short time frame, it is disputable that the practice might bring about concrete social changes or impacts. One participant affirms that the one singularly useful outcome after exercising or piloting social accountability has only been recognised as the experiences and lessons acquired by involving organizations and practitioners.

Most of the time, social accountability initiatives only help to withdraw some lessons learnt. Many donors think it is good enough since there is no long-term grant available, most grants only lasts 3 years with 5 years being maximum time. No political or civic changes can happen in that short term. (Interview, July 2015) 
One participant who has experience in working closely with the local government has also shared that social accountability in Vietnam has yet brought any significant changes. The participant reflects on her experiences when taking part in the Public Expenditure Tracking Survey - a social accountability tool to monitor money flows. The interviewee understands that due to small scale of the activity, actual impacts will not come in short term. However, because the intervention took place in a small area, after several adjustments made to the program by the national government, all recommendations proposed by the study were not applicable for future implementation.

The impacts are not significant. That may be because of the scope of the activities are small and the impacts will come gradually. For example, when we finished PETS study, all the findings were disseminated. However, at that time, the national government issued new regulations to adjust the studied program and its implementation. Hence, all the PETS findings and recommendations were for no use. (Interview, July 2015)

Another factor affecting the success of social accountability practices in Vietnam is that it relies on government authorities to respond. For activities involving information interventions such as CRC and PETS, NGOs can only propose their recommendations after the study. Changes in the performance of authorities and the service delivery process actually depend heavily on the commitment of the officials. For example, one participant has observed that if the in-charge official of the program concerns about the information provided by the study, he/she will take actions to improve the program's quality. Otherwise, they can simply ignore the study and there is no changes generated.

We conducted citizen report card studies on agriculture extension, education, and health services. The recommendations for agriculture extension services had been taken seriously because the director of the centre really cared about the findings. However, findings on health services and education have not brought any significant changes. Our findings are quite small and scattered. After the study, the authorities just simply keep silent, continue with their work and no changes have been brought into reality. (Interview, July 2015) 
The above-mentioned factors suggest that it is hard to report any concrete social changes that have been triggered by practicing social accountability in Vietnam. However, it is necessary to affirm that social accountability is only at a piloting stage when the organizations are testing different methods and introducing the concepts to involving stakeholders. Expectations for real changes in such a relatively short time can be impractical.

There are still some positive signals generated by adopting the practices. One of the improvements brought by the practices of social accountability is the improved capacity of participants, especially on technical skills such as conducting interviews and collecting feedback from stakeholders. This change has been reflected in the sharing of an interviewee who works for an international NGO's local partner. The core team mentioned in his/her sharing consisted of local officials, particularly those who worked at the Fatherland Front and People's Council. They are encouraged to join the data gathering team and interview local people. According to the participant, the official often appreciated skills and knowledge gained from the activities as they saw the importance and benefits of listening to the people and knew how to collect their input systematically.

For now, we can only meet the objective in terms of improving participants' capacity. The member of the core team are normally local officials or people working at the people's council or VFF. If they are determined, they will want to change, improve the implementation of the services they have been studied at their own site. Hence, after the study, the people and even I myself gain more knowledge and strengthen the necessary skills for our work. That are benefits for people who directly involved in the study. With other partners, we do not have any solutions for more significant impacts. (Interview, July 2015)

Since local officials and those working for the Fatherland Front and the People's Council often have difficulties relating to technical capacities and knowledge of a particular policy or program, improving their skills and knowledge via social accountability practices can help them perform better, especially in their monitoring function. As Vietnam Fatherland Front is the organization with the mandate of representing people and monitoring the state, their support in the 
employment of social accountability can be perceived as a necessity to gain deeper and wider emergence of the approach in Vietnam. Moreover, because of the constraints in resources of NGOs, it is a challenge for them to keep up the facilitation and organise social accountability initiatives. Technical transfer can be a smart strategy to sustain momentum of social accountability. Below is the sharing of one local partner in implementing the project. His organization's interest and commitment in social accountability are expressed strongly in his answer.

My organization decides to utilize all of our experiences and resources in order to pursuit social accountability. We are willing to be the pioneer in our areas. (Interview, July 2015)

Another positive impact of social accountability is the benefits it brings to people, especially poor people in remote areas. NGO managers participating in the study agree that at the moment, social accountability practices have just provided a chance or mechanism for people to share their feedback. People from/in remote areas whose chances to raise their voice are limited often express their gratitude toward social benefits brought by social accountability. As shared by one NGO manager, they feel that their voices matter and there are organizations which appreciate their input (Interview, July 2015). For instance, the community in Da Bac District mentioned in the previous chapter did not expect the interviewers or the studies to bring any changes to their situation, they just wanted to be listened and were thankful for being able to tell their stories. However, for organizations, that is just the beginning and what they expect is that people can be more familiar and confident with raising their opinion, their united voices can have more power and motivate responsiveness of the government.

The people have been invited to participate more, though it is a slow process. The initiatives are chances for them to participate. (Interview, July 2015)

The people are thankful since they have chances to raise their voices. They appreciate the chance. Longer-term impacts of the activities are to show for the people and civil society organizations that they can raise their voices and can actually generate pressure, even not massive, but the government cannot simply ignore. (Interview, July 2015) 
Some initiatives are already generating immediate responds from the government. For example, PAPI - after years of conducting and building up data on public administration rankings of all provinces, the reputation of the study has been improved associating to people and media's increasing attention to its results. In recent years, there have been initiatives from some provincial governments to establish teams to review the result and recommend changes to make its rank better upcoming years (PAPI Homepage, 2016). Campaigns mentioned in the study like 'Todocabi', 'Save Son Doong', or' 6700 trees' managed to encourage responds and actions from the government. Todocabi has collected more than 11,000 signatures to support the publication of state budget planning and the publication already became an amendment in the revised law on state budget. 'Save Son Doong' and '6700 trees' have influenced the decisions to stop the construction of the cable car system in Son Doong cave and to cancel the tree cutting plan in Hanoi. Even though these are preliminary responds to the specific cases and the public attention is often easily distracted when new events emerge, they have been good signals that can be formalised into suggestions for advocacy attempts of organizations.

Hence, for more than 10 years of adopting social accountability in Vietnam, organizations are still in the process of piloting and promoting the process. All recommendations made by practicing social accountability instruments greatly rely on government authorities to implement. The impacts of the practices are still limited and insignificant. The visible results of the attempts are improvements in capacity of local officials and local partners who have been involved in the process. Skills like collecting information, interviewing, analysing data, and writing report are often strengthened. Officials and partners who have experienced some social accountability initiatives are more familiar and willing to engage in further activities. Organizations are well aware of the results and in order for them to move forward to the next stage of social accountability, more outcomes in actual changes in service delivery and governance should be the next aim and challenges. 


\section{Shortcomings of the current approaches}

\subsection{Struggles in follow up plans and activities}

One of the biggest limitations of social accountability initiatives implemented in Vietnam is follow up activities. Since the adoption of social accountability and the idea it conveys are relatively new in the society, most organizations have only expected to pilot, test and decide which methods are suitable in the context of Vietnam. However, if the organizations want to pursuit the approach longer and for it to bring more impacts, follow up strategy should get more attention.

After launching activities to disseminate the information collected and recommendations, organizations are confused on deciding on follow up activities and often leave it to the local officials to take recommendations into action. Without a mechanism to motivate responsible officials to fulfil their commitments, the impact of social accountability will only be restricted to the information it provides.

There is almost no activities after the dissemination workshop. What we can do is to ask if the authorities implement any change. There is no further step when we actually reevaluate their actions after the study. (Interview, July 2015)

According to one participant, organizations have already acknowledged the need to have a proper follow up plan. However, not much has been done regarding the issue of follow up.

I attended the National Workshop on Social accountability hosted by AFAP Vietnam. We started discussing on follow up activities, but did not come up with any commitment or any plan. Therefore, things just keep fading by. Organizations see the importance of follow up but have not started taking action regarding that issue. (Interview, July 2015)

The most importance is to follow up with studies' findings. We have to come up with an action plan and to be responded if the issues have been improved and how. People are going to get bored with a study to be conducted every year without any follow up activities and real impacts. (Interview, July 2015) 
It is often explained that the lack of follow up activities is a consequence to the lack of resources. For activities using social accountability tools like Citizen Report Card and Citizen Scorecard, repetition over years of the studies are recommended to gain useful data to compare and conclude if the results have brought impacts to the place. However, due to the lack of necessary resources as well as the short timeframe, re-conducting the studies is perceived as both time and money consuming.

It is not possible for us to revisit and re-evaluate one study due to limitations in resources. (Interview, July 2015)

In addition, as NGOs often select government officials as key stakeholders and, more importantly, as entry points for the implementation of activities, it is challenging to encourage them to be accountable for the follow up plans and fulfil their commitment after the study is completed. As shared below by two participants of the study, local authorities are often reluctant about the follow up of social accountability. Some of the authorities show little willingness in reviewing and improving their performance based on the recommendations of social accountability practices because they already have other responsibilities to take charge of or not ready due to limitation in resources.

Let the local official take charge, they refuse and say they are having other responsibilities. (Interview, July 2015)

It is difficult to follow up since our entry points are not ready to take in the social accountability work. For example, one of our key stakeholders is Ministry of Planning and Investment. They are having many constraints in terms of resources, human, and motivation. (Interview, July 2015)

Thus, follow up activities remain as the gap in the adoption of social accountability in Vietnam. Organizations are becoming more aware of the issue. However, how to follow up still is a difficult question. They need to find a way to tackle the lack of resources, the limitation of time frame, communication loop and lack of motivation with government officials. 


\subsection{Challenges in advocacy}

Advocacy and follow up activities are considered as an element of social accountability (UNDP, 2014). In Vietnam, advocacy is considered as new but potential (Wells Dang, 2014). When discussing advocacy, scholars and practitioners often think about launching campaigns as the response to a policy obstacle where organizations are formed as a coalition. However, as social accountability initiatives in Vietnam are quite small and are focusing more on collecting information, advocacy can only be considered as one component of social accountability practice. Advocating local government to adjust their implementation or decision or encouraging them to fulfil their commitment may be considered as advocacy successes.

In terms of practicing social accountability, there are still struggles in successfully delivering advocacy messages drawn from collected information. Below is the sharing of one participant on his experience on advocacy in Vietnam. According to him, advocacy attempts led by NGOs have not gained its significance as expected due to the reluctance of the government in receiving and responding to the messages.

Many NGOs are very active. However, it is difficult for the reality to change as the way they desire. Until now, there are not many cases that the government took on advocacy message provided by NGOs. They just listen without taking any changes. (Interview, July 2015)

One organization, when discussing advocacy, has provided a short analysis on the strengths, weaknesses, opportunities and challenges of NGOs in delivering advocacy messages. According to a participant, the conditions for organizations to advocate are getting more and more favourable. The skills and access of organizations to resources and knowledge to support the advocacy attempts are also expanded. However, since organizations are following different approaches and missions, coordination among them remains a challenge which can hinder the efforts. In addition, organizations still need to develop and maintain a good relationship with the state, as discussed in the context chapter, to promote the advocacy network.

Strengths: NGOs have better capacities, better network, and they have access to international knowledge. Weaknesses: The commitment among organizations to 
coordinate towards one shared goal is weak, that some is not following a strategic approach loosens the coordination. Opportunities: There is increasing pressure from outside the state and the reality has proved that with involvement of NGOs, policy is closer to the reality. There is more opportunities. Not long ago, people did not dare to discuss advocacy, now the government at all levels are aware that people can stand up to protect their voices. Challenges: it requires skills to work with stakeholders.

Sometimes, it depends on your personal network and communication skills in order to propose changes in a policy or program. (Interview, July 2015)

Without follow up and advocacy, social accountability in Vietnam only contains three out of four elements of social accountability as introduced by UNDP: preparing community and civil society groups to engage, collecting analysing and using information, and undertaking accountability engagements with governments. As organizations in Vietnam often implement information intervention, the next major question is not on the adoption the practice but on the actually utilization of the information and bringing up actual changes in service delivery and/or accountability relation. However, it is also necessary to reconsider the scope of social accountability projects, as most of the interventions are implemented in small areas, the findings or recommendations cannot be applied for a larger scale. Hence, advocacy implications will be limited in local levels only and cannot be significant enough to be considered at higher levels.

\subsection{Scaling up, alignment with government, and technical nature of social accountability}

The current practices of social accountability in Vietnam also have limitations lying on its technical requirements, insufficiency of independence when collaborating with government, and difficulties to scale up or replicate.

Adopting and applying social accountability tools require experiences on the instruments, expertise on the studied policy, program or service as well as a wide range of skills to facilitate the process. Even though organizations express their expectation to transfer the skills and knowledge to local organizations or local government officials, the gap in technical capacity especially on data analysis is not easy to be filled in. According to a participant who works at a 
project management unit, which uses to support the social accountability practices at the local site, without being equipped with technical skills, they are not ready to take charge of the activities.

We, at the PMU, need to improve our skills in analysing, writing reports, selecting samples; otherwise, we cannot implement the social accountability tools ourselves. (Interview, July 2015).

Moreover, it is difficult for the officials at local NGOs or people representation organs to completely replace the position of NGOs even if they already pose all necessary skills and knowledge. Since they have tight relationship with the local government, it will be hard for them to remain unbiased and independent. The officials working at the two districts' Fatherland Fronts and People's Councils in the study have shared positive feedback on the practices of social accountability they have involved as they have seen it as 'supportive and complementary to their work' (Interview, July 2015). However, all of them agree that NGOs should be in charge of coordinating the activities due to their lack of resources, technical expertise, as well as mandates - in case of the People's Councils. Moreover, as mentioned in Chapter 4, since the dual appointment situation still exists, officials working at the VFF or People's Council can also take charge at another position at local governments, the necessary independence for the practices of social accountability will be difficult to be fulfilled.

Another shortcoming of the current practices of social accountability lies in its partnering strategy with the government at all levels. Apparently, the approach has its benefits, especially in the pilot stage of social accountability as discussed in Chapter 5 . However, aligning with the government can affect the independence of the study significantly. From issues like selecting topic for the studies as well as communicating the results, organizations have the tendency to avoid issues which are too 'politically sensitive'. That means that topic selected for the study may not be the most concerned issue in the areas and the message after the study may not be as strong as it should be. The sharing from a manager of a local NGO has reflected their organizations' considerations when selecting a topic for social accountability application. 
Foreseeing reactions from the government is considered as crucial for the organization when choosing the topic.

We usually select topics which are existing concerns among our communities, but the topics must not be beyond of our capacities and should be approved. In theory, the selected topic should be the most significant concern. However, in reality, we need to consider our own benefits and risks when doing the topic. It is good if the people are genuinely interested in the topic, but since we are a small organization, being confrontational with the local government will bring difficulties which needs to be taken into account when deciding on the topic. (Interview, July 2015)

Finally, since the implementation of social accountability interventions requires necessary skills and knowledge, close relationship with local government, and sufficient resources, the requirements constrain the possibility of the practices to be replicated and scaled up. Participants in the study have all expressed their concerns regarding financial resources. Attempts towards more networking have been seen as a solution to increase the coverage of social accountability practices. However, as discussed, organizations are often having different agendas in social accountability, networking remains weak and ineffective. In addition, it is also necessary to question the government's acceptance on more popular and larger scale of social accountability. There is no insights for the issue during the study, however, for organizations aiming at expand their initiatives, it should be realistic for them to plan and undertake it carefully with all the considerations taken into account.

\section{Reflection and discussion on the adoption of social accountability in Vietnam}

During interviews with practitioners, the study has gained their opinions and insights on social accountability regarding its potentials, future approach, key stakeholders, the role of context analysis. It is believed that the practitioners/managers' perspectives and experiences are having influence not only to their organization's approach but also to the practices of social accountability in the future. This section presents and discusses the reflection withdrawn from the interviews, focusing on the sharing of the practitioners. 


\subsection{Strategic approach or tactical approach}

As the adoption of social accountability is only in the pilot process, it is understandable that most of organizations are employing tactical approach in practicing the concept. Tactical approach as discussed is described as bounded interventions, mostly information interventions, limited to local arenas and society side voice only (Fox, 2015). As organizations are introducing and examining the instruments, their activities are often perceived as small-scale, random, and diverse experiments rather than strategic approach. According to one of the participants, social accountability has not been well defined. Organizations are piloting many different approaches and cooperation is yet to be seen.

Social accountability in Vietnam has not yet been formed. There are many ideas but they are still small, discarded, and unclear. Each organization is following its own approach, without any concrete signals for a further cooperation. (Interview, July 2015)

The expectations for the instruments to generate changes, therefore, should be left until the next stage when organizations have their own conclusions on which works and which does not and focusing more on the actual changes that the methods can create. The first National Workshop on the topic held in 2014 was a positive signal for the readiness of organizations to move on from the pilot stage. The workshop was introduced as a kick off platform for organizations to share their experiences, and discuss future development of social accountability in Vietnam.

During the interviews, participants often acknowledges the necessity of long-term strategy and vision in practicing social accountability. As shared by the practitioners, successes in introduction a new instrument or publishing a report with policy recommendations are no longer perceived as objectives which they are looking for. As shared below, practitioners also aware clearly that the success of their actions should be decided by the changes it can generate.

Organizations introduce the tools, collect people's opinion and publish a report. That cannot be the final objective. The objective is to use the opinion for benefits of people. 
With the way we are doing, we are focusing on the means, not the end. (Interview, July 2015)

The necessary thing is not spending donors' money in order to organise workshops but for the people to become more confident. (Interview, July 2015)

Civil society organizations' mission is not to implement new tools. We have piloted and now we need to advocate for successful methods and think on how to use the collected information effectively. (Interview, July 2015)

Thus, it is possible to expect more strategic approach to be employed in the future. Organizations that have featured in the study start to have their own idea on what to do in order for the approach becoming more strategic and more sustainable. Building a roadmap, establishing network and identifying an exit strategy are considered as necessary moves to replace the tactic activities. All the steps certainly require a greater commitment and careful planning.

We need to have a roadmap and do outcome mapping so that we can see how far we have get in our roadmap. (Interview, July 2015)

Piloting is not an end itself. It is a means, we need to have exit strategy from the beginning in order to maintain the system that we have built up when we want to withdraw. In Vietnam, in order for any change to happen, it needs to start from piloting but the practitioners need to prepare for the exit strategy right at the beginning. (Interview, July 2015)

Nonetheless, the emphasis on more strategic approach in practicing social accountability does not necessarily mean organizations will stop piloting new methods and instruments. As there have been no concrete answers on the best or most suitable instruments or approaches, organizations will tend to keep exploring new options and practices but with more concern regarding the practices' actual impacts as well as contribution to long term changes. 


\subsection{Context is the key - Government support remains crucial}

It is clear from the interviews that the government's reaction is crucial in the success of adopting social accountability. The organizations have identified government at all levels as potential entry points and clearly see the importance of getting approval and support from them. After the pioneering stage, organizations are more aware of understanding the context and the importance of stakeholder analysis. The lack of a complete political economy analysis can constrain the effectiveness and sustainability of social accountability initiatives. Sharing on this issue, one of the study participants has stressed the necessity to understand thoroughly the political context and power relations in the context. NGOs often have to obtain the knowledge via their work experience and there is a need for more complete studies on the topic.

In social accountability, political economy analysis is very crucial. Organizations need to have insights on political context and power relations in the context instead of only looking at some tools or mechanisms. We need to be aware of the context in order to build up a roadmap which is more realistic. (Interview, July 2015)

Clearly, the political environment is changing and people as well as the government are more supportive towards the idea of social accountability. However, as discussed in this study, the role of government in approving the activities remains crucial.

The most important factor is to see if the government accept, cooperate, and support our activities. (Interview, July 2015)

The actual challenge is not only to get the support from the government, but also to change their mindset. Governments are often less willing to adapt and shift their ways of doing and perceiving when working with communities (Eversole, 2011). In the case of Vietnam, the 'askgive' mindset as mentioned as well as the long tradition of hierarchy social structure are barriers for the potential impacts of social accountability. The urgent need to challenge the mindset will require more advocacy endeavors. Hence, it is possible to expect that in the next few years, organizations will move towards the direction that challenges the current statepeople relationship. 
For the people to be more active, CSOs need to act as CSOs, people need to have the right to associate. Now, the government still sees people as their people. People and state relationship is still be considered as under the government's regulation. People are seen as policy's beneficiaries. (Interview, July 2015)

\subsection{Reconsider social accountability's expectations}

After years of introducing and promoting the concept of social accountability, organizations have drawn some conclusions on its impacts and held a more realistic view on its potentials. One of the most noticeable perspective is that even without the emergence of social accountability, people's participation is still an irreversible movement in Vietnam. According to the interviewee, with all the changes in the context, it is impossible to stop the movement and for the government to simply ignore the people's voice. The social accountability is considered as a push to speed up the process and to create mechanisms for people to participate in.

By applying grassroots democracy, people are participating more than before but with a very slow speed. Our initiatives generate rooms for them to participate. (Interview, July 2015)

As said, social accountability at this moment only serves as examples to prove that people can participate and contribute to governance and their voices matter. When it comes to scaling up issue, resources, skills, and approval from the government restrict social accountability. Hence, looking for new ideas, especially on ICT and people's campaign can be a more suitable approach.

Finally, there are still excitements on the potentials of social accountability. There are initiatives to be piloted, new approaches to be followed. Hence, CSOs keep endeavoring and testing out new ideas. There is in fact no organizations convinced that the activities can bring changes quickly. Instead, by learning by doing, organizations are looking forward to slowly changing the old-fashioned mindset, providing mechanisms for people to participate; hence, making the idea of participating as a part of life becomes more widespread. 


\section{CHAPTER VII - CONCLUSION}

This thesis aimed to explore the perspectives, practices of organizations regarding social accountability in Vietnam in order to understand the concept's potential and position in the development of the country. The thesis is built up based on two primary questions: What is the position of social accountability in the context of Vietnam? and How can agencies facilitate more effective, appropriate adoption of the concept?. In addition, four supporting subquestions as introduced in the Introduction chapter have also been developed in order to help answer the main research questions. This concluding chapter will reiterate the findings of this thesis with regard to the questions.

\section{Characteristics of social accountability practices in Vietnam}

\subsection{Differences in understanding of the concept and difficulties in networking}

Similar to discussions among international organizations, organizations in Vietnam differ significantly on their understanding of social accountability. It can be suggested that the perception of organizations are often influenced by references provided by World Bank or UNDP. Social accountability has been perceived as a set of instruments, a means to increase the state's responsiveness, or a process with participation of people. The fact that there are two different translations of the term has also reflected the variety in understanding the concept. Without a consensus on the core of social accountability, it will remain challenging for the organizations to cooperate and establish network in the future.

1.2 Organizations have aligned with the state or organizations close to the state to pilot social accountability initiatives.

NGOs often collaborate with the state's agencies in order to have the mandate to practice social accountability which involves some extent of people's monitoring. Besides working with the ministries to assess and improve its own performances, most NGOs are seeing the Vietnam Fatherland Front and People's Council at local levels as the possible entry points for their practices. The two organizations, especially the Vietnam Fatherland Front is the representation for people's voices and is expected to take the leading role in people's monitoring activities. 
Hence, it is easier for organizations to employ social accountability by collaborating with these organizations. However, the practice can hinder the independence of the NGOs and increase paperwork for them in order to maintain the partnership with the organizations though partnership with the ministries and VFF or People's Council is believed to be realistic and necessary for all NGOs to pilot social accountability.

\subsection{Organizations focus more on information interventions with the assumption that collective} voices will have more power.

NGOs are piloting instruments mostly introduced by the World Bank in order to collect information and voices of the people. By gathering and presenting a united voice of the people regarding one issue, it is expected to have a united voice reflecting people's perspectives and can be taken seriously by the government. There are also potential signals for advocacy campaigns attracting the participation of different groups in the society. The campaigns are often taken place in big cities and to respond a concerning issue. The pressure generated by the campaigns is perceived as a promising way to call for responds from the government. However, as campaigns are not familiar in the country's society and are often happened in large cities, organizations which wants to mobilize the mass's engagement will need to study more on their behaviours as well as how to encourage and facilitate the campaigns. Because of its simplicity, information interventions are expected to remain the main practices of NGOs in adopting social accountability in the upcoming years.

\subsection{The practices of social accountability have brought changes in its practitioners' skills and} awareness, though the practices' impacts remain insignificant.

One of the most important expected impacts of social accountability is the responsiveness of the government's officials regarding the issues and recommendations raised by the interventions. However, there are not much changes reported after the employment of social accountability initiatives. One reason for the insignificant changes is the difficulties to identify and measure them. As organizations have no power towards the commitments of the government officials, it is reliant on the in charge authorities to take the recommendations seriously. The most visible impact of social accountability so far is the changes in mindset and 
skills of involving officials and local NGO partners. They are more aware of the importance of listening to the people and are equipped with technical skills like interviewing, analysing and reporting which are expected to support them in their daily work.

\subsection{There are challenges in planning and implementing follow up and advocacy as well as} looking for funding.

Compared to the four components of social accountability practices introduced by UNDP, the practices in Vietnam often consists of the first three components and are weak in term of using information. Follow up and advocacy remain the limitations of the practices due to a number of reasons: limited financial resources, shortage of expertise and difficulties in communication with the state.

\section{Answers to the research questions}

\subsection{Position of social accountability in the context of Vietnam}

When conducting the study, I have always kept in mind one question: is social accountability necessary? In the context of Vietnam, the society is changing quickly; the trend of people to participate in governance is becoming irreversible. Many participants have agreed that the country is having more invited spaces for people's voices and people are more aware of their own rights. Activities like campaigns or measuring people's satisfaction may still happen without being categorized as social accountability. Hence, do we need the introduction of social accountability - a concept originated in countries with backgrounds significantly different?

At the end of the study, I have drawn two conclusions regarding the issue. Firstly, the context is a deciding factor to the emergence of social accountability. Secondly, social accountability has its role in the development, but organizations need to have practical expectations regarding the concept.

Context is crucial in the adoption of social accountability. The statement has been the finding of recent publications on social accountability (World Bank, 2015, UNDP, 2013). In the case of Vietnam, organizations started piloting the concept when there were already favourable conditions in the legal framework, economic and social factors (See Chapter 4). Without the 
willingness in society to the introduction of social accountability, the number of the initiatives as well as its impacts could be restricted significantly. Hence, it can be reckoned that the changes in the context have opened the door for the entry of social accountability. The practices come in when there is the need for it - to offer more ideas and inventions on how to facilitate and strengthen the new trend. There are number of publications which suggest that social accountability will be most effective when it is practiced in the context with high level of transparency and democracy. For example, the impacts of the practices in Philippines have been featured several times as a successful case in World Bank publications (See Chapter 2). However, in my opinion, in the context like Vietnam which is often considered as having weaker governance and lower level of democracy, the emergence of social accountability is still necessary in order to keep the good momentum in the society. By gradually challenging the unfavourable conditions and encouraging new positive changes, the practices of social accountability can help establishing new habits of participation and strengthening democratic values in the countries.

Second, without being categorized as 'social accountability', activities like campaigns and initiatives such as PAPI will still happen. However, the introduction of social accountability has brought two main benefits. Firstly, it provides knowledge and experiences from other countries. There are a wide range of cases and guidelines available that organizations can use as a source of references for activities they want to undertake. Moreover, the fact that the concept has been developed and promoted by influential organizations like World Bank and UNDP brings confidence for organizations interested in adopting the practices. As I observed, organizations often introduce the instruments as mechanisms which already have been practiced in other countries and brought positive impacts. Hence, it is less challenging for them to persuade people and government to approve the new concept. Finally, though current practices of social accountability are often perceived as small and insignificant, it stills provides mechanisms for people to raise their voices, for organizations to facilitate the dialogue between state and people, and for the state to reflect and change their 'ask-give' mindset. A community member- one participant of the study has share that the approach of practicing social accountability benefits people at remote area since all they need is to be listened and to feel 
that their opinion matters (Interview, June 2015). Without the intervention of social accountability, when the conflict becomes more serious, the relationship between the local people would become very fragile and trust of the people to the government would easily be broken.

Hence, social accountability actually brings benefits to the development of Vietnam. However, it is yet to place a significant role due to its small scope and limited impacts. Concreate changes are yet to be seen and will require longer time to be realized. Therefore, in the current context, social accountability remains as a new concept and practices which can complement and support the new waves of people participation and call for increasing accountability of the state.

\subsection{Future of social accountability - visions and recommendations}

Does social accountability have the potential to strengthen its impacts? My answer is it does have the potential, but only when there are changes in the way organizations practice the concept.

The current practices of social accountability mostly focus on information interventions with analysis results and recommendations being outputs of the activities. As discussed in chapter $\mathrm{VI}$, follow up and advocacy remain the weaker components in the whole process despite that the most crucial factor of information interventions does not lie in how to collect the information, but how to use them effectively. Hence, organizations need to invest more on the follow up and advocacy plan in order to bring more concrete changes after the study.

Another shortcoming of social accountability is its small scale and difficulties to be replicated. In order to address the issue, networking among organizations have been considered as one feasible solution. There are attempts to build up network among organizations working in social accountability. However, as priorities and agendas of organizations differ and vary, appointing a committed coordinator or a coordinating team should be important. In addition, organizations need to discuss the solutions for issues in term of translation as well as different understandings of social accountability. There is no need to gain consensus in one definition, but it is crucial to agree on the core of the concept in order to establish an effective network. 
The network will help disseminating knowledge and experiences among members as well as replicating or scaling up the impacts of social accountability.

There are signals that organizations are aware their limitations and are attempting to focus more on the actual impacts of the study. For some organizations, they may be no longer at the piloting stage of social accountability. Hence, they are looking for more strategic, long term approach to practice the concept with the expectation to bring more concrete changes. However, finance remains an essential issue for the attempts. Organizations still rely on funding from donors to undertake their activities which comes with its own condition and normally only takes up to 5 years. Hence, organizations will need to look for other funding alternatives. Collaborating with cooperates, crowd funding from communities, or sponsored by the government can be options that they can consider.

Finally, cooperating with the government and undertake non-confrontational approach will still be the approach of organizations as it is realistic in the context of Vietnam. There will be initiatives from organizations to transfer technology to local and higher level of governments, for example collecting people's reviews and feedback using technology. In the meantime, activities attract people's attention like Todocabi, 6700 trees would also suggest new directions for organizations. Hence, working with diverse group of communities, especially youth and building relationship with the media can be potential steps in the upcoming years of organizations.

\section{Thesis's limitation and future research directions}

As discussed in Chapter 3 on methodology and research designs, the limitation of the thesis is on its qualitative approach. As the scope of the study is quite small, the results of the study cannot be generalized and represent for all cases of social accountability in Vietnam. The findings are built up on experiences and input of specific people which cannot avoid being biased. Moreover, since the researcher only managed to approach government officials at local levels, the study cannot reflect the perceptions of authorities at higher levels. However, within the scope of the study, it is expected to provide honest observations on the adoption of social accountability in Vietnam. Though it is impossible to confirm that all the findings can be applied 
to all organizations, but I am confident that it successes to reflect the sharing provided by all participants of the study. Results of the research, therefore, can clear up a piece of a whole picture on the practice of the term and suggest recommendations for interested individuals and organizations.

For further research on this topic, I would like to conduct a study combining both quantitative and qualitative approach in order to explore the topic more thoroughly. There would be useful if information on all social accountability initiatives in Vietnam is collected and analysed to see its direction changes over time and its impacts. Studies with the participation of more involving people in the government, NGO sector, and people would also be recommended, especially from media and academic sector. 


\section{REFERENCES}

Ackerman, J. (2004). Co-Governance for Accountability: Beyond "Exit" and "Voice". World Development, 32(3), 447-463. http://dx.doi.org/10.1016/j.worlddev.2003.06.015

Ahmad, R. (2008). Governance, Social accountability and the civil society. JOAAG, 3(1).

Alves, M. (2013). Social Accountability as an Innovative Frame in Civic Action: The Case of Rede Nossa São Paulo. Voluntas, 25(3), 818-838. http://dx.doi.org/10.1007/s11266-013-9365-6

Andrews, M. (2008). The Good Governance Agenda: Beyond Indicators without Theory. Oxford Development Studies, 36(4), 379-407. http://dx.doi.org/10.1080/13600810802455120

ANSA-EAP. (2010). Social Accountability Practice in the Philippines: A Scoping Study.

Bingham, L., Nabatchi, T., \& O'Leary, R. (2005). The New Governance: Practices and Processes for Stakeholder and Citizen Participation in the Work of Government. Public Administration Review, 65(5), 547-558. http://dx.doi.org/10.1111/j.1540-6210.2005.00482.x

Bouckaert, G., \& van de Walle, S. (2003). Comparing Measures of Citizen Trust and User Satisfaction as Indicators of 'Good Governance': Difficulties in Linking Trust and Satisfaction Indicators.International Review of Administrative Sciences, 69(3), 329-343. http://dx.doi.org/10.1177/0020852303693003

Brett, E. (2003). Participation and accountability in development management. Journal Of Development Studies, 40(2), 1-29. http://dx.doi.org/10.1080/00220380412331293747

Brinkerhoff, D., \& Wetterberg, A. (2015). Gauging the Effects of Social Accountability on Services, Governance, and Citizen Empowerment. Public Administration Review, 76(2), 274286. http://dx.doi.org/10.1111/puar.12399

Bryman, A. (2012). Social research methods. Oxford: Oxford University Press.

Castree, N., Kitchin, R., \& Rogers, A. (2013). Oxford Dictionary of human geography. Oxford: Oxford University Press. 
Cornwall, A. (2002). Locating Citizen Participation. IDS Bulletin, 33(2), i-x.

http://dx.doi.org/10.1111/j.1759-5436.2002.tb00016.x

Cox, J. (2009). Active citizenship or passive clientelism? Accountability and development in Solomon Islands. Development in Practice, 19(8), 964-980.

http://dx.doi.org/10.1080/09614520903220784

Creswell, J. (2014). Research design. Thousand Oaks, Calif.: Sage Publications.

Doornbos, M. (2001). 'Good Governance': The Rise and Decline of a Policy Metaphor?. Journal of Development Studies, 37(6), 93-108. http://dx.doi.org/10.1080/713601084

Eversole, R. (2010). Remaking participation: challenges for community development practice.Community Development Journal, 47(1), 29-41. http://dx.doi.org/10.1093/cdj/bsq033

Eversole, R. (2011). Community Agency and Community Engagement: Re-theorising Participation in Governance. J. Pub. Pol., 31(01), 51-71. http://dx.doi.org/10.1017/s0143814×10000206

Fischer, F. (2012). Participatory Governance: From Theory to Practice. In D. Levi-Faur, The Oxford Handbook of Governance (1st ed.). Oxford.

Fosnot, C. (2005). Constructivism. New York: Teachers College Press.

Fox, J. (2014). Social accountability: What does the evidence really say?. The World Bank.

Fung, A. (2015). Putting the Public Back into Governance: The Challenges of Citizen Participation and Its Future. Public Administration Review, 75(4), 513-522.

http://dx.doi.org/10.1111/puar.12361

Gaventa, J. (2002). Exploring Citizenship, Participation and Accountability. IDS Bulletin, 33(2), 114. http://dx.doi.org/10.1111/j.1759-5436.2002.tb00020.x

Gaventa, J., \& Valderrama, C. (1999). Participation, citizenship and local governance. In Strengthening Participation in Local Governance. 
Goetz, A., \& Jenkins, R. (2001). Hybrid Forms Of Accountability: Citizen Engagement in Institutions of Public-sector Oversight in India. Public Management Review, 3(3), 363-383. http://dx.doi.org/10.1080/14616670110051957

Goetz, A., \& Jenkins, R. (2005). Reinventing accountability. Houndmills, Basingstoke, Hampshire: Palgrave Macmillan.

Grbich, C. (2013). Qualitative data analysis. London: SAGE Publications.

Grindle, M. (2004). Good Enough Governance: Poverty Reduction and Reform in Developing Countries. Governance, 17(4), 525-548. http://dx.doi.org/10.1111/j.09521895.2004.00256.x

Grindle, M. (2007). Good Enough Governance Revisited. Development Policy Review, 25(5), 533574. http://dx.doi.org/10.1111/j.1467-7679.2007.00385.x

Hout, W. (2009). Development and governance: An uneasy relationship. In W. Hout \& R. Robison, Governance and the Depoliticisation of Development (1st ed.). London: Routledge.

Irvin, R., \& Stansbury, J. (2004). Citizen Participation in Decision Making: Is It Worth the Effort?.Public Administration Review, 64(1), 55-65. http://dx.doi.org/10.1111/j.1540$6210.2004 .00346 . x$

Jayal, N. (2007). New Directions in Theorising Social Accountability?. IDS Bulletin, 38(6), 105112. http://dx.doi.org/10.1111/j.1759-5436.2007.tb00425.x

Joshi, A. (2007). Producing Social Accountability? The Impact of Service Delivery Reforms. IDS Bulletin, 38(6), 10-17. http://dx.doi.org/10.1111/j.1759-5436.2007.tb00414.x

Joshi, A. (2013). Do They Work? Assessing the Impact of Transparency and Accountability Initiatives in Service Delivery. Development Policy Review, 31, s29-s48. http://dx.doi.org/10.1111/dpr.12018

Joshi, A., \& Houtzager, P. (2012). Widgets or Watchdogs?. Public Management Review, 14(2), 145-162. http://dx.doi.org/10.1080/14719037.2012.657837 
Kaufmann, D., Kraay, A., \& Mastruzzi, M. (2010). The Worldwide Governance Indicators: Methodology and Analytical Issues.

Koch, P. (2013). Bringing Power Back In: Collective and Distributive Forms of Power in Public Participation. Urban Studies, 50(14), 2976-2992.

http://dx.doi.org/10.1177/0042098013482511

Leftwich, A. (1993). Governance, democracy and development in the Third World. Third World Quarterly, 14(3), 605-624. http://dx.doi.org/10.1080/01436599308420345

Levi-Faur, D. (2012). Oxford handbook of governance. Oxford: Oxford University Press.

Lindberg, S. (2013). Mapping accountability: core concept and subtypes. International Review of Administrative Sciences, 79(2), 202-226. http://dx.doi.org/10.1177/0020852313477761

Lindberg, S. (2013). Mapping accountability: core concept and subtypes. International Review of Administrative Sciences, 79(2), 202-226. http://dx.doi.org/10.1177/0020852313477761

M. Ackerman, J. (2005). Social accountability in the public sector: A conceptual discussion. The World Bank.

Marshall, C., \& Rossman, G. (2011). Designing qualitative research. Los Angeles: Sage.

Mattner, M. (2004). Power to the people? Local governance and politics in Vietnam. Environment and Urbanization, 16(1), 121-128. http://dx.doi.org/10.1177/095624780401600110

Merriam, S., Johnson-Bailey, J., Lee, M., Kee, Y., Ntseane, G., \& Muhamad, M. (2001). Power and positionality: negotiating insider/outsider status within and across cultures. International Journal of Lifelong Education, 20(5), 405-416. http://dx.doi.org/10.1080/02601370120490

Michels, A. (2011). Innovations in democratic governance: how does citizen participation contribute to a better democracy?. International Review of Administrative Sciences, 77(2), 275-293. http://dx.doi.org/10.1177/0020852311399851 
Mkandawire, T. (2007). 'Good governance': the itinerary of an idea. Development in Practice, 17(4-5), 679-681. http://dx.doi.org/10.1080/09614520701469997

Mudacumura, G., \& Morçöl, G. Challenges to democratic governance in Developing Countries.

Nguyen, T., Le, C., Tran, B., \& Bryant, S. (2015). Citizen Participation in City Governance: Experiences From Vietnam. Public Admin. Dev., 35(1), 34-45. http://dx.doi.org/10.1002/pad.1702

O'Donnell, G. (1998). Horizontal Accountability in New Democracies. Journal of Democracy, 9(3), 112-126. http://dx.doi.org/10.1353/jod.1998.0051

Punyaratabandhu, S. (2004). Commitment to good governance, development and poverty reduction: methodological issues in the evaluation of progress at the national and local levels. In Committee for Development Policy (Background Paper No.4).

Ringold, D., Holla, A., Koziol, M., \& Srinivasan, S. (2012). Citizens and Service Delivery Assessing the Use of Social Accountability Approaches in Human Development. The World Bank.

Roche, C. (2009). Oxfam Australia's experience of 'bottom-up' accountability. Development in Practice, 19(8), 1009-1022. http://dx.doi.org/10.1080/09614520903220818

Rose, G. (1997). Situating knowledges: positionality, reflexivities and other tactics. Prog Hum Geogr,21(3), 305-320. http://dx.doi.org/10.1191/030913297673302122

Sarker, A. (2009). The New Mode of Public Governance and Public Accountability in Developing Countries: An Analysis with Particular Reference to Bangladesh. International Journal Of Public Administration, 32(13), 1101-1123. http://dx.doi.org/10.1080/01900690903188826

Sarker, A., \& Hassan, M. (2008). Civic engagement and public accountability: an analysis with particular reference to developing countries. Public Administration \& Management, 15(2), 381-417. 
Schedler, A. (1999). Conceptualizing Accountability. In A. Schedler, L. Diamond \& M. F.Plattner, The Self-Restraining State: Power and Accountability in New Democracies (1st ed.). Lynne Rienner Publishers.

Schultz, L., Guevara, J., Ratnam, S., Wierenga, A., Wyn, J., \& Sowerby, C. (2009). Global Connections: 'A Tool for Active Citizenship'. Development in Practice, 19(8), 1023-1034. http://dx.doi.org/10.1080/09614520903220776

Sen, A. (2000). A Decade of Human Development. Journal of Human Development, 1(1), 17-23. http://dx.doi.org/10.1080/14649880050008746

Social Accountability Sourcebook Homepage. (2016). Worldbank.org. Retrieved 9 March 2016, from http://www.worldbank.org/socialaccountability_sourcebook/

Sturm, P. (2013). Public sector governance and development performance - An international comparison with special focus on Vietnam.

Taylor, M. (2007). Community Participation in the Real World: Opportunities and Pitfalls in New Governance Spaces. CURS, 44(2), 297-317. http://dx.doi.org/10.1080/00420980601074987

Thomas, M. (2009). What Do the Worldwide Governance Indicators Measure?. Eur J Dev Res, 22(1), 31-54. http://dx.doi.org/10.1057/ejdr.2009.32

Tria Kerkvliet, B. (2010). Governance, Development, and the Responsive-Repressive State in Vietnam.Forum for Development Studies, 37(1), 33-59. http://dx.doi.org/10.1080/08039410903558251

UNDESA,. (2008). People Matter Civic Engagement in Public Governance. Retrieved from http://unpan1.un.org/intradoc/groups/public/documents/un/unpan028608.pdf

UNDP,. (2013). Reflections on social accountability: Catalyzing democratic governance to accelerate progress towards the Millennium Development Goals. New York.

UNDP Vietnam,. (2006). Deepening democracy and increasing popular participation in Vietnam. 
UNDP Vietnam,. (2014). Giám sát có sự tham gia nhằm tăng cường trách nhiệm giải trình ở Việt NamĐối thoại về "phương thức thực hiện" Khung phát triển sau năm 2015. Hanoi.

UNICEF Vietnam,. (2011). Making Social Audit work for Viet NamKey Findings and Lessons Learned from a Pilot of Four Social Audit Tools.

UNPAGlossary. (2016). Unpan.org. Retrieved 10 March 2016, from http://www.unpan.org/Directories/UNPublicAdministrationGlossary/tabid/928/language/ en-US/Default.aspx

Wachhaus, A. (2013). Governance beyond Government. Administration \& Society, 46(5), 573593. http://dx.doi.org/10.1177/0095399713513140

Walker, D. (2009). Citizen-driven reform of local-level basic services: Community-Based Performance Monitoring. Development in Practice, 19(8), 1035-1051. http://dx.doi.org/10.1080/09614520903220792

Weiss, T. (2000). Governance, good governance and global governance: Conceptual and actual challenges. Third World Quarterly, 21(5), 795-814. http://dx.doi.org/10.1080/713701075

Wischermann, J. (2011). Governance and Civil Society Action in Vietnam: Changing the Rules From Within-Potentials and Limits. Asian Politics \& Policy, 3(3), 383-411. http://dx.doi.org/10.1111/j.1943-0787.2011.01277.x

World Bank. (2015). Opening the Black Box: The Contextual Drivers of Social Accountability. New Frontiers of Social Policy. Washington, DC: World Bank.

Yetano, A., Royo, S., \& Acerete, B. (2010). What is Driving the Increasing Presence of Citizen Participation Initiatives?. Environment and Planning C: Government And Policy, 28(5), 783802. http://dx.doi.org/10.1068/c09110 


\section{APPENDIX \\ Participant Information Sheet}

Research Title: Social Accountability - Its Position and Potential in the Development of Vietnam Hello! My name is Ta Thai Ha, and I am a Development Studies student at Victoria University of Wellington, New Zealand. As part of my Masters degree, I am writing a thesis on social accountability and its position and potential in the development of Vietnam. Victoria University requires, and has granted to the study, approval from the University's Human Ethics Committee.

The main objective of this research is to identify the role and potential of social accountability in Vietnam's context. The study will provide an analysis of the potential of the activities and suggest recommendations to improve the effectiveness of the activities in Vietnam. In addition, the project also aims to trigger more discussion on the practical role and practices of social accountability in countries where the approach has not yet been institutionalized. Research findings will be disseminated to local development partners, NGOs and government so that they can update with the emerging of social accountability.

I would like to invite you to participate in an interview in which you will be able to share your experiences and stories of (1) Your understanding and experience with social accountability as a concept and as practical activities; (2) Actual and potential roles of social accountability in Vietnam; (3) Effects of contextual factors on adopting social accountability in Vietnam; and (4) Strategies of your organization to promote social accountability in Vietnam (if relevant).

Our conversation will be conducted in a semi-structured interview that I have prepared in relation to this topic. It will take no longer than one hour.

There are several things that you need to be aware of before you consent to participate in this research:

If you give me your permission, the interview will be recorded to support the researcher's notes in case any ideas have been missed. Following our discussion, you have the right to check the interview notes. Written documents will be stored in a zipped folder. Electronically recorded material made during the interview will be safely stored in my laptop's folders with password 
required to access. The materials will only be seen by my supervisor and myself. The researcher will take all necessary steps to keep interview information safe during time in the field. All interview materials will be destroyed upon completion of the thesis.

It will be your decision as to whether you and your organisation will be identified or will remain confidential in the published thesis. As a participant, you do not have to answer all questions. If you agree to take part in the interview you are free to withdraw at any stage without having to give a reason. You are free to withdraw any information you have provided before data collection and analysis of the research is complete on $1^{\text {st }}$ September 2015.

Upon completion of my thesis, a copy of this thesis will be lodged in the library of Victoria University of Wellington. A summary of findings will be made available to you, if you are interested. The final research may also be published in academic or professional journals and/or disseminated at academic or professional conferences as the opportunity arises. All related publications will adhere to strict confidentiality if requested by the participant.

I hope you will agree to participate in this research and I look forward to speaking with you soon.

Ta Thai Ha

taha1@myvuw.ac.nz
Professor John Overton(Supervisor)

John.Overton@vuw.ac.nz 


\section{Consent to Participate in Research}

Title of project: Social Accountability - Its Position and Potential in the Development of Vietnam

Researcher: Ta Thai Ha, School of Geography, Environment and Earth Sciences, Victoria University of Wellington

- I have read the Participant Information Sheet and understand the purpose of this research project.

- I understand the interview will be electronically recorded and any notes or recorded material from interviews will be destroyed at the end of the research process.

- I understand that all information I provide will be safely stored accessed only by the researcher and research supervisor. Written documents will be stored in zipped folders. Electronically recorded material made during the interview will be stored in the researcher's laptop folders with password required to access.

○ I understand I will have an opportunity to see a summary of the interview.

- I understand I may withdraw myself, and any information I have provided, from this research project without explanation at any time before $1^{\text {st }}$ September 2015.

- I understand the results of this research will be included in a thesis and may be used for publication in academic or professional journals, and for dissemination at academic or professional conferences.

- I understand that all related publications will adhere to strict confidentiality if requested by participants like me.

- I agree to take part in this research.

\section{Please tick as appropriate:}

- I would like to receive a summary of the results of this research when it is completed.

- I consent to my name being used when my comments or opinions are used in this research.

- I request that my name be omitted and a pseudonym assigned by the researcher be used if my comments or opinions are included in this research.

i. I consent to the name of the organisation I work for being used in this research. 
ii. I confirm that I have the authority to speak for my organisation.

I request the name of the organisation I work for to be omitted from this research.

Name: Date:

Organisation:

Phone: Email:

Signed: 


\section{Interview questions}

Research Title: Social Accountability - Its Position and Potential in the Development of Vietnam

\section{Central research questions:}

1. What is the position of social accountability in the context of Vietnam?

2. What should be done in order to attain more effective, appropriate adoption of the social accountability concept?

In order to answer the research questions, the study will collect data and information on the following aspects:

Aspect 1.1. Understanding the context for social accountability in Vietnam

Aspect 1.2. Identifying perception of key actors regarding social accountability

Aspect 1.3. Identifying and analyzing common practices and approaches to adopt social accountability in Vietnam

Aspect 1.4. Identifying and analyzing the extent of achievements and impacts of social accountability in Vietnam

Aspect 2.1. Defining visions of better adoption of social accountability in Vietnam

Aspect 2.2. Suggesting approaches and best practices of social accountability in order to:

a. Improve effectiveness of practices

b. Improve sustainability and generate more positive, significant impacts

Key methods: Desk study and interviews 
Figure 5: Logic of research questions and research aspects

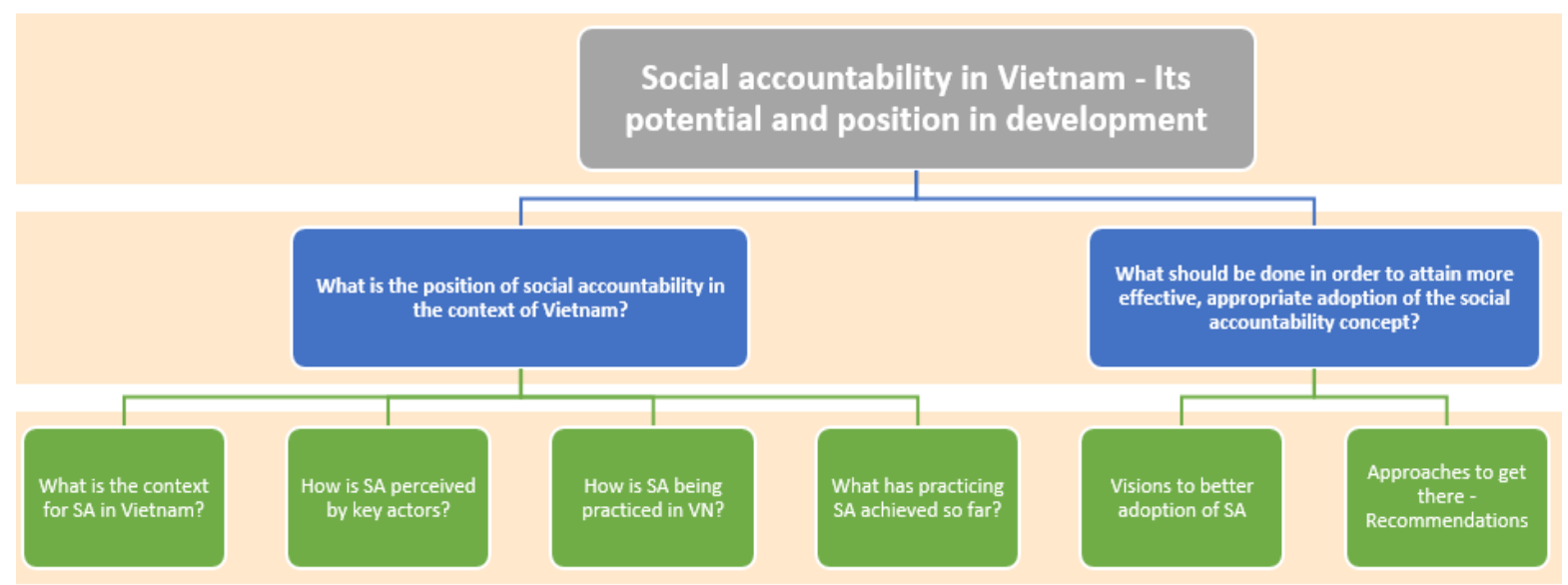




\section{Questions to ask}

\begin{tabular}{|c|c|c|c|c|c|}
\hline Aspect & $\begin{array}{l}\text { Method to } \\
\text { collect data }\end{array}$ & $\begin{array}{l}\text { Materials for } \\
\text { desk study }\end{array}$ & $\begin{array}{l}\text { Interview questions to } \\
\text { development } \\
\text { practitioners }\end{array}$ & $\begin{array}{l}\text { Interview questions to } \\
\text { government officials }\end{array}$ & $\begin{array}{l}\text { Interview questions } \\
\text { to local community } \\
\text { members }\end{array}$ \\
\hline $\begin{array}{l}\text { 1.1. The context } \\
\text { for social } \\
\text { accountability in } \\
\text { Vietnam }\end{array}$ & $\begin{array}{l}\text { Desk study \& } \\
\text { Interview }\end{array}$ & $\begin{array}{l}\checkmark \text { Legal and } \\
\text { constitution } \\
\text { al provision } \\
\checkmark \text { History of } \\
\text { protest and } \\
\text { citizen } \\
\text { engagement } \\
\checkmark \text { Democratic } \\
\text { space } \\
\text { (mechanism } \\
\text { for } \\
\text { representing } \\
\text { people, } \\
\text { media, } \\
\text { activeness of } \\
\text { civil society, } \\
\text { differences } \\
\text { among } \\
\text { places) } \\
\checkmark \text { Cultures of } \\
\text { accountabilit } \\
\text { y } \\
\text { participation } \\
\checkmark \text { State- } \\
\text { market } \\
\text { relations }\end{array}$ & $\begin{array}{l}\text { 1. How existing legal } \\
\text { framework is } \\
\text { affecting your SA } \\
\text { work? } \\
\text { 2. What is your opinion } \\
\text { on citizen } \\
\text { engagement in } \\
\text { governance? } \\
\text { Is there any } \\
\text { differences between } \\
\text { urban and rural } \\
\text { areas? any } \\
\text { Is there } \\
\text { restrictions for people } \\
\text { to raise their voice or } \\
\text { give feedback? } \\
\text { 3. Do you think } \\
\text { engagement of } \\
\text { organizations like } \\
\text { yours in social } \\
\text { accountability is a } \\
\text { new trend? Is there } \\
\text { any differences } \\
\text { between } \\
\text { international NGOs } \\
\text { and local NGOs in this } \\
\text { movement? }\end{array}$ & $\begin{array}{l}\text { 1. What do you think } \\
\text { about citizen } \\
\text { participation in } \\
\text { political } \\
\text { accountability? In } \\
\text { term of: } \\
\text { ourrent } \\
\text { movements } \\
\text { legal framework } \\
\text { relevance to } \\
\text { development } \\
\text { (poverty in } \\
\text { reduction) } \\
\text { Vietnam } \\
\text { What is your } \\
\text { opinion on that } \\
\text { statement: } \\
\text { governments must } \\
\text { be accountable to } \\
\text { inform and explain } \\
\text { about its decisions } \\
\text { and actions for } \\
\text { concerned society } \\
\text { actors and can be } \\
\text { sanctioned } \\
\text { accordingly? }\end{array}$ & $\begin{array}{l}\text { 1. Do you care } \\
\text { about } \\
\text { 'government's } \\
\text { work'? To what } \\
\text { extent? What is } \\
\text { your } \\
\text { responsibility } \\
\text { with improving } \\
\text { the work of } \\
\text { government? } \\
\text { 2. In case you have } \\
\text { problems with } \\
\text { public services or } \\
\text { feedback to } \\
\text { governments } \\
\text { (local or higher } \\
\text { levels)' decisions, } \\
\text { what will you } \\
\text { normally do? }\end{array}$ \\
\hline
\end{tabular}




\begin{tabular}{|c|c|c|c|c|}
\hline $\begin{array}{l}\text { 1.2. Perception of } \\
\text { key actors } \\
\text { regarding social } \\
\text { accountability }\end{array}$ & Interview & $\begin{array}{l}\text { 1. How do you define } \\
\text { social accountability? } \\
\text { Is social } \\
\text { accountability } \\
\text { individual activities, a } \\
\text { process, or an } \\
\text { outcome? } \\
\text { Do you think social } \\
\text { accountability is new } \\
\text { in the context of } \\
\text { Vietnam? } \\
\text { 2. What sources of } \\
\text { information do you } \\
\text { use to learn about } \\
\text { social accountability? } \\
\text { 3. What makes your } \\
\text { organization } \\
\text { interested in SA? } \\
\text { 4. To which actors do } \\
\text { you think SA will } \\
\text { benefit? And how? }\end{array}$ & $\begin{array}{l}\text { 1. Have you ever } \\
\text { heard of social } \\
\text { accountability? If } \\
\text { yes, how do you } \\
\text { define social } \\
\text { accountability? } \\
\text { 2. From what sources } \\
\text { do you know about } \\
\text { the social } \\
\text { accountability } \\
\text { concept? } \\
\text { What agencies } \\
\text { should take lead of } \\
\text { practicing social } \\
\text { accountability in } \\
\text { Vietnam? } \\
\text { What role can SA } \\
\text { take in the existing } \\
\text { accountability } \\
\text { mechanisms } \\
\text { (horizontal } \\
\text { vertical)? }\end{array}$ & $\begin{array}{l}\text { 1. What is your } \\
\text { impression of the } \\
\text { word 'social } \\
\text { accountability'? } \\
\text { Has your } \\
\text { impression } \\
\text { changed after } \\
\text { being involved in } \\
\text { the work? } \\
\text { 2o what extend } \\
\text { are you willing to } \\
\text { participate in } \\
\text { other social } \\
\text { accountability } \\
\text { activities? Are } \\
\text { you willing to } \\
\text { lead any SA } \\
\text { initiatives? } \\
\text { Any supports or } \\
\text { conditions } \\
\text { needed for your } \\
\text { participation? } \\
\text { Do you think your } \\
\text { community will } \\
\text { consider the } \\
\text { social accountability } \\
\text { approach when } \\
\text { needed? }\end{array}$ \\
\hline
\end{tabular}




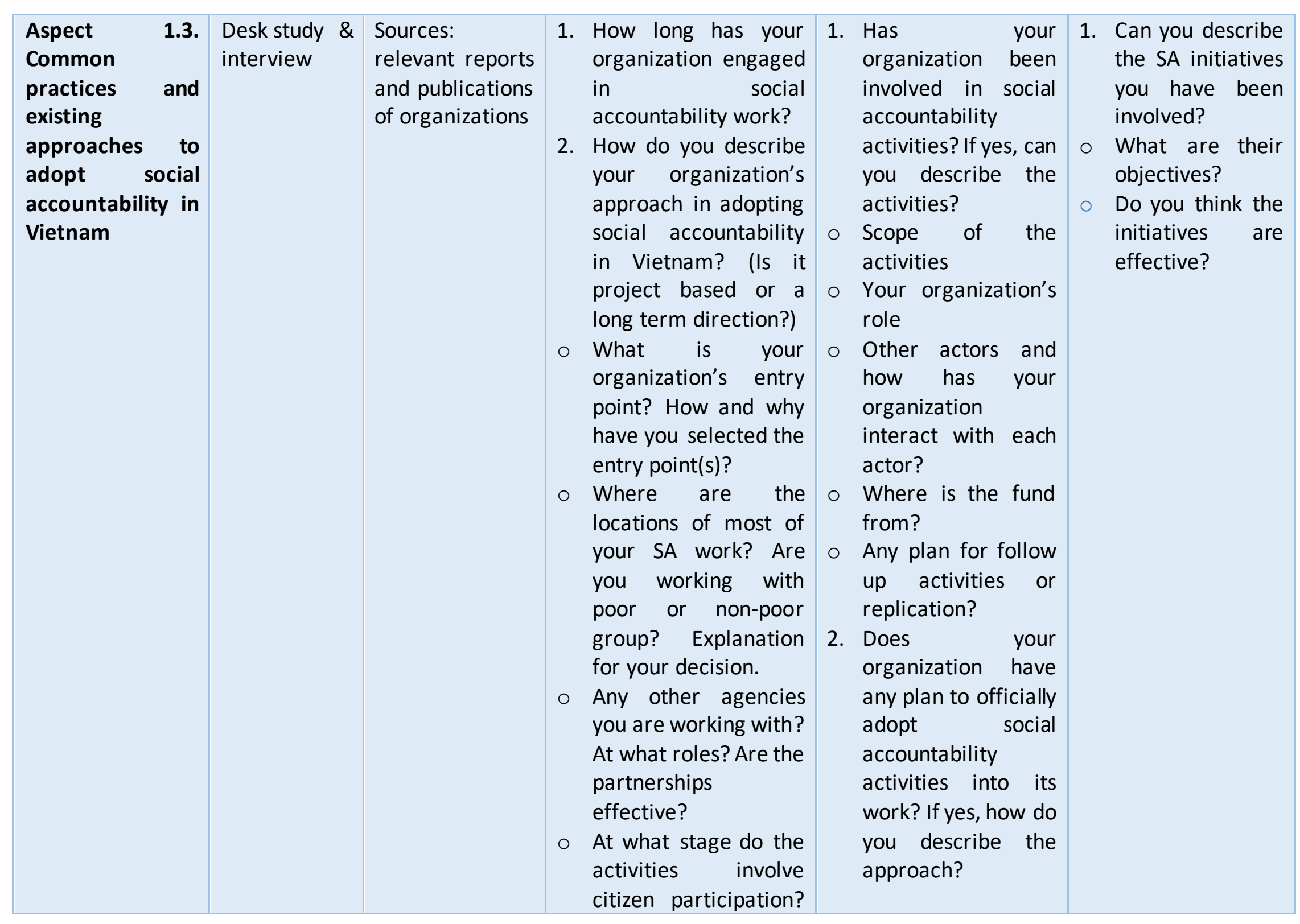




\begin{tabular}{|c|c|c|c|c|c|c|}
\hline & & & 3. & $\begin{array}{l}\text { Why not on the other } \\
\text { stages? } \\
\text { How do you describe } \\
\text { follow up plans of the } \\
\text { activities and how } \\
\text { have the plans been } \\
\text { implemented? } \\
\text { What challenges are } \\
\text { you facing in } \\
\text { practicing social } \\
\text { accountability in } \\
\text { Vietnam? } \\
\text { What are your } \\
\text { strategies to address } \\
\text { these challenges? }\end{array}$ & $\begin{array}{l}\text { 3. How do you } \\
\text { describe any } \\
\text { challenges and } \\
\text { opportunities for } \\
\text { your organization to } \\
\text { adopt social } \\
\text { accountability } \\
\text { officially? }\end{array}$ & \\
\hline $\begin{array}{l}\text { Aspect 1.4. The } \\
\text { extent } \\
\text { achievements } \\
\text { and impacts of } \\
\text { social } \\
\text { accountability in } \\
\text { Vietnam }\end{array}$ & $\begin{array}{l}\text { Desk study \& } \\
\text { interview }\end{array}$ & $\begin{array}{l}\text { Organizations' } \\
\text { reports and } \\
\text { relevant media } \\
\text { coverage }\end{array}$ & 1. & $\begin{array}{l}\text { How does your } \\
\text { organization evaluate } \\
\text { impacts and } \\
\text { outcomes of SA } \\
\text { activities? } \\
\text { What are your } \\
\text { accomplishments so } \\
\text { far in adopting social } \\
\text { accountability in } \\
\text { Vietnam? } \\
\text { To what extent have } \\
\text { the accomplishments } \\
\text { met your } \\
\text { expectations when } \\
\text { starting to exercise }\end{array}$ & $\begin{array}{l}\text { 1. What are the } \\
\text { benefits that SA } \\
\text { related activities } \\
\text { have brought to } \\
\text { your organization's } \\
\text { work? }\end{array}$ & $\begin{array}{l}\text { 2. How do you } \\
\text { describe the } \\
\text { impacts of the } \\
\text { social } \\
\text { accountability } \\
\text { activities that you } \\
\text { have been } \\
\text { involved in on } \\
\text { your life? And on } \\
\text { your community? }\end{array}$ \\
\hline
\end{tabular}




\begin{tabular}{|c|c|c|c|c|}
\hline & & $\begin{array}{l}\text { social accountability } \\
\text { practices in Vietnam? } \\
\text { 4. Is your organization } \\
\text { going to scale up or } \\
\text { replicate any SA } \\
\text { practice? If yes, how? }\end{array}$ & & \\
\hline $\begin{array}{l}\text { Aspect } 2.1 . \\
\text { Visions of better } \\
\text { adoption of social } \\
\text { accountability in } \\
\text { Vietnam }\end{array}$ & Interview & $\begin{array}{l}\text { 1. What are your } \\
\text { expectation for the } \\
\text { potential of social } \\
\text { accountability } \\
\text { activities in Vietnam? } \\
\text { And its limitations? } \\
\text { 2. How do you describe } \\
\text { a successful SA } \\
\text { adoption? }\end{array}$ & $\begin{array}{l}\text { 1. What are your } \\
\text { expectation for the } \\
\text { potential of social } \\
\text { accountability in } \\
\text { activities And its } \\
\text { Vietnam? Ans? } \\
\text { limitations? }\end{array}$ & \\
\hline $\begin{array}{l}\text { Aspect } 2.2 . \\
\text { Suggestions to: } \\
\text { (a) Improve } \\
\text { effectiven } \\
\text { ess of SA } \\
\text { practices }\end{array}$ & Interview & $\begin{array}{l}\text { 1. What are your } \\
\text { recommendations for } \\
\text { more effective social } \\
\text { accountability } \\
\text { initiatives? }\end{array}$ & & $\begin{array}{l}\text { 1. What support do } \\
\text { you need if you } \\
\text { want to employ } \\
\text { social } \\
\text { accountability in } \\
\text { your community? }\end{array}$ \\
\hline $\begin{array}{l}\text { (b) Improve } \\
\text { sustainabi } \\
\text { lity and } \\
\text { impacts }\end{array}$ & Interview & $\begin{array}{l}\text { 2. What are your } \\
\text { recommendations for } \\
\text { more successful } \\
\text { adoption of SA } \\
\text { initiatives in VN? (Is } \\
\text { there a need for } \\
\text { institutionalization?) }\end{array}$ & $\begin{array}{l}\text { 1. What are your } \\
\text { recommendations } \\
\text { for more successful } \\
\text { adoption of SA } \\
\text { initiatives in VN? }\end{array}$ & \\
\hline
\end{tabular}

